\title{
Verification of Equation for Evaluating Dislocation Density during Steady-state Creep of Metals
}

\author{
Manabu Tamura ${ }^{1}$ \\ ${ }^{1}$ Free Scientist, Japan \\ Correspondence: Manabu Tamura, Free Scientist, Japan. E-mail: mtamura.1943@pep.ne.jp
}

Received: November 23, 2016

Accepted: January 3, 2016

Online Published: March 21, 2017

doi:10.5539/jmsr.v6n2p20

URL: http://dx.doi.org/10.5539/jmsr.v6n2p20

\begin{abstract}
Ninety-two sets of observed dislocation densities for crept specimens of 21 types of ferritic/martensitic and austenitic steels, $\mathrm{Al}, \mathrm{W}, \mathrm{Mo}$, and $\mathrm{Mg}$ alloys, $\mathrm{Cu}$, and $\mathrm{Ti}$ including germanium single crystals were collected to verify an equation for evaluating the dislocation density during steady-state creep proposed by Tamura and Abe (2015). The activation energy, $Q_{\mathrm{ex}}$, activation volume, $V_{\mathrm{ex}}$, and Larson-Miller constant, $C_{\mathrm{ex}}$, were calculated from the creep data. Using these parameter constants, the strain rate, and the temperature dependence of the shear modulus, a correction term, $\gamma$, was back-calculated from the observed dislocation density for each material. $\gamma$ is defined in the present paper as a function of the temperature dependences of both the shear modulus and pre-exponential factor of the strain rate. The values of $\gamma$ range from -394 to $233 \mathrm{kJmol}^{-1}$ and average $2.1 \mathrm{kJmol}^{-1}$, which is a value considerably lower than the average value of $Q_{\mathrm{ex}}\left(410.4 \mathrm{kJmol}^{-1}\right)$, and values of $\gamma$ are mainly within the range from 0 to $50 \mathrm{kJmol}^{-1}$. The change in Gibbs free energy, $\Delta G$, for creep deformation is obtained using the calculated value of $\gamma$, and the empirical relation $\Delta G \cong \Delta G_{\mathrm{D}}$ is found, where $\Delta G_{\mathrm{D}}$ is the change in Gibbs free energy for self-diffusion of the main componential element of each material. Experimental data confirm the validity of the evaluation equation for the dislocation density.
\end{abstract}

Keywords: dislocation density, creep equation, steady-state creep, Gibbs free energy, diffusion, metal

\section{Introduction}

The measurement of dislocation density has been recognized as a major step in clarifying deformation mechanisms (Dorn \& Mote, 1964; Kassner, Ziaai-Moayyed, \& Miller, 1985), because the dislocation density during deformation is closely related to deformation resistance (Taylor, 1934; Orowan, 1940). Moreover, variations in the dislocation density during the creep of commercially available heat-resistant steel have been systematically studied for the evaluation of the creep lives of the steel (Sawada, Maruyama, Komine, \& Nagae, 1997; Bazazi, 2009). Dislocation densities have been measured employing the etch pit method (T. Hasegawa, R. Hasegawa, \& Karashima, 1970), transmission electron microscopy (TEM) (Ham, 1961), scanning electron microscopy (Kamaladasa \& Picard, 2010), X-ray diffraction (XRD) analysis (Shintani \& Murata, 2011), and the stress or strain rate change test (SCH) (Yoshinaga, Matsuo, \& Kurishita, 1984). However, it is not unusual that the differences among the dislocation densities of the same specimen measured employing the different methods are more than an order of magnitude (Hayakawa et al., 2007a; Umezaki, Murata, Nomura, \& Kubushiro, 2014; Roodposhti, Sarkar, Murty, \& Scattergood, 2015). This suggests the importance of not only selecting an appropriate method for a given specimen but also of considering the physical meanings of the observed values (Yoshinaga, Horita, \& Kurishita, 1981; Pesicka, Kuzel, Dronhofer, \& Eggeler, 2003). In any method employed, much effort is required to prepare specimens and to precisely evaluate dislocation densities.

Tamura et al. (2015) introduced an equation that can be used to directly evaluate a dislocation density from a set of steady-state creep rates under several assumptions. They derived an evaluation equation for the dislocation density by describing the creep rate using Orowan's equation (Equation 1 in the text) and assuming that the average dislocation velocity in Orowan's equation obeys the thermal activation equation (Equation 3 in the text). However, the temperature dependence of the pre-exponential factor in the equation for the creep rate cannot be determined experimentally, and the change in Gibbs free energy for creep (Equation 9 in the text) is therefore described by introducing a correction term, $\gamma$, which is the only adjustable parameter in the evaluation equation for the dislocation density. Finally, the value of $\gamma$ for a state at the minimum creep rate (MCR) of tempered martensitic $9 \mathrm{Cr}-1 \mathrm{~W}$ steel was calculated as $-32.3 \mathrm{kJmol}^{-1}$ according to metallurgical considerations. As a 
result, the dislocation density was estimated as $3 \mathrm{E} 13 \mathrm{~m}^{-2}$ using this value of $\gamma$ and the dislocation density is close to the value observed in many cases of tempered martensitic steel. It is important to generalize this evaluation method according to metallurgical considerations, which will be discussed elsewhere. The present report inspects the validity of the proposed evaluation equation for dislocation density from another angle. Here, as many data sets of both the observed values of dislocation density and the related creep data for the steady-state creep of metals as possible were collected and the values of $\gamma$ were calculated back from the dislocation densities collected. This investigation focuses on cases where $\gamma$ is negligibly small or cases where the proper value of $\gamma$ is needed. As a result, if many cases of $\gamma \approx 0$ are confirmed, a sufficient condition that forms a proposition that the evaluation equation is valid is demonstrated to be partially satisfied.

Sherby, Orr, and Dorn (1953) found that the apparent activation energy for creep, $Q_{\mathrm{aac}}$, is equal to the activation enthalpy for self-diffusion, $Q_{\mathrm{D}}$, for six types of pure metals tested at $T / T_{\mathrm{m}} \approx 0.5$, where $T$ and $T_{\mathrm{m}}$ are the test temperature and melting temperature in units of Kelvin, respectively, and it was summarized in 1968 that this relation holds for 19 types of pure metals and $\mathrm{AgBr}, \mathrm{Al}_{2} \mathrm{O}_{3}, \mathrm{MgO}, \mathrm{NaCl}$, and $\mathrm{UO}_{2}$ (Sherby \& Burke, 1968). After the first finding of Sherby et al. (1953) Dorn (1957) confirmed this relation holds for 10 types of pure metals, and Garofalo (1966) confirmed this relation holds for 18 types of pure metals and $\mathrm{AgBr}$. The cited investigations, in addition to detailed discussions on the dislocation motion by other researchers, revealed for certain that the creep of the pure materials is controlled by self-diffusion based on a single-vacancy mechanism. However, since the apparent activation energy for the creep or rupture of heat-resistant steels for practical use is considerably large, the relation $Q_{\mathrm{aac}}=Q_{\mathrm{D}}$ does not hold. For this relation to hold even for practical heat-resistant steels, the concept of internal stress was introduced (Williams \& Wilshire, 1973; Cadek, 1987), but this introduced new problems in that complicated work was necessary to measure the internal stresses and that the physical meanings of both the internal stress and stress exponent were not necessarily clear (Yoshinaga,1977).

Meanwhile, when the value of $\gamma$ is calculated for each dislocation density, we can determine the change in Gibbs free energy for creep, $\Delta G$, and therefore, we can compare $\Delta G$ with the change in Gibbs free energy for self-diffusion, $\Delta G_{\mathrm{D}}$. We can thus further deepen the discussion on the validity of the evaluation equation for dislocation density through the comparison of these variables.

If the evaluation equation for the dislocation density is judged to be reasonable through this research, we can calculate the dislocation density using only a set of minimum creep rates, though we need to assume an adequate value of $\gamma$. Furthermore, if we assume this equation can be applied to the entire transition creep range except the range immediately after loading and we monitor nondestructively variations in the dislocation density using a set of creep curves, we can receive within a short time a sign indicating an unexpected decrease in the long-term creep rupture strength of heat resistant steel, which is one of the critical problems in developing ferritic/martensitic heat-resistant steel (Tamura et al., 2015). If we get an early sign of an unexpected decrease in the long-term rupture strength of a heat-resistant steel for which a preliminary design has been completed, we can redesign the chemical composition and heat treatment of the heat-resistant steel under development without wasting time.

\section{Outline of an Evaluation Equation}

The evaluation equation was introduced as follows (Tamura et al., 2015). The creep rate in a steady state of a crystal due to the glide motion of dislocations is described by Orowan's equation (Orowan, 1940):

$$
\dot{\varepsilon}=M \rho b u,
$$

where $\dot{\varepsilon}, M, \rho, b$, and $u$ are the creep rate under uniaxial tension, the factor of conversion from shear strain to tensile strain, the dislocation density, the length of the Burgers vector, and the average dislocation velocity, respectively. Equation 1 indicates that the dislocation density can be evaluated if the average dislocation velocity is described in a form using measurable parameters that can be induced from creep curves. Schoeck (1980) described the average velocity of dislocations that glide through a crystal in a thermally activated process:

$$
u=\bar{\lambda} v_{\text {eff }} \exp (-\Delta G / R T),
$$

where $\bar{\lambda}$ is the mean distance that the dislocation travels and is comparable to the average obstacle spacing, and $v_{\text {eff }}$ and $R$ are the effective jump frequency and gas constant, respectively. The pre-exponential factor of Equation 2 depends on the microstructure and may change during creep. These variables cannot be estimated using creep curves. Therefore, the argument in the form of Equation 2 is not fruitful. Accordingly, in the previous paper (Tamura et al., 2015) we assumed that a dislocation can repeat single jumps perpendicular to a dislocation and towards the force with the help of a thermally activated process similar to self-diffusion through the crystal lattice. Finally, the average dislocation velocity is given by 


$$
u=b v_{\mathrm{D}} \kappa \exp (-\Delta G / R T)
$$

where $v_{\mathrm{D}}$ and $\kappa$ are the Debye frequency and the ratio of the geometric mean to the algebraic mean, respectively. This assumption means that the velocity of a gliding dislocation for each elementary step in any of the following cases can be described by an equation of Arrhenius type and the average velocity is given by Equation 3, when the dislocation overcomes a potential barrier of dispersed particles by climbing or when atoms around a dislocation core move according to a mechanism like self-diffusion in a field where a potential barrier of dispersed particles is not so high. The pre-exponential factor of Equation 3 becomes $b v_{\mathrm{D}} \kappa=2500 \mathrm{~ms}^{-1}$, if we assume that $b=$ $2.5 \mathrm{E}-10 \mathrm{~m}, \kappa=1$, and $v_{\mathrm{D}}=1 \mathrm{E} 13 \mathrm{~s}^{-1}$. The obtained value is approximately equivalent to the velocity of sound in metals and we can therefore regard the pre-exponential factor of Equation 3 as a constant, because the sound velocity in metals is approximately insensitive to the structure. Equation 3 does not ignore the meaning of the pre-exponential factor of Equation 2. Rather, we consider that the effect of $\bar{\lambda} v_{\text {eff }}$ in Equation 2 on the creep rate is reflected in $\Delta G$ in Equation 3.

The change in Gibbs free energy, $\Delta G$, in an equilibrium state is expressed generally as

$$
\Delta G=Q-\Delta S T-\sigma V,
$$

where $Q, \Delta S, \sigma$, and $V$ are an increase in internal energy through the activation motion of a dislocation, the change in entropy, the applied normal tensile stress, and the activation volume, respectively. From Equations 1, 3, and 4 , we obtain the creep rate rewriting $\dot{a}_{0}=M \rho b^{2} v_{\mathrm{D}} \kappa$ :

$$
\dot{\varepsilon}=\dot{a}_{0} \exp (\Delta S / R) \exp (-(Q-\sigma V) / R T) .
$$

The experimentally obtained activation volume and activation energy are defined as

$$
V_{\mathrm{ex}}=R T(\partial \ln \dot{\varepsilon} / \partial \sigma)_{T}
$$

and

$$
Q_{\mathrm{ex}}=R T^{2}(\partial \ln \dot{\varepsilon} / \partial T)_{\sigma}+\sigma V_{\mathrm{ex}} .
$$

Combining Equations 5, 6, and 7, we obtain the relation

$$
(Q-\sigma V)=Q_{\mathrm{ex}}-\sigma V_{\mathrm{ex}}-R T^{2}\left(\partial \ln \dot{a}_{0} / \partial T\right)_{\sigma} .
$$

Therefore, as long as the third term of Equation 8 is clearly formulated, we cannot analytically solve Equation 5 . Shoeck (1980) solved this problem by making reasonable assumptions such as $\dot{a}_{0}=\dot{a}_{0}(\sigma / \mu, T)$, where $\mu$ is the shear modulus, and derived the equation

$$
\Delta G=Q_{\mathrm{ex}} / \phi+V_{\mathrm{ex}} \sigma(1-\phi) / \phi+\gamma,
$$

where

$$
\gamma=R T^{2} / \phi \cdot\left(\partial \ln \dot{a}_{0} / \partial T\right)_{\mu}
$$

and

$$
\phi=1-\partial \ln \mu / \partial \ln T
$$

In some cases, the temperature dependence of $\gamma$ (i.e., the temperature dependence of $\dot{a}_{0}$ ) can be neglected in Equations 9 and 10 (Schoeck, 1980); however, $\dot{a}_{0}$ contains the variable of the dislocation density itself and we therefore consider the correction term, $\gamma$, as an adjustable parameter in this study. Selecting the adequate value as $\gamma$, we can calculate $\Delta G$ in Equation 9 and thus, according to Equations 1 and 3, the dislocation density is expressed by

$$
\rho=\dot{\varepsilon} / M b^{2} v_{\mathrm{D}} \kappa \cdot \exp \left[\left(Q_{\mathrm{ex}} / \phi+V_{\mathrm{ex}} \sigma(1-\phi) / \phi+\gamma\right) / R T\right] .
$$

In contrast, the correction term, $\gamma$, is estimated from the observed dislocation density:

$$
\gamma=R T \ln \left(\rho M b^{2} v_{\mathrm{D}} \kappa / \dot{\varepsilon}\right)-Q_{\mathrm{ex}} / \phi-V_{\mathrm{ex}} \sigma(1-\phi) / \phi .
$$

$Q_{\mathrm{ex}}$ and $V_{\mathrm{ex}}$ in Equation 9 are formulated using Equations 6 and 7 and the values of $Q_{\mathrm{ex}}$ and $V_{\mathrm{ex}}$ are calculated as follows. By rearranging Equations 5 and 8, we obtain

$$
\log \dot{\varepsilon}=-\left(Q_{\mathrm{ex}}-V_{\mathrm{ex}} \sigma\right) / 2.3 R T+C_{\mathrm{ex}}
$$

and

$$
C_{\mathrm{ex}}=\Delta S / 2.3 R+\log \left(M \rho b^{2} v_{\mathrm{D}} \kappa\right)+T / 2.3 \cdot(\partial \ln \rho / \partial T)_{\sigma},
$$


and subsequently, the logarithm of the creep rate in Equation 14 is analyzed by multiple regression analysis against $1 / T$ and $\sigma / T$ and we then obtain $Q_{\mathrm{ex}}, V_{\mathrm{ex}}$, and $C_{\mathrm{ex}}$ as regression coefficients and a constant. The creep rate in Equation 14 is then defined as the creep rate in a steady state, but the MCR is also regarded as the creep rate in Equation 14 in this study. Furthermore, though we cannot calculate the values of each term on the right side of Equation 15, $C_{\mathrm{ex}}$ in Equation 15 has been regarded as the universal constant, i.e., the Larson-Miller constant and $C_{\mathrm{ex}} \approx 20$, independent of not only the creep rate and test conditions but also the types of materials when the creep data are arranged using the units of Kelvin and hours (Tamura, Abe, Shiba, Sakasegawa, \& Tanigawa, 2013).

Equation 14 indicates that a linear relationship holds between $\log \dot{\varepsilon}$ and $\sigma$ at a constant temperature and it is well known experimentally for many heat-resistant steels and alloys that the MCR is inversely proportional to the logarithm of time to rupture, $t_{\mathrm{r}}$, (Monkman \& Grant, 1956). Equation 14 can therefore give the relation between $\log t_{\mathrm{r}}$ and $\sigma$ at a constant temperature. It has been confirmed experimentally that this relation holds for creep rupture data of many heat-resistant steels and alloys with widely varying temperature and stress (Tamura, Esaka, \& Shinozuka, 1999; Tamura, Esaka, \& Shinozuka, 2003). These results indicate that material constants, such as $Q_{\mathrm{ex}}$, $V_{\mathrm{ex}}$, and $C_{\mathrm{ex}}$, can be obtained and the related deformation mechanisms may be discussed for each material and a variety of test conditions. Certainly, although creep data with widely ranging test conditions for a specified material may be correlated using a single linear relation like Equation 14, the goodness of fit of an equation like Equation 14 to the creep data improves when all data ranging over 100,000 hours are classified into two or three groups. The changes in deformation mechanisms among these data groups can be discussed qualitatively, though an atomistic model of deformation cannot be specified even though the values, $Q_{\mathrm{ex}}, V_{\mathrm{ex}}$, and $C_{\mathrm{ex}}$, are calculated.

\section{Analysis Method}

\subsection{Material and Data for Analysis}

Types of materials for analysis are limited to metallic materials, the creep of which is controlled mainly by a dislocation creep mechanism, to avoid ambiguity that might arise when expanding the range of investigation. Finally, dislocation densities of 21 types of materials including steel materials, body-centered cubic (BCC) metals (Mo alloy, W, and W-Re alloy), face-centered cubic (FCC) metals (Al, Al-Mg alloy, $\mathrm{Cu}$, and $\mathrm{Ni}$ ), hexagonal closed-packed (HCP) metals (Ti and Mg alloy), and Ge were selected. Ge is not a metal, but deforms at high temperatures in a manner similar to the deformation of a metal. This report uses abbreviations such as $2.25 \mathrm{Cr}-1 \mathrm{Mo}$ steel and Gr. 91 steel (T-91, P-91, Gr. 91 of $9 \mathrm{Cr}-1 \mathrm{Mo}-\mathrm{VNb}$ steel), which are derived from well-known industrial standards, and TZM and AZ31, which are popular alloy names. In calculating the value of $\gamma$ in Equation 13, it is desirable to use creep data and dislocation density data obtained under similar conditions using the same material, but this is seldom possible. Therefore, in the present study, (1) the material for dislocation density measurements can be metallurgically regarded as an equivalent material for creep tests and (2) the test conditions for the dislocation density measurements are not far from the test conditions for the creep tests. Moreover, the following cases are analyzed. Although Equation 1 holds also for a nonsteady state, Equation 2 for a thermally activated process is generally considered to hold in a steady state. In this sense, we analyze the steady-state creep rates or the MCRs tested under uniaxial tensile creep stresses, but flow stresses due to tension or torsion under a constant strain rate are also analyzed, if the flow rates are judged to be in a steady state.

Concerning dislocation density measurements, the dislocation densities measured employing TEM for a thin foil of a crept specimen for which the test temperature, stress, and strain rate are reported are preferentially selected, but the dislocation densities measured by XRD analysis and $\mathrm{SCH}$ are also analyzed if necessary. Moreover, we need information on not only the dislocation density but also the temperature, stress, and strain rate for the analysis. However, in the case of hot-rolled specimens, only a rolling temperature may be reported. In such cases, the flow stress is estimated using a typical rolling speed and related creep data, and the usability of the dislocation density of the rolled specimen is then judged by checking the estimated flow stress. We note that Robinson and Sherby (1969) estimated a reasonable value of the dislocation density of pure $\mathrm{W}$ referring to the relation between the apparent activation energy and the homologous temperature, $T / T_{\mathrm{m}}$, and employing a method suggested by Hart (1957). This value does not come from direct observations, but has been fully discussed and is thus accepted. Moreover, in the case of a lack of data for the dislocation density in a steady state, the initial dislocation density or the dislocation density after rupture is referred to if these values can be metallurgically regarded as those of a steady state.

\subsection{Calculation of $\gamma$}

The values of $\gamma$ are calculated by analyzing 92 sets of data collected according to the above-mentioned considerations. The correction term, $\gamma$, is calculated using Equation 13 and the dislocation density and related creep data. In the calculation, we assume for any material that $M=0.5, v_{\mathrm{D}}=1 \mathrm{E} 13 \mathrm{~s}^{-1}$, and $\kappa=1$. The length of the Burgers vector is calculated from the lattice constant for the main componential element of the material at 
room temperature. In the case of metals having an HCP lattice, the distance between nearest-neighbor atoms in a basal plane is regarded as the length of the Burgers vector.

\subsection{Temperature Dependence of the Shear Modulus}

Before we calculate the correction term, $\gamma$, using Equation 13, we must calculate $\phi$ in Equation 13. For this purpose, the temperature dependence of the shear modulus of several materials was investigated. Figure 1 shows the relationship between the homologous temperature and the specific shear modulus for several materials; i.e., the shear modulus at a certain temperature divided by the shear modulus at room temperature, $\mu_{\mathrm{T}} / \mu_{\mathrm{RT}}$ for carbon steel (Ledbetter \& Reed, 1973), Gr.91, Type 316, and Ti (American Standard for Mechanical Engineering [ASME] BVP Code, 2015), 18Cr steel (Manninen \& Saynajakangas, 2013), Al (Takeuchi, Noda, Komori, Nyuko, \& Kitagawa, 1977), Cu (Ledbetter \& Naimon, 1974), W (Armstrong \& Brown, 1964), and Ge (Kardashev \& Nikanorov, 1985). Test temperatures for creep data collected for many heat-resistant steels are concentrated around $T / T_{\mathrm{m}} \approx 0.6$, which corresponds to $\partial \ln \mu / \partial \ln T \approx-0.5$. Thus, in most cases, the value of $\phi$ is considered to be constant; i.e., $\phi \approx 1.5$. However, the specific shear modulus for $18 \mathrm{Cr}$ steel, $\mathrm{Cu}, \mathrm{Al}$, and $\mathrm{W}$ may considerably decrease at higher temperatures and the value of $\phi$ therefore increases as shown in Figure 1. Meanwhile, values of the shear modulus at high temperatures around which hot working tests have been conducted may be lacking. In these cases, the calculation of $\gamma$ is limited within a temperature range where the shear modulus data exist, without extrapolating a trend curve. When Young's moduli at high temperatures are available, they are converted to shear moduli arranging Poisson's ratio from 0.30 to 0.32 . Furthermore, when the elastic properties of a specified material are not available, the elastic properties of a main componential element or an alloy for which the chemical composition is similar to that of the material considered are used, because the elastic properties can be regarded to be insensitive to the microstructure.

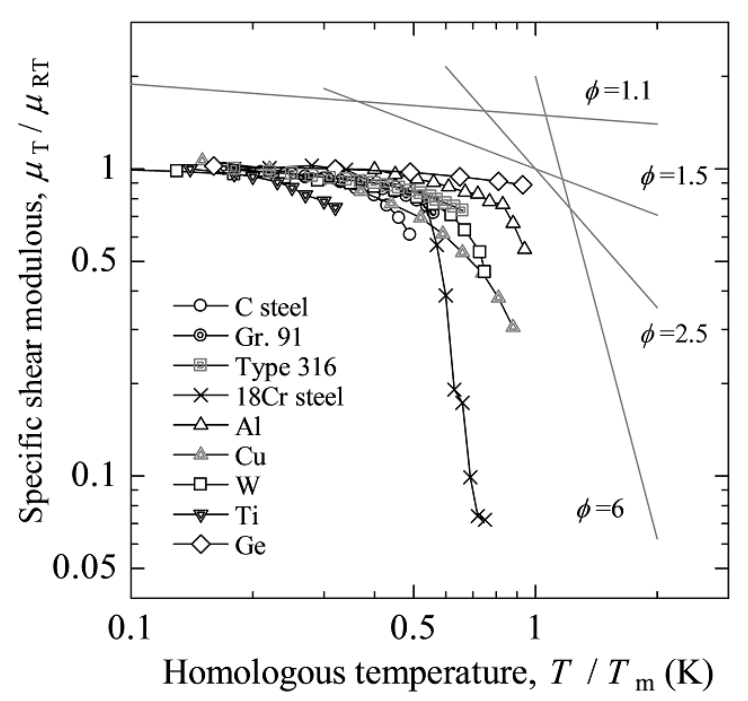

Figure 1. Specific shear modulus as functions of homologous temperature for carbon steel, Gr. 91, Type 316, $18 \mathrm{Cr}$ steel, $\mathrm{Al}, \mathrm{Cu}, \mathrm{W}, \mathrm{Ti}$, and $\mathrm{Ge}$. Citations for each material are shown in the text. $\phi$ is defined by Equation 11

\section{Results of Analysis}

The method used to analyze $\gamma$ in the present study is the same for all 21 types of materials and the results of analysis for 1Cr-Mo steel are given as a typical example in this section. The results for the other 20 types of materials are given in the appendix (Figures A1-A22).

Hayakawa et al. (2007a) reported the dislocation densities around the MCR at temperatures ranging 600 to $650{ }^{\circ} \mathrm{C}$ for $1 \mathrm{Cr}-0.5 \mathrm{Mo}$ steel in a fully annealed condition obtained employing TEM and an SCH method. Figure 2 shows the correlation between the stress and MCR of a $1 \mathrm{Cr}-0.5 \mathrm{Mo}$ steel tube from data sheet No. $1 \mathrm{~B}$ of the National Institute for Materials Science (NIMS), heat MBM (NIMS, 1996), which corresponds to the test conditions of the dislocation density observation. In this report, stress is expressed on a linear scale according to Equation 5 as shown in Figure 2, rather than the logarithmic scale usually used. The goodness of fit of Equation 14 to the MCR data improves when all data are classified into two groups: Gr. I (higher stress) and Gr. II (lower stress). The values of $Q_{\mathrm{ex}}, V_{\mathrm{ex}}$, and $C_{\mathrm{ex}}$ for $G r$. I become $743.7 \mathrm{kJmol}^{-1}, 241.1 \mathrm{~cm}^{3} \mathrm{~mol}^{-1}$, and 22.31 , respectively, while 
$Q_{\mathrm{ex}}, V_{\mathrm{ex}}$, and $C_{\mathrm{ex}}$ for $G r . I I$ become $435.9 \mathrm{kJmol}^{-1}, 419.6 \mathrm{~cm}^{3} \mathrm{~mol}^{-1}$, and 19.15 , respectively, using Equation 14 and the MCR data. These values seem to be comparable to those for the time to rupture of similar steels (Tamura et al., 1999; Tamura et al., 2013). A high value of $Q_{\mathrm{ex}}$ for $G r$. I is considered to result from an increase in resistance against mobile dislocations due to the increase in dislocation density immediately after the loading of higher stress. Regression lines are drawn in the figure for each temperature of Grs. I and II using these parameter constants. The dislocation densities were reported for specimens that crept at temperatures higher than the test temperatures used by the NIMS, but the data point obtained at $630^{\circ} \mathrm{C}$ and $60 \mathrm{MPa}$ by Hayakawa et al. (2007a) (solid square) lies near the regression line at $630^{\circ} \mathrm{C}$ for the NIMS data. There is a difference between the MCRs of Hayakawa et al. and the NIMS at $630^{\circ} \mathrm{C}$, but such a difference should be metallurgically allowed. Other data obtained by Hayakawa et al. (2007a) were reported without a strain rate, and therefore, the data are plotted on each regression line with cross marks at the reported temperatures and stresses. The observed dislocation densities and the values of $\gamma$ calculated for each data point using Equation 13 are listed in Figure 2. The dislocation densities at 600 and $650{ }^{\circ} \mathrm{C}$ were observed employing TEM and that at $630^{\circ} \mathrm{C}$ was calculated employing an SCH method. Hayakawa et al. (2007a) reported the dislocation densities as functions of creep strain to rupture at 600 to $650{ }^{\circ} \mathrm{C}$ and indicated that the dislocation densities observed by TEM were approximately one order of magnitude higher than those by SCH over the whole range of creep strain. Therefore, when the dislocation density is observed at 630 ${ }^{\circ} \mathrm{C}$ employing TEM, the dislocation density may become larger than that shown in the figure measured employing an SCH method. In that case, the value of $\gamma$ may become larger (shift to the positive side) according to Equation 13. In any case, the absolute values of $\gamma$ are not so large when compared with the value of $Q_{\mathrm{ex}}$ for $G r$. II. The temperature-dependence term of the shear modulus is set at $\phi=1.733$ to 1.897 using Young's modulus of a low-alloy steel and $v=0.30$ (ASME, 2015).

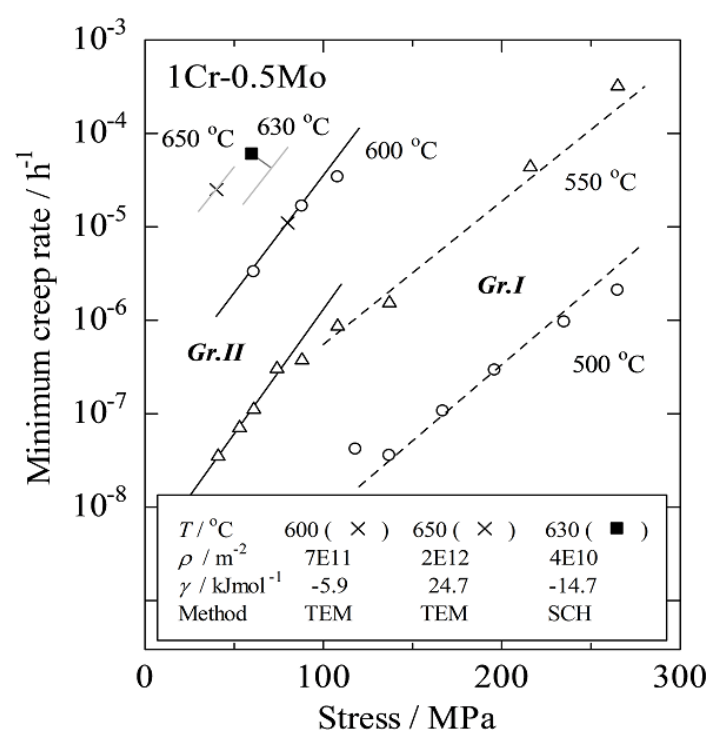

Figure 2. MCRs for 1Cr-0.5Mo steel (NIMS, 1996) as functions of stress. The values of $\gamma$ are also shown for the dislocation density observed by TEM at 600 and $650^{\circ} \mathrm{C}$ and the evaluated dislocation density obtained in an SCH method at $630{ }^{\circ} \mathrm{C}$ (Hayakawa, 2007a)

\section{Discussion}

\subsection{Extent of Test Conditions and Dislocation Density}

\subsubsection{Test Conditions for Creep and Hot Deformation}

Test conditions for creep and hot deformation of materials analyzed are described in Section 4 and the appendix. The creep rates or flow rates range from $1.2 \mathrm{E}-7 \mathrm{~h}^{-1}$ to $1000 \mathrm{~h}^{-1}$ and the geometric mean is $3.6 \mathrm{E}-3 \mathrm{~h}^{-1}$, with most values being distributed between $1.2 \mathrm{E}-4 \mathrm{~h}^{-1}$ and $1 \mathrm{~h}^{-1}$. The homologous temperatures range from 0.46 to 0.72 and average 0.60 . In other words, test conditions for which the values of $\gamma$ are calculated are in the range of so-called high-temperature dislocation creep (i.e., $T / T_{\mathrm{m}} \approx 0.6$ ), excepting that the values of $T / T_{\mathrm{m}}$ are 0.28 for CP-Ti (Figure A20), 0.98 for Ge (Figure A22), 0.81 for pure Ni (Figure A15), and 0.77 for pure $\mathrm{Al}$ at 450 ${ }^{\circ} \mathrm{C}$ (Figure A11). 
Although the instantaneous strain is generally small at sufficiently high temperatures, rather high stresses are applied at mid-range or low temperatures to detect observable MCRs, and as a result, many dislocations are introduced immediately after loading, which may affect the observed dislocation densities even in steady-state creep. The magnitude of the applied stress is then generalized by the proof stress at a certain temperature. The values of $P S$ for most heat-resistant steels at high temperatures are documented in data sheets published by the NIMS (2.25Cr-1Mo, 1986a; Type 304, 1986b; 1Cr-0.5Mo, 1996; Alloy 800, 1998; Type 316, 2000; Gr.91, 2007). For the values of $P S$ of X20 CrMoV 121 (X20, hereinafter) steel, the minimum values of Deutsche Industrie Normen were referred to. Regarding the values of $P S$ of Al and Al alloys (Watanabe Shoji Co., 2002), Cu (Japan Copper and Brass Association, 2006), Ni (Jenkins et al., 1958), W and W alloy (Sharafat, Martinez, \& Ghoniem, 1999), TZM (Mrotzek, Hoffmann, Martin, \& Oettel, 2007), CP-Ti (Japan Institute of Metals, 1993), and AZ31 (Nguyen et al., 2014), the cited references were used. The values of $P S$ at high temperatures of Ge were not found. The average of $\sigma / P S=0.66$ for the test conditions at which calculations of $\gamma$ were conducted. In other words, under most of the test conditions examined, the applied stresses are below each $P S$; however, under 15 test conditions in total, the applied stresses are larger than each PS. Among these 15 cases, there are one to four cases for each steel or alloy, with the exceptions of carbon steel, low-alloy steel, and $18 \mathrm{Cr}$ steel.

\subsubsection{Dislocation Density}

Among the referred dislocation densities (i.e., 92 cases), the dislocation densities are observed by TEM in 49 cases, with the average dislocation density obtained by TEM being $3.2 \mathrm{E} 13 \mathrm{~m}^{-2}$ (with the geometric mean being $1 \mathrm{E} 13 \mathrm{~m}^{-2}$ ), and with most values being concentrated in the range from $1 \mathrm{E} 12$ to $1 \mathrm{E} 14 \mathrm{~m}^{-2}$. Meanwhile, there are 36 cases of employing an $\mathrm{SCH}$ method, giving an average dislocation density of $2 \mathrm{E} 13 \mathrm{~m}^{-2}$ (with the geometric mean being $7.5 \mathrm{E} 11 \mathrm{~m}^{-2}$ ), which seems slightly lower than the density obtained employing TEM. However, we should consider that approximately half of the reported dislocation densities obtained employing an $\mathrm{SCH}$ method range from 1E9 to $2 \mathrm{E} 11 \mathrm{~m}^{-2}$; i.e., the values are considerably low. Four cases of CP-Ti and AZ31 were measured employing XRD analysis and had an average dislocation density of $4.1 \mathrm{E} 15 \mathrm{~m}^{-2}$, which is about two orders of magnitude higher than densities for the other metals and alloys obtained employing TEM or XRD and reported in this paper (see Figure 2 and Figures A1 to A22 in the appendix).

The differences among the dislocation densities evaluated employing TEM and an SCH test are as follows. Hayakawa et al. (2007) themselves reported that the dislocation densities obtained by TEM are more than one order of magnitude larger than those obtained employing an $\mathrm{SCH}$ method for any creep strain up to the rupture of $1 \mathrm{Cr}-0.5 \mathrm{Mo}$ steel tested at 600 and $650{ }^{\circ} \mathrm{C}$ as shown in Figure 2. They interpreted this fact as the dislocation densities observed employing TEM containing also immobile dislocations. However, a comparison of Figures A12 (Horiuchi et al., 1972) and A13 (Yoshinaga et al., 1984) shows in contrast that the dislocation densities measured using an SCH method are approximately 7 times those obtained by TEM for similar Al-Mg alloys tested under similar conditions. It is thus concluded that there are no essential differences in the dislocation densities obtained by a TEM observation and an SCH method, apart from the case for a detailed investigation of causes of the differences between individual cases. However, it should be remembered that the dislocation densities measured by Hayakawa et al. (1970; 2003; 2007a; 2007b) for alloy steels employing an SCH method are relatively low.

Incidentally, the differences in the dislocation densities evaluated employing TEM and XRD analysis are as follows. Umezaki et al. (2014) concluded from an investigation of the dislocation densities of type-304 stainless steel deformed under tension at $650{ }^{\circ} \mathrm{C}$ that there is no essential difference in the dislocation densities obtained by TEM and XRD analysis, though the dislocation densities obtained by TEM are a little higher than those obtained by XRD analysis. Moreover, Pesicka et al. (2003) reported that there was little difference in the dislocation densities obtained by TEM and XRD analyses for X20 steel that had crept at $650{ }^{\circ} \mathrm{C}$ with different heat treatments.

Meanwhile, dislocation densities of HCP metals have been measured in many cases using an indirect method, like XRD analysis, and we cannot find any report of a direct comparison between the methods of TEM and XRD The following gives the dislocation densities of deformed HCP metals reported in the literature, while dislocation densities of $\mathrm{CP}-\mathrm{Ti}$ are mainly reported with a type of Burgers vector, because several slip systems are usually activated in CP-Ti, besides twinning (Hanada, 1990). The dislocation density of warm-rolled CP-Ti at $40 \%$ reduction (Dragomir et al., 2005) was $\rho_{\mathrm{x}}=4 \mathrm{E} 14 \mathrm{~m}^{-2}$ (Figure A20), where the Burgers vector population of type $<\mathrm{a}>$ was the highest, and the dislocation densities of crept AZ31 Mg alloy at $350{ }^{\circ} \mathrm{C}$ (Roodposhti et al., 2015) were $\rho_{\mathrm{x}}=3 \mathrm{E} 15$ to $8 \mathrm{E} 15 \mathrm{~m}^{-2}$ (Figure A21), where basal slip planes were assumed to be activated. Both $\mathrm{CP}-\mathrm{Ti}$ and AZ31 Mg alloy are HCP metals and their dislocation densities were obtained by analyzing peak profiles of an XRD pattern. Alkhazraji et al. (2014) obtained $\rho_{\mathrm{x}}=1 \mathrm{E} 14$ to $4 \mathrm{E} 14 \mathrm{~m}^{-2}$ for the dislocation 
densities of cold-rolled CP-Ti at $40 \%$ to $80 \%$ reduction employing a synchrotron accelerator, where dislocations with Burgers vector of type $<\mathrm{a}>$ were tacitly understood to be primarily activated on prism planes. Fabian, Trojanova, and Kuzel (2007) obtained $\rho_{\mathrm{x}}=1.2 \mathrm{E} 14$ to $4.0 \mathrm{E} 14 \mathrm{~m}^{-2}$ as the dislocation densities on basal planes of crept pure Mg with ultra-fine grains under compression employing XRD analysis, where approximate $90 \%$ of the total dislocation density was accounted for by basal plane dislocations. Janecek et al. (2012) obtained $\rho_{\mathrm{x}}=$ $1 \mathrm{E} 14 \mathrm{~m}^{-2}$ as the dislocation density of AZ31 Mg alloy heavily deformed at $180{ }^{\circ} \mathrm{C}$ employing XRD analysis and analyzing the positron lifetime, without clearly reporting the types of Burgers vector. Zhang, Watzinger, Kong, and Blum (2000) obtained $\rho=1.2 \mathrm{E} 13 \mathrm{~m}^{-2}$, which is a little lower than values obtained employing XRD, as the dislocation density of crept AZ91 Mg alloy employing TEM, without reporting any information on the type of Burgers vector. Adams (1965) obtained $\rho_{\text {etch pit }}=2.6 \mathrm{E} 10 \mathrm{~m}^{-2}$ as the average dislocation density on basal slip planes of $\mathrm{Zn}$ single crystals that crept by $\varepsilon=0.06$ at room temperature employing an etch pit technique. However, in most cases the dislocation densities of HCP metals were indirectly studied employing $\mathrm{X}$-ray diffraction and the abovementioned dislocation densities of HCP metals, ranging from $\rho_{\mathrm{x}}=$ $1 \mathrm{E} 14$ to $8.0 \mathrm{E} 15 \mathrm{~m}^{-2}$, are rather high as compared with dislocation densities of metals having a cubic lattice observed employing TEM, which range from $\rho=5 \mathrm{E} 11$ to $3.5 \mathrm{E} 14 \mathrm{~m}^{-2}$ (see Figure 2 and Figures A3 to A8, A10 to A12, A14 to A19, and A22). The dislocation densities observed for CP-Ti and Mg alloy (Figures A20 and A21) employing XRD analysis are still higher than those observed for martensitic steels employing TEM $\left(\rho=1 \mathrm{E} 14\right.$ to $3.5 \mathrm{E} 14 \mathrm{~m}^{-2}$ ) (see Figures A3 to A5). In other words, it has been accepted that the dislocation densities of HCP metals obtained by XRD analysis as shown in Figures A20 and A21 in the appendix may be somewhat higher than those of the corresponding specimens measured employing TEM or an etch-pit technique, though direct comparisons among different methods using the same specimen have not been reported. Alkhazraji et al. (2014) reported that the dislocation density obtained by XRD analysis was higher than that obtained employing TEM, which can be explained by dislocations in a thin foil for TEM observation readily leaving the specimen surface under the action of the traction force acting on dislocations near both sides of free surfaces.

\subsection{Reliability and Deviation of the Values of $Q_{e x}$ and $\gamma$}

The relative reliability of the calculated values of $Q_{\mathrm{ex}}$ in this study is considered to be as high as that of $9 \mathrm{Cr}-1 \mathrm{~W}$ steel (i.e., within about 3\%) (Tamura et al., 2015) because most of data shown in Figure 2 and Figures A1-A22 are classified into several groups and the goodness of fit of Equation 14 to each creep data group is therefore similar to that in the case of $9 \mathrm{Cr}-1 \mathrm{~W}$ steel. Relative reliability of the calculated values of $\gamma$ in this study is considered to be at the same level as that of $Q_{\mathrm{ex}}$ because the main component of $\gamma$ is $Q_{\mathrm{ex}}$ as shown by Equation 13. In other words, the relative reliabilities of both $Q_{\mathrm{ex}}$ and $\gamma$ are considered to be sufficiently high. However, we should discuss in detail the deviation based on the test methods adopted for each data set rather than the reliability based on the scattering of experimental data.

The change in $\gamma$ due to a change in the observed dislocation density is evaluated using Equation 13 as

$$
\Delta \gamma=2.3 R T \Delta(\log \rho) \text {. }
$$

As explained in Section 5.1.2, the difference between the dislocation densities of Al-Mg alloy measured employing TEM and SCH methods is within one order of magnitude. However, Hayakawa (2003, 2007a, 2007b) measured dislocation densities in ferritic/martensitic steels employing an $\mathrm{SCH}$ method and reported that the values were about two orders of magnitude lower than those measured employing TEM, the reason for which was given in the previous section. In this paper, the dislocation density is discussed mainly on the basis of TEM data, and therefore, when dislocation densities of the ferritic/martensitic steels investigated by Hayakawa are measured employing TEM instead of an SCH method, the change in $\gamma$ at $T=1000 \mathrm{~K}$ is calculated according to Equation 16 as

$$
\Delta \gamma_{\mathrm{TEM} / \mathrm{SCH}}=2.3 R T \Delta(\log \rho) \sim+38 \mathrm{kJmol}^{-1} .
$$

This value is approximately $5 \%$ to $9 \%$ of the measured values of $Q_{\mathrm{ex}}$ and is not so large.

Meanwhile, the circumstances are rather complex for HCP metals, especially CP-Ti. The dislocation densities referred to for HCP metals (Figures A20 and A21) are obtained by XRD analysis. These values as explained in Section 5.1.2 are considered to be larger than those obtained employing TEM for metals other than HCP metals and still larger than those for martensitic steels (Figures A3-A5). Although we could not find literature making a detailed comparison of the dislocation densities of the same specimen measured employing both TEM and XRD methods, if we assume that the imaginary dislocation density obtained employing TEM is one order of magnitude lower than that obtained by XRD analysis, the change in $\gamma$ at $T=1000 \mathrm{~K}$ can be calculated according to Equation 16 as 


$$
\Delta \gamma_{\mathrm{TEM} / \mathrm{XRD}}=2.3 R T \Delta(\log \rho) \sim-19 \mathrm{kJmol}^{-1} .
$$

When we measure the dislocation densities for CP-Ti and Mg alloy employing TEM, the values of $\gamma$ are considered to shift in the negative direction according to Equation 18 . This change is approximately $5 \%-11 \%$ of the measured values of $Q_{\mathrm{ex}}$ and is not so large.

We next discuss the effect of slip systems on $\gamma$, because the length of the vector is one of the variables in the calculation of $\gamma$, given by Equation 14, and there is a possibility of an increase in the average length of the Burgers vector, especially for CP-Ti (Hanada, 1990). Roodposhti et al. (2015) and Fabian et al. (2007) confirmed that the major Burgers vector is type $<\mathrm{a}>$ for Mg alloys, and the assumption mentioned in Section 3.2 that the length of the Burgers vector is the distance between nearest-neighbor atoms in a basal plane is therefore valid. However, Dragomir et al. (2005) reported that in a warm-rolled CP-Ti specimen $40 \%$ of the activated Burgers vector is of type $<\mathrm{a}+\mathrm{c}>$, though the majority is still type $<\mathrm{a}>$. In these cases, the length of the Burgers vector may increase to some extent on average, which shifts the value of $\gamma$ of CP-Ti in the positive direction. Although the change due to the diversity of the type of Burgers vector cannot be estimated, the form of Equation 13 suggests that the effect is not as large as the effect of a change in the dislocation density (Equation 18).

Twinning is another concern when we evaluate the value of $\gamma$ for HCP metals. The referred creep data of HCP metals (Taira et al., 1960; Dragomir et al., 2005; Hyun et al., 2014; Roodposhti et al., 2015) do not contain any information on twinning deformation. Twinning should affect the values of $Q_{\mathrm{ex}}$ through the temperature dependence of the strain rate, given by Equation 7, and the strain rate due to twinning directly affects the value of $\gamma$ through Equation 13. Although we cannot evaluate the effect of twinning on the value of $\gamma$, deformation due to twinning may be negligible at high temperatures (Akhtar, 1975; Hanada, 1990).

Moreover, we should discuss the deviation of $Q_{\mathrm{ex}}$ for CP-Ti itself. Although the creep test temperatures of $\mathrm{Mg}$ alloy as shown in Figure A21 are around $T / T_{\mathrm{m}} \approx 0.67$, those for CP-Ti are rather low, around $T / T_{\mathrm{m}} \approx 0.28$. When the test temperature is low $\left(T / T_{\mathrm{m}}<0.5\right)$, the apparent activation energies for the creep of pure metals become lower than those for self-diffusion owing to defect-assisted diffusion. Sherby, Lytton, \& Dorn (1957) and Robinson et al. (1969) reported the relationship between the homologous temperature, $T / T_{\mathrm{m}}$, and the apparent activation energy for the creep of $\mathrm{Al}, \mathrm{Cu}$, and $\mathrm{W}$, and it can be estimated on the basis of the trends of these experimental results that the apparent activation energy for creep at $T / T_{\mathrm{m}} \approx 0.28$ is $70 \%$ of the apparent activation energy for creep at $T / T_{\mathrm{m}} \geq 0.5$. Therefore, for the creep of CP-Ti at $T / T_{\mathrm{m}} \approx 0.5$, where many metals adopted in this study crept at around $T / T_{\mathrm{m}} \geq 0.5$, the experimentally obtained activation energy is given by

$$
Q_{\mathrm{ex}, T / T_{m} 0.5}=Q_{\mathrm{ex}} / 0.7=562 \mathrm{kJmol}^{-1}, Q_{\mathrm{ex}}=393.5 \mathrm{kJmol}^{-1} .
$$

According to this simple discussion, $Q_{\mathrm{ex}}$ estimated at $T / T_{\mathrm{m}} \approx 0.5$ is $562-393.5=168.5 \mathrm{kJmol}^{-1}$ larger than $Q_{\mathrm{ex}}$ observed at $T / T_{\mathrm{m}} \approx 0.28$. The increase in $\gamma$ due to the increase in $Q_{\mathrm{ex}}$ is estimated from Equation 13 as

$$
\Delta \gamma_{T}=-\left(Q_{\mathrm{ex}} / \phi\right)_{T / T_{m} 0.5}+\left(Q_{\mathrm{ex}} / \phi\right)_{T / T_{m} 0.28} \approx-116 \mathrm{kJmol}^{-1},
$$

where the value of $\phi$ at $T / T_{\mathrm{m}} \approx 0.5$ is not experimentally obtained and the value $\phi=1.444$ at $T / T_{\mathrm{m}} \approx 0.28$ is thus used instead in the above estimation. The first term in Equation 13 contains a variable of dislocation density, and the dislocation density may change according to the change in the test temperature; unfortunately, we cannot estimate this effect. Even neglecting this effect and the effects of twinning deformation and the changes in the Burgers vector, the change in $\gamma$, when CP-Ti creeps at $T / T_{\mathrm{m}} \approx 0.5$ similarly to the many other metals studied here, is estimated to be as large as $\Delta \gamma=-116-19=-138 \mathrm{kJmol}^{-1}$ according to Equations 18 and 20 . This value corresponds to about $-35 \%$ of the observed $Q_{\mathrm{ex}}$ at $T / T_{\mathrm{m}} \approx 0.28$ as shown in Figure A20 in the appendix A20. Finally, it can be said that $\gamma$ for CP-Ti described in Figure A20 is a different kind of parameter as compared with parameters for most other metals.

\subsection{Validity of the Evaluation Equation for Dislocation Density}

\subsubsection{Distribution of $\gamma$}

The values of $\gamma$ indicated in Figure 2 and Figures A1 to A22 are distributed from -394 to $233 \mathrm{kJmol}^{-1}$ and average $+2.1 \mathrm{kJmol}^{-1}$. In a frequency table (Table 1) of $\gamma$ with intervals of $50 \mathrm{kJmol}^{-1}$, the frequency of the distribution is highest between 0 and $50 \mathrm{kJmol}^{-1}$; i.e., 41 of the 98 cases. The range of the peak width of $\pm 50 \mathrm{kJmol}^{-1}$ (i.e., from -50 to $100 \mathrm{kJmol}^{-1}$ ) accounts for about $60 \%$ of all values. Most of the values for pure $\mathrm{Al}$ and $\mathrm{Al}$ alloys fall in this band. Table 1 uses abbreviations such as LAS for carbon steel and low-alloy steels and $\mathrm{Al}$ for pure $\mathrm{Al}$ and $\mathrm{Al}$ alloys. In the present report, the abbreviations $\mathrm{Cu}, \mathrm{Ni}, \mathrm{W}, \mathrm{Mo}, \mathrm{Ti}, \mathrm{Mg}$, and $\mathrm{Ge}$ are frequently used to denote material groups, while the abbreviation $\mathrm{Al}$ specifically refers to the element aluminum. 
In the range $\gamma<-150 \mathrm{kJmol}^{-1}$ (i.e., large negative values), we find two cases of Mo, two cases of type-316 stainless steel, and seven cases of high-alloy martensitic steel (HAMS). The two cases of Mo involve $75 \%$ swaged TZM alloy and fully recrystallized TZM alloy, but high stress of $\sigma=1.3 P S$ was applied for the latter. Moreover, high stresses of about $\sigma=1.6 P S$ were applied also for the two cases of type-316 steel. Meanwhile, the applied stresses for the seven cases of HAMS were below each proof stress, but all seven cases of HAMS are Gr. 91 steel with high initial dislocation densities as observed by TEM; i.e., approximately $\rho=1 \mathrm{E} 14 \mathrm{~m}^{-2}$ (Panait et al., 2010). In materials that had large negative values of $\gamma$, many dislocations were introduced before loading owing to the martensitic microstructure, work hardening by swaging, or large instantaneous strain, and these materials are therefore called hard materials.

Meanwhile, in the range $\gamma>100 \mathrm{kJmol}^{-1}$ (i.e., large positive values), there is a case of pure $\mathrm{Ni}$, two cases of $18 \mathrm{Cr}$ steel, four cases of $\mathrm{Cu}$, and seven cases of $\mathrm{W}$ and $\mathrm{W}$ alloy. These materials hardly have strong strengthening factors and have microstructures like those of pure metals. These materials were tested at rather high homologous temperatures, the average being $T / T_{\mathrm{m}}=0.6$, and low stress levels, the average being $\sigma / P S=$ 0.45 . These materials with positive large values of $\gamma$ are called soft materials.

Table 1. Frequency table of $\gamma$ for Materials Examined

\begin{tabular}{lll}
\hline Range $\left(\mathrm{kJmol}^{-1}\right)$ & Frequency & Material \\
\hline$<-200$ & 1 & Mo \\
$-200 /-150$ & 10 & Mo, ASS(2), HAMS(7) \\
$-150 /-100$ & 6 & Ti, Ge, HAMS(4) \\
$-100 /-50$ & 7 & ASS(7) \\
$-50 / 0$ & 11 & Al, HAMS(2), ASS(3), LAS(5) \\
$0 / 50$ & 41 & $\operatorname{Mo}, \operatorname{HAMS}(2), \operatorname{LAS}(7), \operatorname{ASS}(10), \operatorname{Al}(21)$ \\
$50 / 100$ & 8 & $\mathrm{HAMS}, \mathrm{Cu}(2), \operatorname{Al}(2), \operatorname{Mg}(3)$ \\
$100 / 150$ & 10 & $\mathrm{Cu}(4), \mathrm{W}(5)$ \\
$150 / 200$ & 2 & W, Ni \\
$200 / 250$ & 2 & W, 18Cr \\
\hline
\end{tabular}

LAS= C-steel, $1 \mathrm{Cr}-0.5 \mathrm{Mo}, 2.25 \mathrm{Cr}-1 \mathrm{Mo}$

HAMS $=$ Gr. 91, Gr. 92, Co-modified Gr. 92, 9Cr(Forged rotor), X20 CrMoV 121

$18 \mathrm{Cr}=\mathrm{Fe}-18 \mathrm{Cr}-\mathrm{Ti}-\mathrm{Nb}$

ASS $=$ Type 304, Type 316

$\mathrm{Al}=$ Pure Al, Al-5.2Mg, Al-6.2Mg

$\mathrm{Cu}=$ Pure $\mathrm{Cu}$

$\mathrm{Ni}=$ Pure $\mathrm{Ni}$

$\mathrm{W}=$ Pure $\mathrm{W}, \mathrm{W}-0.5 \operatorname{Re}$

$\mathrm{Mo}=\mathrm{TZM}$-recrystallized, TZM-75\% swaged

$\mathrm{Ti}=\mathrm{CP}-\mathrm{Ti}$

$\mathrm{Mg}=\mathrm{AZ3} 1 \mathrm{Mg}$ alloy

$\mathrm{Ge}=\mathrm{Ge}$ single crystal

Numbers in parentheses denote frequency

\subsubsection{Correlation between $\gamma$ and $Q_{\mathrm{ex}}$}

The first term on the right side of Equation 13, an equation for calculating $\gamma$, is a function of the temperature, dislocation density, and strain rate, while the third term is a function of stress and the activation volume; i.e., these terms have multiple variables. Meanwhile, the second term has only one variable, namely the experimentally obtained activation energy, $Q_{\mathrm{ex}}$. Figure 3 then shows the correlation between $Q_{\mathrm{ex}}$ and $\gamma$. Data points are distributed between the lines $\gamma=-0.33 Q_{\mathrm{ex}}$ and $\gamma=+0.79 Q_{\mathrm{ex}}$ and there are many data points near the line $\gamma=0$, which is evident from Table 1. Although all data points seem to be distributed randomly, the data points of the ferrous material are distributed closely around their regression line drawn in the figure. The absolute value of the reciprocal of the slope of the regression line (i.e., 1.86) is approximately close to the average of the 
temperature-dependence term of the shear modulus, $\phi=2.28$, as suggested by Equation 13. It is generally accepted that materials with large values of $Q_{\mathrm{ex}}$ have high strength; therefore, it can be understood from the data points around the regression line that the values of $\gamma$ of a hard material become negative and large. This trend is true for the Mo data group. The regression lines for $\mathrm{Al}$ and $\mathrm{W}$ data groups separately are drawn as broken lines with negative slopes like the slope of the regression line for the ferrous material. Data points for $18 \mathrm{Cr}$ steel and W, which are categorized as soft materials, are around the left side of each regression line, where the values of $Q_{\mathrm{ex}}$ are small and the $\gamma$ values are large and positive. The data points of the other soft materials, namely $\mathrm{Cu}, \mathrm{Ni}$, and $\mathrm{Mg}$, are also distributed in the area where the values of $Q_{\mathrm{ex}}$ are small and the $\gamma$ values are large and positive, though regression lines for these materials are not drawn because the numbers of data for each are limited. It can be said from the correlations for each data group shown in Figure 3 that there exists a certain combination of material and test conditions which satisfies the relation of $\gamma=0$ for each data group.

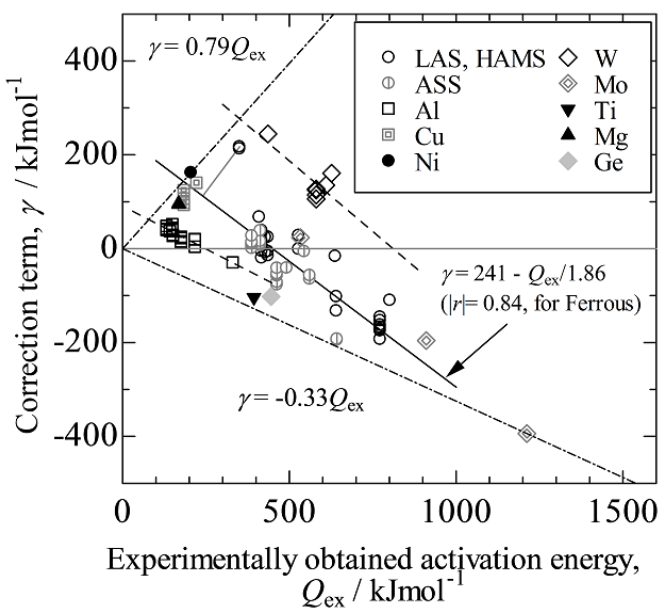

Figure 3. Correlation between the experimentally obtained activation energy, $Q_{\mathrm{ex}}$, and the correction term, $\gamma$. Regression lines are given for ferrous materials, the $\mathrm{W}$ data group, and the Al data group. All data are plotted between two dot-dash lines. The abbreviations in the column denote data groups explained in Table 1

\subsubsection{Introduction of Uncorrected Dislocation Density, $\rho_{0}$}

Defining the dislocation density for $\gamma=0$ in Equation 12 as uncorrected dislocation density, $\rho_{0}$, Equation 13 can be rewritten as a simple equation,

$$
\gamma=R T \ln \left(\rho / \rho_{0}\right)
$$

Figure 4 shows the relation between $\rho_{0}$ and $\gamma$ for all data investigated. In the explanation of Table 1, we use the term "hard material" when $\gamma \ll 0$ and the term "soft material" when $\gamma \gg 0$. Therefore, the terms hard and soft are schematically illustrated in the figure. The correlation for all data in Figure 4 is considerably better than that in Figure 3, as expected from Equation 21. The regression line for the ferrous material is drawn in the figure with a solid line, and the correlation coefficient of $|r|=0.95$ is better than that of $|r|=0.84$ in Figure 3 . The first term of the regression equation, $206 \mathrm{kJmol}^{-1}$, corresponds to the value of $\gamma$ for $\rho_{0}=1 \mathrm{~m}^{-2}$, i.e., a near-perfect crystal, and the coefficient of the second term, $16.9 \mathrm{kJmol}^{-1}$, relates to the value of the average test temperature for the ferrous material times the gas constant, $2.3 R T_{\mathrm{av}}$. The intersection of the regression line and $\gamma=0$, $\rho_{0}$ (obs), is $1.5 \mathrm{E} 12 \mathrm{~m}^{-2}$ for the ferrous material. This intersection clearly indicates that the calculated dislocation density obtained using Equation 12 for the ferrous material assuming $\gamma=0$ is equal to the observed dislocation density. It is therefore reasonable that $1.5 \mathrm{E} 12 \mathrm{~m}^{-2}$ is close to the observed dislocation densities of the crept ferrous materials in a steady state, as is seen in Figure 2 and Figures A6, A7, A8, and A10.

Incidentally, the uncorrected dislocation density, $\rho_{0}$, which can be calculated using only experimental creep data for an individual data set without adjusting $\gamma$, depends on the temperature, stress, creep rate, and temperature-dependence term of the shear modulus, $\phi$, and the values are distributed widely as shown in Figure 4. As mentioned above, type-316 stainless steel with high applied stresses is already hardened at an early stage of transition creep, before the strain of the MCR, and HAMS is also hardened by its martensitic structure before creep tests. Therefore, in the cases of a hard material, the relation $\rho_{0} \gg \rho$ (obs) is satisfied, where $\rho$ (obs) is the 
observed dislocation density, and thus the values of the uncorrected term, $\gamma$, become negative and large as seen in Figure 4 and Figures A3, A4, A6, and A10. In contrast, in the cases of $18 \mathrm{Cr}$ steel, LAS tested at higher temperatures, HAMS tested at higher temperatures and lower stresses, and austenitic stainless steel (ASS) with low applied stresses, the relation $\rho_{0}<\rho$ (obs) holds, and thus, the values of the uncorrected term, $\gamma$, become positive as seen in Figure 4 and Figures A3 to A5, A8 to A10, and A12.

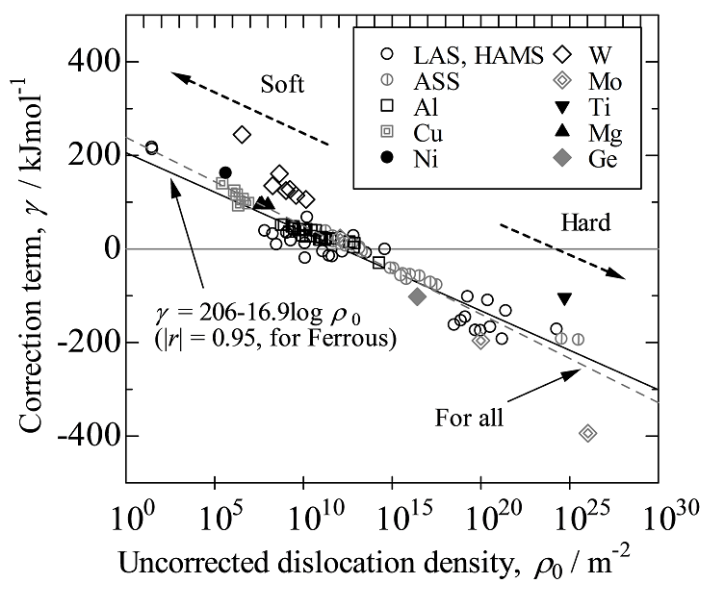

Figure 4. Correlation between the uncorrected dislocation density, $\rho_{0}$, and correction term, $\gamma$. Regression lines are given for ferrous materials (solid line) and all data (broken line). Symbols in the column denote data groups, explained in Table 1. Materials are schematically categorized as "soft" and "hard" according to Table 1 and the explanation given in Section 5.3.1

\subsubsection{Feasibility of $\gamma \approx 0$ in the Evaluation Equation for Dislocation Density, Equation 12}

Figure 5 shows the relation between the homologous temperature of the LAS, HAMS, ASS, Al, $\mathrm{Cu}$, and $\mathrm{W}$ data groups and $\rho_{0}$, because many data in Figure 4 overlap near the line $\gamma=0$. In Figure 5, the relation $\rho_{0}(\mathrm{obs})=$ $1.5 \mathrm{E} 12 \mathrm{~m}^{-2}$ for the ferrous material is drawn with a broken line, the value of which denotes the dislocation density at $\gamma=0$ and at the same time corresponds to the imaginarily observed dislocation density. In the figure, the positive values of $\gamma$ are shown by symbols distinguished from the negative values for each data group. The value of $\rho_{0}$ tends to decrease with an increase in $T / T_{\mathrm{m}}$ and, above $T / T_{\mathrm{m}} \approx 0.6$ or when $\rho_{0}<\rho_{0}$ (obs) for the ferrous material, the slope tends to become more gradual. The data of LAS and HAMS were recorded at $T / T_{\mathrm{m}}<$ 0.6 and are roughly classified into a high-strength group (solid circles, $\gamma<0$ ) and a low-strength group (double circles, $\gamma>0$ ). The uncorrected dislocation density, $\rho_{0}$, of the high-strength group is large, ranging from 1E18 to $1 \mathrm{E} 25 \mathrm{~m}^{-2}$, but $\rho_{0}$ of the low-strength group is below $1 \mathrm{E} 13 \mathrm{~m}^{-2}$. Thereby, we find the middle group with $\gamma<$ 0 and $\rho_{0} \approx 1 \mathrm{E} 12 \mathrm{~m}^{-2}$ (circles). In this middle group, X20 steel tested at $550{ }^{\circ} \mathrm{C}$ and $120 \mathrm{MPa}$ and considered a member of $G r$. I (Figure A6, $\gamma=-8.4 \mathrm{kJmol}^{-1}$ ) is included. This is because degradation may happen during long-term testing, which reduces $\rho_{0}$ as for LAS, even though X20 steel is an HAMS. In this group, the data of Panait et al. for which degradation was confirmed by long-term tests (Figure A3) and the data for forged rotors tested at $600{ }^{\circ} \mathrm{C}$ and $160 \mathrm{MPa}$ are also included. Figure 5 shows that the HAMS is classified into two groups with different values of $\rho_{0}$, hard (solid circles) and soft (open circles) groups, even though the relation $\gamma<0$ holds for both HAMS groups. The main factor that explains the difference between the two groups is the experimentally obtained activation energy, $Q_{\mathrm{ex}}$, and the boundary between hard and soft groups is $Q_{\mathrm{ex}} \approx 640 \mathrm{kJmol}^{-1}$. In the middle group, we find also the LAS of carbon steel, $1 \mathrm{Cr}-0.5 \mathrm{Mo}$ steel, and $2.25 \mathrm{Cr}-1 \mathrm{Mo}$ steel that were tested at low temperatures of $T / T_{\mathrm{m}}<0.5$, which resulted in an increase in $\rho_{0}$ and $\gamma<0$. The low-strength group (double circles, $\gamma>0$ ) is mainly composed of LAS, but contains forged rotors tested at $650{ }^{\circ} \mathrm{C}$ (Figure A5) and X20 steel tested at $650^{\circ} \mathrm{C}$ and evaluated as a member of $G r$. I (Figure A6). The data of ASS are also classified into two groups according to the sign of $\gamma$. The main factor of the difference is the experimentally obtained activation energy, $Q_{\mathrm{ex}}$, and when $Q_{\mathrm{ex}} \gtrsim 440 \mathrm{kJmol}^{-1}$, the correction term, $\gamma$, is negative and $\rho_{0}$ becomes large. In the Al group (square and double squares), we find a single case of $\gamma<0$ tested at $450{ }^{\circ} \mathrm{C}$ shown in Figure A11. The Al group with $\gamma>0$ can be further classified into two groups depending on the value of $Q_{\mathrm{ex}}$ and $\gamma$ is small and $\rho_{0}$ is a little larger when $Q_{\mathrm{ex}} \gtrsim 165 \mathrm{kJmol}^{-1}$. For pure $\mathrm{Cu}$ and the $\mathrm{W}$ group, $\gamma>0$ and $\rho_{0}$ is small in all cases. 


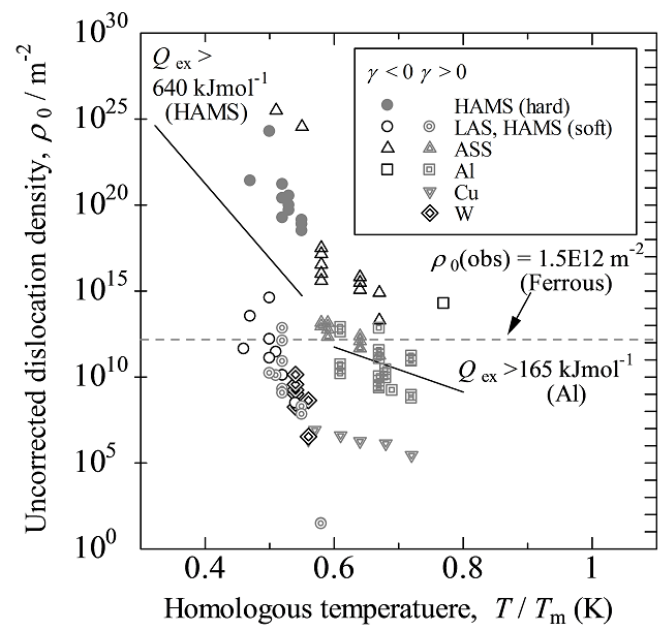

Figure 5. Uncorrected dislocation density, $\rho_{0}$, as a function of homologous temperature, $T / T_{\mathrm{m}}$. Symbols in the column denote data groups, explained in Table 1. $\rho_{0}$ (obs) $\left(\rho_{0}\right.$ for $\gamma=0$ in Figure 4) for ferrous material is drawn as a broken line. Data for HAMS and the Al data group are classified into two groups according to the experimentally obtained activation energy, $Q_{\mathrm{ex}}$

\subsubsection{Validity of the Evaluation Equation for Dislocation Density, Equation 12}

Figures 4 and 5 confirm that the approximation of $\gamma \approx 0$ in Equation 12 (i.e., $\rho_{0}(\mathrm{obs})=1.5 \mathrm{E} 12 \mathrm{~m}^{-2}$ ) holds for many kinds of materials in LAS, HAMS, ASS, and Al data groups. Therefore, Table 1, Figure 4, and Figure 5 indicate that the proposition that the correction term of Equation 12 can be assumed to be approximately zero, $\gamma \approx$ $0 \mathrm{kJmol}^{-1}$, is confirmed by many experimental results, and therefore, it can be concluded that a sufficient condition for Equation 12 to be valid for the calculation of dislocation densities in a steady-state creep is partially satisfied. Moreover, Figure 4 shows that $\rho_{0}$ (obs) for all data including those of ferrous and non-ferrous materials tends to converge in a narrow range between $1 \mathrm{E} 12$ and $1 \mathrm{E} 14 \mathrm{~m}^{-2}$. This range is similar to the range of dislocation densities usually observed employing TEM. We are thus able to confirm that the dislocation density calculated using Equation 12 and assuming $\gamma=0$ is equal to the observed dislocation density if we can choose appropriate test conditions for any material, e.g., $T / T_{\mathrm{m}} \approx 0.6$ in Figure 5 . We thus conclude that the evaluation equation of the dislocation density in a steady state of metals is valid, although we made several assumptions when introducing Equation 12.

\subsection{Relation between Steady-state Creep and Self-diffusion}

The correction terms of Equations 9 and 12, $\gamma$, were calculated back using the observed dislocation densities and the changes in Gibbs free energy can therefore be calculated using Equation 9 for each steady-state creep of the materials investigated. Figure 6 shows the relation between the experimentally obtained activation energy and the change in Gibbs free energy for steady-state creep. We can confirm that these two variables are related to a weak positive correlation. This is expected because $Q_{\mathrm{ex}}$ is a main configuration factor of $\Delta G$. However, this is not true regarding an individual material. For example, $Q_{\mathrm{ex}}$ values of ASS (open triangles) are widely distributed, ranging from 388 to $643 \mathrm{kJmol}^{-1}$, but $\Delta G$ values are in a narrow range of 205 to $269 \mathrm{kJmol}^{-1}$ and, moreover, we cannot significantly confirm even a positive correlation. Similar phenomena are found for LAS, HAMS, W, Mo, and Al data groups. 


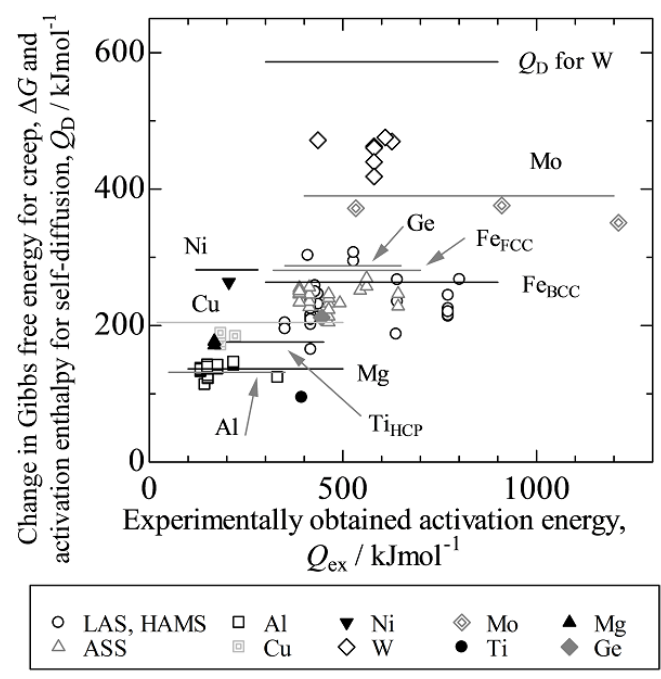

Figure 6. Correlation between the experimentally obtained activation energy, $Q_{\mathrm{ex}}$, and the change in Gibbs free energy for creep, $\Delta G$. Symbols in the column denote data groups, explained in Table 1; however, symbols in the figure denote the name of the element that is the main constituent element for each data group. Horizontal lines near each data group denote the activation enthalpy for the self-diffusion, $Q_{D}$, of each element

Horizontal bars in the figure indicate the values of activation enthalpy, $Q_{\mathrm{D}}$, for self-diffusion of a main constituent element in each material. We find that, in most cases, the relation $Q_{\mathrm{D}} \gtrsim \Delta G$ holds in Figure 6. Figure 7 then shows the relation between $\Delta G$ and $Q_{\mathrm{D}}$, where the diffusion data for each main constituent element refer to Fe (Oikawa, 1982), Al (Neumann, Reimers, \& Bartdorff, 1975), Cu (Lam, Rothman, \& Nowicki, 1974), Ni (Maier, Mehrer, Lessmann, \& Schule, 1976), W (Mundy, Rothman, Lam, Hoff, \& Nowicki, 1978), Mo (Askill \& Tomlin), Ti (Koppers, Derdau, Friesel, \& Herzig), Mg (Shewmon, 1963; Ganeshan, Hector Jr., \& Liu, 2010), and Ge (Letaw, Jr., Portnoy, \& Slifkin,1956). In referring to diffusion data, we selected diffusion data that were experimentally obtained at temperatures near the temperatures at which creep tests were conducted. The figure reveals that $\Delta G$ and $Q_{\mathrm{D}}$ have a strong correlation not only for cubic structure materials but also for HCP and diamond structure materials. We obtained the relation $Q_{\mathrm{D}}=1.16 \Delta G$.

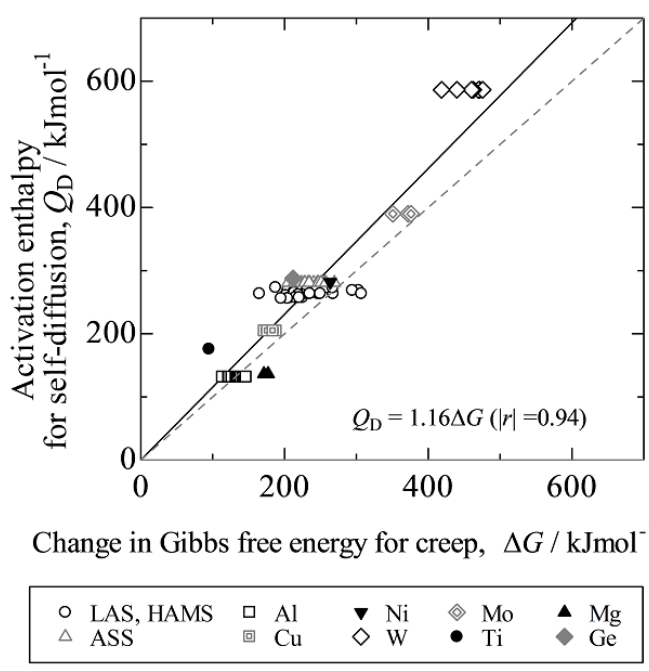

Figure 7. Correlation between the change in Gibbs free energy for creep, $\Delta G$, and activation enthalpy for self-diffusion, $Q_{\mathrm{D}}$. Symbols in the column denote data groups, explained in Table 1 
Diffusion data for self-diffusion, especially in a cubic structure, are usually explained by a single-vacancy mechanism. Meanwhile, since Sherby et al. (1953) found the relation $Q_{\mathrm{aac}}=Q_{\mathrm{D}}$ for some pure metals, creep phenomena of metals have been interpreted using a mechanism of dislocation motions with the help of the formation and migration of single vacancies, whether the creep mechanism is based on a climb model or a jog model. However, for most heat-resistant steels and alloys that have actual uses, it is well known that the relations $Q_{\mathrm{ex}}=Q_{\mathrm{aac}}$ and $Q_{\mathrm{ex}} \gg Q_{\mathrm{D}}$ hold (Tamura et al., 1999; Tamura et al., 2003; Tamura et al., 2013). To solve this apparent inconsistency, many studies have been performed as mentioned in Section 1, because the vacancy mechanism has been believed beyond doubt to be true even for the creep of most heat-resistant steels. However, the results of these activities are complicated and are not so easy to understand. Therefore, we have now calculated the changes in Gibbs free energy during steady-state creep using creep curves. We should not be satisfied simply by getting the relation $Q_{\mathrm{D}}=1.16 \Delta G$ (Figure 7). Rather, we need to relate $\Delta G$ for creep with the change in Gibbs free energy for self-diffusion evaluated employing a single vacancy model.

Mehrer (2007) expressed the diffusion coefficient for crystalline solids according to the single-vacancy mechanism of self-diffusion as

$$
D=D_{0} \exp \left(-Q_{\mathrm{D}} / R T\right)
$$

and

$$
D_{0}=g f v_{\mathrm{D}} a^{2} \exp \left(\Delta S_{\mathrm{D}} / R\right),
$$

where $g, f, a$, and $\Delta S_{\mathrm{D}}$ are respectively the geometrical factor for random diffusion, the correlation factor, the lattice parameter, and the change in entropy for diffusion. Mehrer summarized the values of $g$ and $f$ for BCC, FCC, and HCP structures on the basis of a two-dimensional model (2D-HCP) and diamond structure as presented in Table 2. The values of $D_{0}$ together with those of $Q_{\mathrm{D}}$ are reported for the main constituent elements in the literature mentioned above, and we can therefore calculate the changes in Gibbs free energy, $\Delta G_{\mathrm{D}}$, for the self-diffusion of each main constituent element at a temperature at which the dislocation density was observed. Figure 8 shows the relation between $\Delta G$ and $\Delta G_{\mathrm{D}}$. It is found that $\Delta G \cong \Delta G_{\mathrm{D}}$; i.e., the changes in Gibbs free energy during the steady-state creep of many types of metals including heat-resistant steels having practical uses are approximately equal to the changes in Gibbs free energy for self-diffusion of the main constituent elements of the materials. In this study, as much information on the dislocation density and deformation rate in a steady state as possible was collected and analyzed as mentioned above on the basis of several assumptions. As a result, we obtained the definite relation $\Delta G \approx \Delta G_{\mathrm{D}}$ as seen in Figure 8. Therefore, although the two variables have a strong correlation with a high correlation coefficient, individual data points are scattered around the regression line $\Delta G_{\mathrm{D}}=0.98 \Delta G$. We should pay particular attention to the behavior of HCP metals. Regarding Ti and Mg, the changes in Gibbs free energy for self-diffusion in a basal plane were calculated employing a two-dimensional model, because calculation models for non-basal planes like the model expressed by Equation 23 have not yet been developed. For AZ31 Mg alloy, dislocation densities are estimated employing an XRD method assuming basal plane slip (Roodposhti et al., 2015). In the case of the warm-rolled CP-Ti, however, it is confirmed only that the major slip direction is along the nearest-neighbor atom direction and it is not guaranteed that a basal slip system is the major system (Dragomir et al., 2005). It is thus considered that the change in Gibbs free energy for self-diffusion (i.e., the vertical axis of Figure 8), $\Delta G_{D}$, of CP-Ti should be plotted for reference.

The dislocation density of AZ31 Mg alloy is evaluated employing XRD analysis and the dislocation densities obtained are considered to be one order of magnitude higher than those obtained employing TEM as mentioned in Section 5.2. If we measure the dislocation density of AZ31 Mg alloy employing TEM, by which many data quoted in this report were obtained, and obtain values that are one order of magnitude lower, the values in each case decrease by approximately $-19 \mathrm{kJmol}^{-1}$ according to Equations 13 and 18 and the values of $\Delta G$ for creep decrease according to Equation 9. In this case, data points of the $\mathrm{Mg}$ data group shift to the left by approximately $-19 \mathrm{kJmol}$ ${ }^{-1}$ and become closer to the regression line.

Meanwhile, concerning CP-Ti, it seems inappropriate that $\Delta G$ for the creep of CP-Ti calculated using the estimated $\gamma$ at $T / T_{m}=0.28$ (Figure A20) is directly compared with values of $\Delta G$ for other metals that are calculated using values of $\gamma$ estimated at much higher temperatures. However, because the summation of the first and second terms of Equation 9 is $\gamma+Q_{\mathrm{ex}} / \phi$, the effects of the test temperature on $\gamma$ and $Q_{\mathrm{ex}}$ cancel each other out and the effect of the test temperature on $\Delta G$ is thus considered to be negligible. Therefore, $\Delta G$ for creep of $\mathrm{CP}-\mathrm{Ti}$ is considered to be affected by employing an XRD method as is the case for Mg alloy; i.e., the data point of $\mathrm{CP}-\mathrm{Ti}$ in Figure 8 should be considered to be shifted to the left similarly to the case for $\mathrm{Mg}$ alloy when we compare $\Delta G$ for the creep of CP-Ti with values for other metals calculated employing TEM. 
Table 2. Values of $f$ and $g$ for each crystal structure

\begin{tabular}{lcc}
\hline Structure & $f$ & $g$ \\
\hline BCC & 0.727 & 1 \\
FCC & 0.782 & 1 \\
2D-HCP & 0.560 & 1 \\
Diamond & 0.500 & 0.124 \\
\hline
\end{tabular}

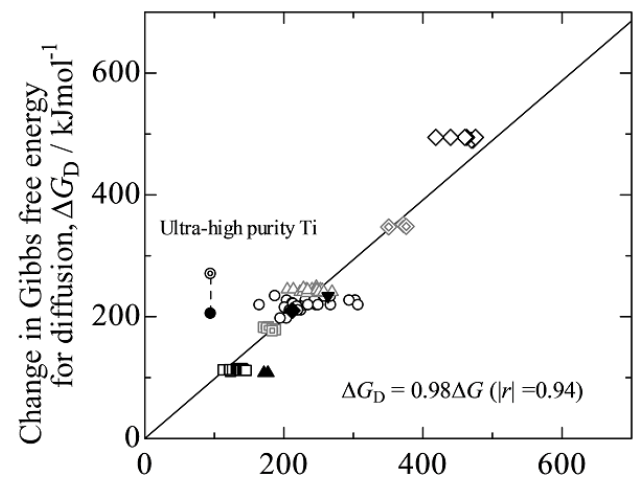

Change in Gibbs free energy for creep, $\Delta G / \mathrm{kJmol}^{-1}$

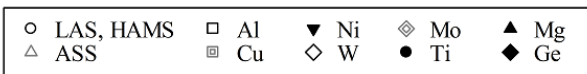

Figure 8. Correlation between the change in Gibbs free energy for creep, $\Delta G$, and the change in Gibbs free energy for self-diffusion, $\Delta G_{\mathrm{D}}$, of the main constituent element for each data group. Symbols in the column denote data groups, explained in Table 1. Diffusion data with a high value of $\Delta G_{\mathrm{D}}$ for ultra-high-purity titanium are also plotted for discussion (see the main text). A regression line that passes through the origin for all data except the high-purity titanium data is drawn

By the way, the value of $\Delta G_{\mathrm{D}}$ of HCP Ti (solid circle in Figure 8) was calculated using Equations 22 and 23 and the diffusion coefficient reported by Koppers et al. (1997), where CP-Ti with an HCP structure was used with impurity levels similar to those of CP-Ti that was used in creep tests. The regression line in Figure 8 is calculated for all data including a data point of $\mathrm{Ti}$ (solid circle). Most diffusion coefficients for self-diffusion in a basal plane of Ti reported in the literature (Dyment \& Libanati, 1968) are $\Delta Q_{\mathrm{D}} \approx 150 \mathrm{kJmol}^{-1}$ and $D_{0} \approx 1 \mathrm{E}-10 \mathrm{~m}^{2} \mathrm{~s}^{-1}$. However, using these values and Equation 23 results in negative values of the apparent change in entropy for diffusion, $\Delta S_{\mathrm{D}}$. The apparent changes in entropy for diffusion of $\mathrm{Zr}$ and Hf, which are both IV-a group elements, with an HCP structure are calculated using Equation 23 and both observed values of $D_{0}$ are also negative (Dyment et al., 1968). However, the change in entropy for diffusion should theoretically be positive (Zener, 1952; Mendelev \& Bokstein, 2010). Regarding this problem, Koppers et al. (1997) themselves conducted a series of diffusion experiments using $\alpha$-Ti with ultra-high purity and confirmed that $\Delta Q_{\mathrm{D}}=306.0 \mathrm{kJmol}^{-1}$ and $D_{0} \approx 1.4 \mathrm{E}-$ $3 \mathrm{~m}^{2} \mathrm{~s}^{-1}$. These values are similar to those of many metals with a cubic or an HCP structure and $\Delta \mathrm{S}_{\mathrm{D}}$ of ultra-high pure $\alpha$-Ti becomes positive when using these values. $\Delta G_{\mathrm{D}}$ was recalculated using $\Delta Q_{\mathrm{D}}$ and $D_{0}$ of ultra-high pure $\alpha$-Ti and a new data point is plotted as a double circle in Figure 8. Unfortunately, the new plot is away from the original regression line, though $\Delta \mathrm{S}_{\mathrm{D}}$ becomes positive. That $D_{0}$ of $\alpha$-Ti with a normal impurity level is apparently small, resulting in $\Delta S_{\mathrm{D}}<0$, can be explained phenomenologically as follows. The diffusion coefficient for self-diffusion increases by adding a small amount of impurity to ultra-high purity Ti with an HCP structure, but the increase becomes large at lower temperatures and the slope of an Arrhenius plot therefore decreases and $D_{0}$ becomes small. Perez, Nakajima, and Dyment (2003) reviewed that the addition of Co to $\alpha$-Ti increases the diffusion coefficient by more than an order of magnitude and proposed the mechanisms of ultra-fast diffusion. However, the enhancement of self-diffusion of $\alpha$-Ti due to the addition of a very small amount of impurity has not been explained. Both values of $\Delta G_{\mathrm{D}}$ of $\alpha$-Ti shown in Figure 8 are calculated assuming the vacancy mechanism. However, it is well known that interstitial diffusion is far faster than substitutional diffusion (Mehrer, 2007) and, moreover, Mendelev and Bokstein (2010) reported on the basis of a molecular dynamics study that the self-diffusion of $\alpha-\mathrm{Zr}$ based on the interstitial diffusion mechanism is faster than that based on the vacancy mechanism and that the difference in the diffusion coefficient between the substitutional and vacancy mechanisms 
is greater at lower temperatures. In other words, it is unclear how to calculate $\Delta G$ for HCP metals, which transform to BCC structures at higher temperatures, and therefore, plotting $\mathrm{HCP}$ data, especially data of $\mathrm{Ti}$, in Figure 8 itself may be a problem. However, this problem is beyond the scope of the present study.

The goodness of fit of Equation 14 to the creep data for CP-Ti shown in Figure A20 is not as good as that in similar figures. For the aim of improving only the fitness of Gr. II in Figure A20, excluding the low-strain-rate data may be effective. However, in that case, there are fewer data and the reliability is thus lower. Moreover, the strain rate and stress of the rolled data (cross mark in Figure A20) are not observed values. However, for all cases in the calculations using different values of the strain rate and stress estimated, values of $\Delta G$ of CP-Ti become approximately $100 \mathrm{kJmol}^{-1}$ as long as the dislocation density and rolling temperature observed do not change, and thus $\Delta G_{\mathrm{D}}$ is certainly at least twice the change in Gibbs free energy of the hot deformed CP-Ti with an HCP structure. Incidentally, we see scattering around the regression line in cases other than HCP metals. Such scattering may be caused by inconsistency; e.g., the dislocation density was not observed using the same specimen used to obtain the values of $Q_{\mathrm{ex}}, V_{\mathrm{ex}}$, and $C_{\mathrm{ex}}$. Therefore, Figure 9 shows the relation between $\Delta G$ and $\Delta G_{\mathrm{D}}$ for the selected cases where the dislocation density was observed employing only TEM and creep or steady-state hot deformation tests, from which the values of $Q_{\mathrm{ex}}, V_{\mathrm{ex}}$, and $C_{\mathrm{ex}}$ were calculated, and using the same material in the creep or steady-state hot deformation test as that used in the TEM observation. If this restriction is strictly applied, all data of ferritic/martensitic steel are excluded. Therefore, the data of two cases of $1 \mathrm{Cr}-0.5 \mathrm{Mo}$ steel and a case of Gr. 91 steel are plotted in Figure 9, where each material is specified using the same industrial standard, although the TEM observations and creep tests were conducted by different research groups. Figure 9 reconfirms that $\Delta G \approx \Delta G_{\mathrm{D}}$ for material with a cubic lattice structure, including $\mathrm{Ge}$, and the correlation coefficient is much improved from $94 \%$ to $98 \%$.

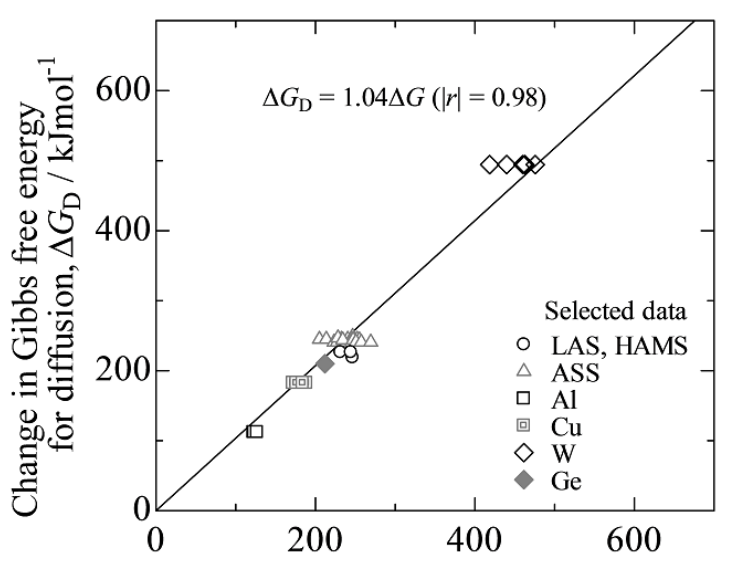

Change in Gibbs free energy for creep, $\Delta G / \mathrm{kJmol}^{-1}$

Figure 9. Figure similar to Figure 8, but for selected data where the dislocation density is measured employing TEM and creep data were presented by the same research group that made the TEM observation. Three data for LAS and HAMS are added, where although the dislocation density and creep were measured by different authors, the materials tested are classified in the same group on an industrial scale

From the above discussion it can be concluded that the changes in Gibbs free energy during steady-state creep or the deformation rate at high temperatures, $\Delta G$, of many metallic materials including heat-resistant steels having practical uses and also Ge single crystals are almost equal to the changes in Gibbs free energy for self-diffusion, $\Delta G_{\mathrm{D}}$, based on the well-known vacancy mechanism, even though the experimentally obtained activation enthalpy for creep, $Q_{\mathrm{ex}}$, is much greater than the activation enthalpy for self-diffusion, $Q_{\mathrm{D}}$. This conclusion of $\Delta G \cong$ $\Delta G_{\mathrm{D}}$ may be true also for HCP metals such as Mg alloy, although this relation does not sufficiently hold for HCP metals such as Ti, which are in the IV-a group of the periodic table and do not have stable HCP structures at higher temperatures. The relation $\Delta G \cong \Delta G_{\mathrm{D}}$ surely indicates that the deformation mechanism of metals with a cubic lattice including high-strength heat-resistant steel is closely related with the diffusion of single vacancies. This interpretation was originally proposed for pure metals by Sherby, Orr, and Dorn (1953) and has since been widely accepted as a tacit understanding even for heat-resistant steel having high strength. Therefore, the validity of Equation 12, an equation used to evaluate the dislocation density, is confirmed. 


\section{Conclusion}

Ninety-two data sets including the dislocation density in a steady-state deformation and the related creep or hot deformation rate of 21 types of metals (having BCC, FCC, and HCP structures) and Ge single crystals were collected. Using these observed dislocation densities, variations in the correction term, $\gamma$, used in the equations for calculating the change in Gibbs free energy and the dislocation density during steady-state creep were investigated. Moreover, the validity of the equation used to evaluate the dislocation density, which was previously proposed by the author and his colleague, was examined. The following are the main findings of the study.

1) There are many cases of $\gamma \approx 0$. In this case, the changes in Gibbs free energy for creep can be estimated only using creep data or hot deformation data for a steady state.

2) The values of $\gamma$ for high-Cr martensitic heat resistant steels with high strength and austenitic stainless steels with high applied stresses are negative and large.

3) The values of $\gamma$ for pure metals and similar materials tested at rather high temperatures and low stresses are positive and large.

4) The changes in Gibbs free energy during creep evaluated using the calculated values of $\gamma$ are almost equal to the changes in Gibbs free energy during the self-diffusion of each main constituent element of the materials based on the single vacancy mechanism for all materials investigated except pure Ti. This indicates that the creep mechanism of almost all materials investigated is closely related with the formation and migration of single vacancies.

5) The equation used to evaluate the dislocation density during steady-state creep, Equation 12, is considered valid, though it has the correction term of $\gamma$.

\section{List of symbols}

$\varepsilon \quad$ Tensile strain

$\dot{\varepsilon} \quad$ Steady-state creep rate under uniaxial tension

$\phi \quad$ Function of the temperature dependence of the shear modulus, Equation 11

$\gamma \quad$ Correction term in Equations 9 and 12 for calculating the dislocation density

$\kappa \quad$ Ratio of the geometric mean to the algebraic mean

$\bar{\lambda} \quad$ Average spacing of obstacles

$\mu \quad$ Shear modulus

$v_{\text {eff }} \quad$ Effective jump frequency

$v_{\mathrm{D}} \quad$ Debye frequency

$\rho \quad$ Dislocation density in a steady state measured by TEM

$\rho_{0} \quad$ Uncorrected dislocation density, dislocation density calculated from Equation 12 for $\gamma=0$

$\rho_{0}$ (obs) Uncorrected dislocation density that corresponds to the observable dislocation density

$\rho_{\mathrm{i}} \quad$ Initial dislocation density

$\rho_{\mathrm{t}} \quad$ Total dislocation density

$\rho_{\text {sch }} \quad$ Dislocation density obtained in a stress or strain rate change test

$\rho_{\mathrm{tr}} \quad$ Dislocation density of the ruptured specimen

$\rho_{\mathrm{x}} \quad$ Dislocation density measured employing XRD analysis

$\sigma \quad$ Applied normal tensile stress

a Lattice constant for a cubic structure or the inter-atom distance in a basal plane in an HCP structure

$\dot{a}_{0} \quad$ Pre-exponential factor of Equation 5

$b \quad$ Length of the Burgers vector

$C_{\text {ex }} \quad$ Larson-Miller constant, Equation 15

$\Delta G \quad$ Change in Gibbs free energy for creep

$\Delta G_{\mathrm{D}} \quad$ Change in Gibbs free energy for self-diffusion 


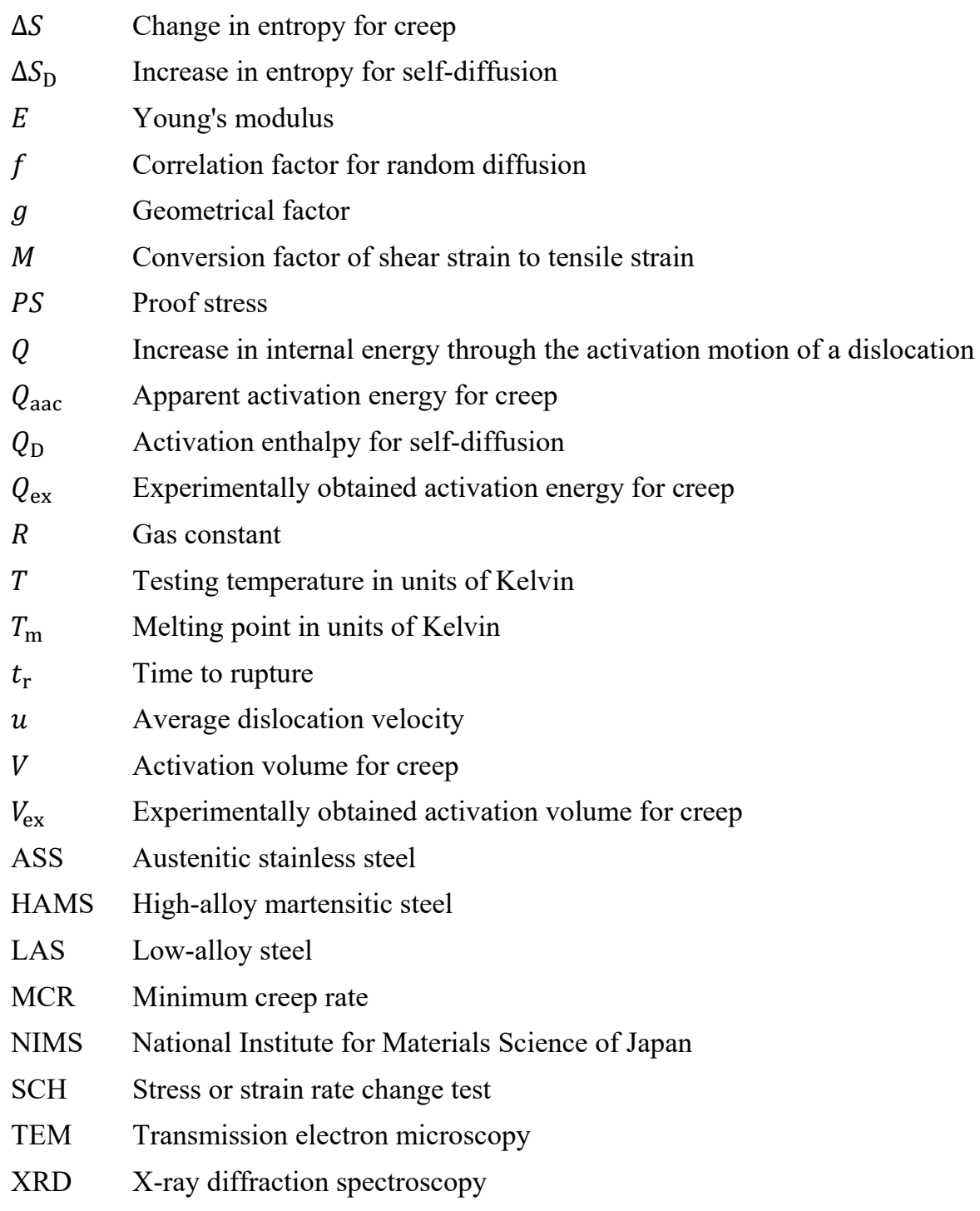

\section{References}

Adams, K. H. (1965). Dislocation Mobility and Density in Zinc Single Crystals (Dissertation). California Institute of Technology, Pasadena, CA. Retrieved from http://resolver.caltech.edu/CaltechETD:etd-091020 02-095733

Agronov, D., Freund, E., \& Rosen, A. (1985). The Contribution of Particle Strengthening on the Creep Resistance of Molybdenum Alloys. In Proc. 11th Plansee Seminar (pp. 65-75). Reutte, Austria. Retrieved from https://catalog.hathitrust.org/Record/007475928

Agronov, D., Freund, E., \& Rosen, A. (1986). Effects of Substructure on the Creep Properties of TZM Alloy. In H. J. McQueen, J. -P. Bailon, J. I. Dickson, J. J. Jonas, \& M. G. Akben (Eds.), Strength of Metals and Alloys (ICSMA 7) vol. 1, (pp. 695-700). Pergamon Press, Oxford, ENG. Retrieved from https://books.google.co.jp/books?id=UT0vBQAAQBAJ\&pg=PR22\&lpg=PR22\&dq=Effects+of + Substructu re + on + the + Creep + Properties + of + TZM + Alloy \&source $=$ bl\&ots $=$ sRO551vpHU\&sig $=$ WKAi5BiEXPVJciac 3 b0wA6NkbXw\&hl=ja\&sa=X\&ved=0ahUKEwjZ64Oh8 bPAhWFzLwKHWTEDzAQ6AEIJDAA\#v=onep age \&q=Effects $\% 20$ of $\% 20$ Substructure $\% 20$ on $\% 20$ the $\% 20$ Creep $\% 20$ Properties $\% 20$ of $\% 20 T Z M \% 20$ Alloy \& $\mathrm{f}=$ false

Akhtar, A. (1975). Basal Slip and Twinning in $\alpha$-Titanium Single Crystals. Metall. Trans. A, 6A, 1105-1113. http://dx.doi.org/10.1007/BF02661366

Alkhazraji, H., Salih, M. Z., Zhong, Z., Mhaede, M., Brokmeier, H. -G., Wagner, L., \& Schell, N. (2014). Estimation of Dislocation Density in Cold-Rolled Commercially Pure Titanium by Using Synchrotron Diffraction. Met. Mater. Trans. B, 45B, 1557-1564. http://dx.doi.org/10.1007/s11663-014-0066-3 
Andersson-Ostling, H. C. M., \& Sandstrom, R. (2009). Survey of Creep Properties of Copper Intended for Nuclear Waste Disposal. In Swedish Nuclear Fuel and Waste Management Co. (Ed.), Technical Report TR-09-32. Stockholm, Sweden. Retrieved from http://www.skb.se/upload/publications/pdf/TR-09-32Nyweb

Armstrong, P. E., \& Brown, H. L. (1964). Dynamic Young's Modulus Measurements above $1000{ }^{\circ} \mathrm{C}$ on Some Pure Polycrystalline Metals and Commercial Graphite. Trans. Met. Soc. AIME, 230, 962-966. Retrieved from http://www.onemine.org/document/abstract.cfm?docid=25617\&title=Institute-of-Metals-Division--Dynamic -Youngaposs-Modulus-Measurements-above-1000C-on-Some-Pure-Polycrystalline-Metals-and-CommercialGraphites

Askill, J., \& Tomlin, D. H. (1963). Self-diffusion in Molybdenum. Phil. Mag., 8, 997-1001. http://dx.doi.org/ $10.1080 / 14786436308214459$

ASME. (2015). ASME BVP Code Sec. II Part D (metric) (pp. 785-792). ASME, Two Park Av., NY. Retrieved from https://www.asme.org/products/codes-standards/bpvciid-2015-bpvc-section-iimaterialspart

Barrett, C. R., Lytton, J. L., \& Sherby, O. D. (1967). Effect of Grain Size and Annealing Treatment on Steady-state Creep of Copper. Trans. Metall. Soc. AIME, 239, 170-180. Retrieved from http://www.onemine.org/document/abstract.cfm?docid=26656\&title=Part-II--Papers--Effect-of-Grain-Sizeand-Annealing-Treatment-on-SteadyState-Creep-of-Copper

Bazazi, A. A. (2009). Evolution of Microstructure during Long-term Creep of a Tempered Martensite Ferritic Steel (Dissertation). Ruhr-univ., Bochum, Germany. Retrieved from http://www-brs.ub.ruhr-uni-bochum.de /netahtml/HSS/Diss/AghajaniBazaziAli/diss.pdf

Cadek, J. (1987). The Back-Stress Concept in Power-law Creep of Metals: A Review. Materials Science and Engineering, 94, 79-92. http://dx.doi.org/10.1016/0025-5416(87)90324-7

Challenger, K. D., \& Moteff, J. (1973). Quantitative Characterization of the Structure of AISI 316 Stainless Steel Resulting from Creep. Metall. Trans., 4, 749-55. http://dx.doi.org/10.1007/BF02643084

Ciulik, J. R. (2005). Creep and Dynamic Abnormal Grain Growth of Commercial-purity Molybdenum (Dissertation). Univ. Texas, Austin, TX. Retrieved from http://repositories1.lib.utexas.edu/handle/2152/ 9678? show $=$ full

Cuddy, L. J. (1970). Internal Stresses and Structures Developed during Creep. Metall. Trans., 1, 395-401. http://dx.doi.org/10.1007/BF02811548

Dorn, J. E. (1957). The Spectrum of Activation Energies for Creep. Creep and Recovery (pp. 255-283). ASM, Cleveland, OH. Retrieved from https://books.google.co.jp/books/about/The_Spectrum_of_Activation _Energies_for.html?id=ODqwHAAA CAAJ\&rediresc $=\mathrm{y}$

Dorn, J. E., \& Mote, J. D. (1964). Physical Aspects of Creep. In A. M. Freudenthal, B. A. Boley, \& H. Liebowitz (Eds.), High Temperature Structures and Materials (pp. 95-168). Pergamon Press, Oxford, EN. Retrieved from https://publications.lbl.gov/islandora/object/ir\%3A137638

Dragomir, I. C., Li, D. S., Castello-Branco, G. A., Garmestani, H., Snyder, R. L., Ribarik, G., \& Ungar, T. (2005). Evaluation of Dislocation Density and Character in Hot Rolled Titanium Determined by X-ray Diffraction. Mater. Characterization, 55, 66-74. http://dx.doi.org/10.1016/j.matchar.2005.03.002

Dudova, N., Plotnikova, A., Molodov, D., Belyakov, A., \& Kaibyshev, R. (2012). Structural Changes of Tempered Martensitic 9\%Cr-2\%W-3\%Co Steel during Creep at $650{ }^{\circ}$ C. Mater. Sci. Eng. A, 534, 632-639. Retreived from http://dspace.bsu.edu.ru/bitstream/123456789/4756/3/Dudova_N_Structural.pdf

Dushman, S., Dunbar, L. W., \& Huthsteiner H. (1944). Creep of Metals. J. Appl. Physics, 15, 108-124. Retrieved from http://scitation.aip.org/content/aip/journal/jap

Dyment, F., \& Libanati, C. M. (1968). Self-diffusion of Ti, Zr, and Hf in their HCP Phases, and Diffusion of $\mathrm{Nb}^{95}$ in HCP Zr. J. Mater. Sci., 3, 349-359. http://dx.doi.org/10.1007/BF00550978

Fabian, T., Trojanova, Z., \& Kuzel, R. (2007). The Evaluation of Dislocation Structure as a Function of Deformation Temperature in UFG Magnesium Determined by X-ray Diffraction. In K. U. Kainer (Ed.), Magnesium (pp. 512-515). Wiley-VCH, Weinheim, DE. Retrieved from https://books.google.co.jp/books?id=WIGLNjp0MKMC\&pg=PA512\&lpg=PA512\&dq=T.+Fabian,+Z.+Tro janova, + and + R. + Kuzel+Magnesium\&source $=$ bl\&ots=64rtT19k69\&sig=HaW9EamW3erfAxc66JyL9PxHY

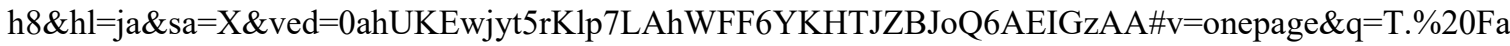
bian\%2C\%20Z.\%20Trojanova\%2C\%20and\%20R.\%20Kuzel\%20Magnesium\&f=false 
Farraro, R., \& McLellan, R. B. (1977). Temperature Dependence of the Young's Modulus and Shear Modulus of Pure Nickel, Platinum, and Molybdenum. Metall. Trans. A, 8A, 1563-1565. http://dx.doi.org/10.1007/ BF02644859

French, H. J., Cross, H. C., \& Peterson, A. A. (1928). Creep in Five Steels at Different Temperatures. Technologic Papers of the Bureau of Standards, 22(362), 235-267. Retrieved from http://nvlpubs.nist.gov/nistpubs/nbstechnologic/nbstechnologicpaperT362.pdf

Ganeshan, S., Hector Jr., L. G., \& Liu, Z. -K. (2010). First-principles Study of Self-diffusion in HCP Mg and Zn. Computational Mater. Sci., 50, 301-307. http://dx.doi.org/10.1016/j.commatsci.2010.08.019

Garofalo, F. (1966). Fundamentals of Creep and Creep-rupture in Metals. In M. E. Fine, J. Weertman, \& J. R. Weertman (Eds.), Fundamentals of Creep and Creep-rupture in Metals (pp. 1-257), Macmillan Series in Materials Science. Macmillan Com., NY. Retrieved from https://books.google.co.jp/books/about/ Fundamentals_of_creep_and_creep_rupture.html $? \mathrm{id}=\mathrm{jGd} 8 \mathrm{AAAAIAAJ} \& \mathrm{redir}$ esc $=\mathrm{y}$

Ham, R. K. (1961). The Determination of Dislocation Densities in Thin Film. Phil. Mag., 6, 1183-1184. http://dx.doi.org/10.1080/14786436108239679

Hanada, S. (1990). Plastic Deformation Mechanisms in a Titanium. Tetsu-to-Hagane, 76, 495-502. Retrieved from https://www.jstage.jst.go.jp/article/tetsutohagane1955/76/4/76_4_495/_article

Hart, E. W. (1957). On the Role of Dislocations in Bulk Diffusion. Acta Met., 5, 597. http://dx.doi.org/10.1016/0001-6160(57)90127-X

Hasegawa, T., Hasegawa, R., \& Karashima, S. (1970). Etch-pit Studies of the Dislocation Structures Developed during Creep Deformation of Copper Single Crystals. Trans. JIM, 11, 101-106. http://doi.org/10.2320/ matertrans 1960.11 .101

Hasegawa, T., Karashima, S., \& Ikeuchi, Y. (1973). High-temperature Creep Rate and Dislocation Structure in a Dilute Copper-aluminium Alloy. Acta Metall., 21, 887-895. http://dx.doi.org/10.1016/0001-6160(73) 90146-6

Hasegawa, Y. (2014). Grade 92 Creep-strength-enhanced Ferritic Steel. In A. Shibli (Ed.), Coal Power Plant Materials and Life Assessment (pp. 52-86). Woodhead Pub., Cambridge, UK. Retrieved from https://www.amazon.co.jp/Coal-Power-Plant-Materials Assessment/dp/0857094319

Hayakawa, H., Terada, D., Yoshida, F., Nakashima, H., \& Goto, Y. (2003). Evaluation of Mobile Dislocation Density of Modifed 9Cr-1Mo Steel by Stress Change Test. Tetsu-to-Hagane, 89, 1076-1081. Retrieved from https://www.jstage.jst.go.jp/article/tetsutohagane1955/89/10/89_10_1076/_pdf

Hayakawa, H., Nakashima, S., Kusumoto, J., Kanaya, A., Terada, D., Yoshida, F., \& Nakashima, H. (2007a). Evaluation of Creep Deformation Mechanism of Heat Resistant Steel by Stress Change Test. In Proc. Creep8: 8th Int. Conf. on Creep and Fatigue at Elevated Temperatures, Paper No. CREEP2007-26501. ASME, Two Park Av., NY. http://dx.doi.org/10.1115/CREEP2007-26501

Hayakawa, H., Terada, D., Yoshida, F., Nakashima, H., Kanaya, A., \& Nakashima, S. (2007b). Characterization of Creep Deformation Behavior of 2.25Cr-1Mo Steel by Stress Change Test. Tetsu-to-Hagane, 93, 465-471. http://doi.org/10.2355/tetsutohagane.93.466

Horiuchi, R., \& Otsuka, M. (1972). Mechanism of High Temperature Creep of Aluminium-Maganesium Solid Solution Alloys. Trans. JIM, 13, 284-293. http://doi.org/10.2320/matertrans1960.13.284

Hyun, C. -Y., \& Kim, H. -K. (2014). Creep Deformation Behavior of AZ31 Magnesium Alloy over Wide Range of Temperature and Stress. Materials at High Temperatures, 31, 34-40. Retreived from http://dx.doi.org/10. 1179/0960340913Z.0000000005

Ishikawa, K., Watanabe, H., \& Mukai, T. (2005). High Temperature Compressive Properties Over a Wide Range of Strain Rates in an AZ31 Magnesium Alloy. J. Mater. Sci., 40, 1577-1582. http://dx.doi.org/10.1007/ s10853-005-0656-1

Janecek, M., Cizek, J., Gubicza, J., \& Vratna, J. (2012). Microstructure and Dislocation Density Evolutions in MgAlZn Alloy Processed by Severe Plastic Deformation. J. Mater. Sci., 47, 7860-7869. http://dx.doi.org/10.1007/s10853-012-6538-4

Japan Copper and Brass Association. (2006). Data Base for Cu Alloy Products, Tokyo, Japan. Retrieved from https://www.copper-brass.gr.jp/db_access/banjoudb/main.htm 
Japan Institute of Metals. (1993). Metals Data Book (pp. 186-195). Sendai, Japan. Retrieved from http://jim.or.jp/NEWBOOK/n-b_007.html

Jenkins, W. D., \& Johnson, C. R. (1958). Creep of Annealed Nickel, Copper, and Two Nickel-copper Alloys. J. Research of NBS, 60, 173-191. Retrieved from http://nvlpubs.nist.gov/nistpubs/jres/60/jresv60n3p173 Alb.pdf

Kamaladasa, R. J., \& Picard, Y. N. (2010). Basic Principales and Application of Electron Channeling in a Scanning Electron Microscope for Dislocation Analysis. In A. Mendez-Vilas \& J. Diaz, (Eds.), Microscopy: Science, Technology, Applications and Education vol. 3 (1583-1590), Formatex Microscopy Series No. 4. Badajoz, Spain. Retrieved from http://www.formatex.info/microscopy4/1583-1590.pdf

Kardashev, B. K., \& Nikanorov, S. P. (1985). Temperature Dependences of Elastic Constants. Elasticity and Dislocation Inelasticity of Crystals, Nauka Publ. House, Moscow. Retrieved from http://www.ioffe.ru/SVA/ $\mathrm{NSM} /$ Semicond/ Ge/mechanic.html\#Elastic

Kassner, M. E., Ziaai-Moayyed, A. A., \& Miller, A. K. (1985). Some Trends Observed in the Elevated-temperature Kinetic and Isotropic Hardening of Type 304 Stainless Steel. Metall. Trans. A, 16A, 1069-1076. http://dx.doi.org/10.1007/BF02811676

Kassner, M. E. (1990). A Case for Taylor Hardening during Primary and Steady-state Creep in Aluminium and Type 304 Stainless Steel. J. Mater. Sci., 25, 1997-2003. http://dx.doi.org/10.1007/BF01045755

Koppers, M., Derdau, D., Friesel, M., \& Herzig, C. (1997). Self-diffusion and Group III (Al,Ga,In) Solute Diffusion in HCP Titanium. Defect and Diffusion Forum, 143-147, 43-48. http://dx.doi.org/10.4028/ www.scientific.net/DDF.143-147.43

Kushima, H., Kimura, K., \& Abe, F. (1999). Degradation of Mod. 9Cr-1Mo Steel during Long-term Creep Deformation. Tetsu-to-Hagane, 85, 841-847. http://smds.nims.go.jp/openTest/en/content/creeplist.html

Lam, N. Q., Rothman, S. J., \& Nowicki, L. J. (1974). Self-diffusion in Copper at Low Temperatures. phys. stat. sol. (a), 23, K35-K38. http://dx.doi.org/10.1002/pssa.2210230148

Ledbetter, H. M., \& Reed, R. P. (1973). Elastic Properties of Metals and Alloys, 1. Iron, Nickel, and Iron-nickel Alloys. J. Phys. Chem. Ref. Data, 2, 531-613. http://dx.doi.org/10.1063/1.3253127

Ledbetter, H. M., \& Naimon, E. R. (1974). Elastic Properties of Metals and Alloys. II. Copper. J. Phys. Chem. Ref. Data, 3, 897-930. Retreived from http://dx.doi.org/10.1063/1.3253150

Letaw, Jr., H., Portnoy, W. M., \& Slifkin, L. (1956). Self-diffusion in Germanium. AFOSR-TN-56-129, STIA Doc. No. AD-86006. Univ. Illinois, Urbana, IL. Retrieved from http://www.dtic.mil/dtic/tr/fulltext/u2/ 086006.pdf

Maier, K., Mehrer, H., Lessmann, E., \& Schule, W. (1976). Self-diffusion in Nickel at Low Temperatures. phys. stat. sol. (b), 78, 689-698. http://dx.doi.org/10.1002/pssb.2220780230

Majumdar, S., Kapoor, R., Raveendra, S., Sinha, H., Samajdar, I., Bhargava, P., \& Suri, A. K. (2009). A Study of Hot Deformation Behavior and Microstructural Characterization of Mo-TZM Alloy. J. Nucle. Mater., 385, 545-551. http://dx.doi.org/10.1016/j.jnucmat.2008.12.049

Manninen, T., \& Saynajakangas, J. (2013). Structural Application of Ferritic Stainless Steels. The Research Fund for Coal and Steel RTD, Finland. Retrieved from http://www.ioffe.ru/SVA/NSM/Semicond/Ge/ mechanic.html\#Elastic

Matsunaga, T., Kameyama, T., Takahashi, K., \& Sato, E. (2009). Constituitive Relation for Ambient-temperature Creep in Hexagonal Close-packed Metals. Mater. Trans., 50, 2858-2864. http://doi.org/10.2320/matertrans.M2009223

Mehrer, H. (2007). Diffusion in Solids Fundamentals, Methods, Materials, Diffusion-Controlled Processes, Springer-Verlag, Berlin, DE. Retrieved from http://www.springer.com/la/book/9783540714866

Mehtonen, S. (2014). The Behavior of Stabilized High-chromium Ferritic Stainless Steels in Hot Deformation, C495. Acta Univ. Oulu, Finland. Retrieved from http://jultika.oulu.fi/files/isbn9789526204949.pdf

Mendelev, M. I., \& Bokstein, B. S. (2010). Molecular Dynamics Study of Self-diffusion in Zr. Phil. Mag., 90, 637-654. Retrieved from https://arxiv.org/ftp/arxiv/papers/0902/0902.1338.pdf

Milicka, K. (1989). Interpretation of Steady State Creep of Austenitic Steels 1. 21Cr-32Ni Steel. Kovove Materialy, 27, 209-227. Retrieved from http://www.kovmat.sav.sk/?ro= 
Moiseeva, I. V., Okrainets, P. N., \& Pishchak, V. K. (1984). Variation in Dislocation Density in Nickel under Creep. Ukrainskij Fizicheskij Zhurnal, 29, 274-279. Retrieved from http://kyrgyzpost.kg/ru/home/item/ ukrainskij-fizicheskij-zhurnal-ukrainian-journal-of-physics.html

Monkman, F. C., \& Grant, N. J. (1956). An Empirical Relationship between Rupture Life and Minimum Creep Rate in Creep-rupture Tests. Proceedings of American Society for Testing and Materials, 56, 593-620. Retrieved from https://www.astm.org/DIGITAL_LIBRARY/STP/MMR/PAGES/PRO1956-56.htm

Mrotzek, T., Hoffmann, A., Martin, U., \& Oettel, H. (2007). Evolution of Microstructure during Hot Deformation of the PM Molybdenum Alloy TZM. Mater. Sci. Forum, 539-543, 2725-5730. http://dx.doi.org/10.4028/www.scientific.net/MSF.539-543.2725

Mundy, J. N., Rothman, S. J., Lam, N. Q., Hoff, H. A., \& Nowicki, L. J. (1978). Self-diffusion in Tungsten. Physical Rev. B, 18, 6566-6575. https://doi.org/10.1103/PhysRevB.18.6566

Myshlyaev, M. M., \& Khodos, I. I. (1971). Creep and Dislocation Structure of Germanium Single Crystals. phys. stat. sol. (b), 43, 83-88. Retreived from http://dx.doi.org/10.1002/pssb.2220430108

Neumann, G., Reimers, P., \& Bartdorff, D. (1975). Calculation of the Activation Energy of Self-diffusion in Aluminium from Impurity Diffusion Data. Z. Physikalische Chemie Neue Folge, 97, 23-28. http://dx.doi.org/10.1524/zpch.1975.97.1_2.023

Nguyen, N. -T., Seo, O. S., Lee, C. A., Lee, M. -G., Kim, J. -h., \& Kim, H. Y. (2014). Mechanical Behavior of AZ31B Mg Alloy Sheets under Monotonic and Cyclic Loadings at Room and Moderately Elevated Temperatures. Materials, 7, 1271-95. http://dx.doi.org/10.3390/ma70211271

NIMS. (1986a). NIMS Creep Data Sheet No. 3B (JIS STBA 24, 2.25Cr-1Mo, Tubes), NIMS, Tsukuba, Japan, pp. 1-30. Retrieved from http://smds.nims.go.jp/openTest/en/content/creeplist.html

NIMS. (1986b). NIMS Creep Data Sheet No. 4B (JIS SUS 304H, 18Cr-8Ni, Tubes), NIMS, Tsukuba, Japan, 1986, pp. 1-32. Retrieved from http://smds.nims.go.jp/openTest/en/content/creeplist.html

NIMS. (1996). NIMS Creep Data Sheet No. 1 B (JIS STBA 22, 1Cr-0.5Mo, Tubes), NIMS, Tsukuba, Japan, 1996, pp. 1-35. Retrieved from http://smds.nims.go.jp/openTest/en/content/creeplist.html

NIMS. (1998). NIMS Creep Data Sheet No. $26 B$ (JIS NCF 800H, 21Cr-32NiTiAl, Tubes), NIMS, Tsukuba, Japan, pp. 1-42. Retrieved from http://smds.nims.go.jp/openTest/en/content/creeplist.html

NIMS. (2000). NIMS Creep Data Sheet No. 6B (JIS SUS 316H, 18Cr-12NiMo, Tubes), NIMS, Tsukuba, Japan, pp. 1-36. Retrieved from http://smds.nims.go.jp/openTest/en/content/creeplist.html

NIMS. (2007). NIMS Creep Data Sheet, Atlas of Creep Deformation Properties No. D-1 (ASME SA-387/SA-387M Grade 91), NIMS, Tsukuba, Japan, 2007, pp. 1-167. Retrieved from http://smds.nims.go.jp/openTest/en/content/creeplist.html

Panait, C. G., Zielinska-Lipiec, A., Koziel, T., Czyrska-Filemonowicz, A., Gourgues-Lorenzon, A. -F., \& Bendick, W. (2010). Evaluation of Dislocation Density, Size of Subgrains and MX-type Precipitatesin a P91 Steel during Creep and during Thermal Ageing at $600{ }^{\circ} \mathrm{C}$ for More than 100000 h. Mater. Sci. Eng. A, 527, 4062-4069. Retrieved from https://hal.inria.fr/file/index/docid/491033/filename/PanaitMSEA527.pdf

Perez, R. A., Nakajima, H., \& Dyment, F. (2003). Diffusion in $\alpha$-Ti and Zr. Mater. Trans., 44, 2-13. Retrieved from https://www.jim.or.jp/journal/e/pdf3/44/01/2.pdf

Pesicka, J., Kuzel, R., Dronhofer, A., \& Eggeler, G. (2003). The Evolution of Dislocation Density during Heat Treatment and Creep of Tempered Martensitic Ferritic Steels. Acta Mater., 51, 4847-4862. Retreived from http://dx.doi.org/10.1016/S1359-6454(03)00324-0

Ohara, H. (1958). Creep of High Purity Nickel. Hitachi-Hyoron, Hitachi, Japan, 40, 289-285. Retrieved from http://www.hitachihyoron.com/jp/

Oikawa, H. (1982). Lattice Self-diffusion in Solid Iron: A Critical Review. Technology Reports of the Tohoku University, Sendai, Japan, 47, 67-77. Retrieved from https://inis.iaea.org/search/search.aspx?orig_q $=\mathrm{RN}: 15057350$

Orowan, E. (1940). Evolution of Microstructure during Long-term Creep of a Tempered Martensite Ferritic Steel. Proc. Physical Soc., 52, 8-22. Retrieved from http://iopscience.iop.org/article/10.1088/ 0959-5309/52/1/303

Raj, S. V., \& Langdon, T. G. (1989). Creep Behavior of Copper at Intermediate Temperatures-I. Mechanical Characteristics. Acta Metall., 37, 843-852. http://dx.doi.org/10.1016/0001-6160(89)90011-4 
Robinson, S. L., \& Sherby, O. D. (1969). Mechanical Behavior of Polycrystalline Tungsten at Elevated Temperature. Acta Metall., 17, 109-125. http://dx.doi.org/10.1016/0001-6160(69)90132-1

Roodposhti, P. S., Sarkar, A., Murty, K. L., \& Scattergood, R. O. (2015). Dislocation Density Evolution during Creep of AZ31 Mg Alloy: A Study by X-ray Diffraction Line Profile Analysis. Metallography, Microstructure, and Analysis, ASM Int., 4, 1-7. Springer, NY. http://dx.doi.org/10.1007/s13632-015-0220-6

Sawada, K., Maruyama, K., Komine, R., \& Nagae, Y. (1997). Microstructural Changes during Creep and Life Assessment of Mod. 9Cr-1Mo Steel. Tetsu-to-Hagane, 83, 466-471. http://doi.org/10.2320/ materia1962.16.197

Schoeck, G. (1980). Thermodynamics and Thermal Activation of Dislocations. In F.R.N. Nabarro, (Ed.), Dislocation in Solids vol. 3, Moving Dislocations (pp. 63-163). North-Holland Pub., Amsterdam, NL. Retrieved from http://www.worldcat.org/title/dislocations-in-solids/oclc/562603633?ht=edition\&referer=

Sharafat, S., Martinez, R., \& Ghoniem, N. M. (1999). Design Window for Tungsten Alloys. Presented at Apex Study Gr. Meeting (pp. 1-35). UCLA, CA. Retrieved from http://www.fusion.ucla.edu/apex/meeting7/ ghoniem1.pdf

Sherby, O. D., \& Dorn, J. E. (1954). Effect of Subgrain Size on the High Temperature Strength of Polycrystalline Aluminium as Determined by Constant Strain Rate Tests. Data are shown in Figure 3 in a paper by Heimerl, G. J. (June 1954). Technical Note 3195 (pp. 1-35). National Advisory Committee for Aeronautics, Langley Field, VA. http://dx.doi.org/10.1016/0001-6160(75)90104-2

Sherby, O. D., Lytton, J. L., \& Dorn, J. E. (1957). Activation Energies for Creep of High-purity Aluminum. Acta Metall., 5, 219-227. http://dx.doi.org/10.1016/0001-6160(57)90169-4

Sherby, O. D., \& Burke, P. E. (1968). Mechanical Behavior of Crystalline Solids at Elevated Temperature. In B. Chalmers and W. Hume-Rothery (Eds.) Progress in Materials Science, 13, 325-90. Pergamon Press, Oxford, ENG. http://dx.doi.org/10.1016/0079-6425(68)90024-8

Sherby, O. D., Orr, R. L., \& Dorn, J. E. (March 1953). Technical Report No. 25, Series No. 22 N7-onr-295, Task Order II, NR-031-048, Issue No. 25 (pp. 1-44). Univ. California Inst. Eng. Research, Berkeley, CA. Retrieved from http://www.dtic.mil/dtic/tr/fulltext/u2/005978.pdf

Shewmon, P. G. (1963). Diffusion in Solids, McGraw-Hill Book Com., NY. http://dx.doi.org/10.1016/ 0038-1101(64)90025-5

Shintani T., \& Murata Y. (2011). Evaluation of the Dislocation Density and Dislocation Character in Rolled Type 304 Steel Determined by Profile Analysis of X-ray Diffraction. Acta Materialia, 59, 4314-4322. http://dx.doi.org/10.1016/j.actamat.2011.03.055

Somekawa, H., Hirai, K., Watanabe, H., Takigawa, Y., \& Higashi, K. (2005). Dislocation Creep Behavior in Mg-Al-Zn Alloys. Mater. Sci. Eng. A, 407, 53-61. http://dx.doi.org/10.1016/j.msea.2005.06.059

Spiradek, K., Bauer, R., \& Zeiler, G. (1994). Materials for Advanced Power Engineering, Part I, In D. Coutsouradis, J. H. Davidson, J. Edward, J. Greenfield, T. Khan, M. Malik, D. B. Meadowcroft, V. Regis, R. B. Scarlin, F. Schubert, and D. V. Thornton, (Eds.). Kluwer Academic Pub., Netherlands (pp. 251-62). Retreived from https://books.google.co.jp/books?id=wF3RECzsNWAC\&pg=PA251\&lpg=PA251\&dq= K.+Spiradek,+R.+Bauer,+and+G.+Zeiler:\&source=bl\&ots=zt-Q6h_lu2\&sig=w_CiV1S41Z-ay6RJHX8d4P nzzKE\&hl=ja\&sa $=X \& v e d=0$ ahUKEwiuwqPG5vbPAhUExbwKHa8VDokQ6AEIIzAB\#v=onepage\&q=K. \%20Spiradek\%2C\%20R.\%20Bauer\%2C\%20and\%20G.\%20Zeiler\%3A\&f=false

Staker, M. R., \& Holt, D. L. (1972). The Dislocation Cell Size and Dislocation Density in Copper Deformed at Temperatures between 25 and $700{ }^{\circ} \mathrm{C}$. Acta Metall., 20, 569-79. http://dx.doi.org/10.1016/0001-6160(72) 90012-0

Straub, S., Meier, M., Ostermann, M., \& Blum, W. (1993). Entwicklung der Mikrostruktur und der Festigkeit des Stahles X20CrMoV 121 bei $823 \mathrm{~K}$ waehrend Zeitstandbeanspruchung und Gluehreng. VGB Kraftwerkstechnik, 73, 744-752. Retrieved from http://www.speciation.net/Database/Journals/VGBKraftwerkstechnik-;i519

Straub, S. (1995). Verformungsverhalten und Mikrostruktur Warmfester Martensitischer 12\%-Chromstahle (Dissertation). Univ. Erlangen-Nurnberg, Dusseldorf, Germany. Data are shown in Figure 2 in a paper by Naumenko, K., Altenbach, H., \& Kutschke, A. (Septmber 2009). A Constitutive Model for Creep and Long-term Strength in Advanced Heat Resistant Steels and Structures. In J. Ambrosio (Ed.), 7th Euromech 
Solid Mechanics Conference (pp. 1-14), August 27, 2015, Lisbon, Portugal. Available from: Holm Altenbach. Retrieved from https://www.researchgate.net/publication/264883394_A_CONSTITUTIVE MODEL_FOR_CREEP_AND_LONG-TERM_STRENGTH_IN_ADVANCED_HEAT_RESISTANT_ST EELS_AND_STRUCTURES

Taira, S., Koterazawa, R., \& Fukumori, Y. (1960). Dynamic Creep and Fatigue of Commercially Pure Titanium at Room and Elevated Temperatures. J. Japan Soc. Testing Mater., MTRA of Japan, Tokyo, Japan, 9, 480-485. Retrieved from http://www.mtraj.jp/journal.html

Takeuchi, Y., Noda, N., Komori, S., Nyuko, H., \& Kitagawa, T. (1977). Empirical Formulae of Temperature Dependency of Elastic Moduli of Several Steels and Aluminium Alloys. J. of Soc. Mater. Sci., 26, $210-214$. Kyoto, Japan. Retrieved from http://www.jsms.jp/e.files/journal/J_form.htm

Tamura, M., Esaka, H., \& Shinozuka, K. (1999). Stress and Temperature Dependence of Time to Rupture of Heat Resisting Steels. ISIJ Int., 39, 380-387. Retreived from http://doi.org/10.2355/isijinternational.39.380

Tamura, M., Esaka, H., \& Shinozuka, K. (2003). Applicability of an Exponential Law in Creep of Metals. Materials Transactions, 44, 118-126. Retrieved from https://www.jim.or.jp/journal/e/pdf3/44/01/118.pdf

Tamura, M., Abe, F., Shiba, K., Sakasegawa, H., \& Tanigawa, H. (2013). Larson-Miller Constant of Heat-resistant Steel. Met. Mater. Trans. A, 44A, 2645-2661. http://dx.doi.org/10.1007/s11661-013-1631-0

Tamura, M. (2015). Method of Estimating the Long-term Rupture Strength of $11 \mathrm{Cr}-2 \mathrm{~W}-0.4 \mathrm{Mo}-1 \mathrm{Cu}-\mathrm{Nb}-\mathrm{V} \mathrm{Steel}$. Met. Mater. Trans. A, 46A, 1958-1972. http://dx.doi.org/10.1007/s11661-015-2784-9

Tamura, M., \& Abe, F. (2015). Changes in Estimated Dislocation Density during Creep in Martensitic Heat-resistant Steel. J. Mater. Sci. Research, 4(4), 48-69. http://dx.doi.org/10.5539/jmsr.v4n4p48

Taylor, G. I. (1934). A Theory of the Plasticity of Crystals. Kristallographie, 89, $375-85$. http://dx.doi.org/10.1524/zkri.1934.89.1.375

Umezaki, S., Murata, Y., Nomura, K., \& Kubushiro, K. (2014). Quantative Analysis of Dislocation Density in an Austenitic Steel after Plastic Deformation. J. Jap. Inst. Met. Mater., 78, 218-224. Retreived from http://doi.org/10.2320/jinstmet.J2014001

Vandervoort, R. R. (1970). The Creep Behavior of W-5Re. Metall. Trans., 1, 857-864. http://dx.doi.org/10.1007/BF02811765

Watanabe Shoji Co., (2002). Al-Minihandbook, Watanabe Shoji Co., Tokyo, Japan. Retrieved from http://www.zerocut-watanabe.co.jp/contents/handbook/hand012.html

Williams, K. R \& Wilshire, B. (1973). On the Stress- and Temperature-dependence of Creep of Nimonic 80A. Metal Science J., 7, 176-179. http://dx.doi.org/10.1179/030634573790445695

Yamoah, N. K. G. (2013). Microstructural Characterization of SUS 444 Ferritic Stainless Steel (MasterThesis). Virginia Polytechnic Institute and State University, Blacksburg, VA. Retrieved from https://vtechworks.lib.vt.edu/bitstream/handle/10919/23253/Yamoah_NG_T_2013.pdf?sequence=1

Young, C. M., Robinson, S. L., \& Sherby, O. D. (1975). Effect of Subgrain Size on the High Temperature Strength of Polycrystalline Aluminium as Determined by Constant Strain Rate Tests. Acta Met., 23, 633-639. http://dx.doi.org/10.1016/0001-6160(75)90104-2

Yoshinaga, H. (1977). What is the Internal Stress during Deformation of Metals? Bulletin of Japan Institute of Metals, 16, 197-203. http://doi.org/10.2320/materia1962.16.197

Yoshinaga, H., Horita, Z., \& Kurishita, H. (1981). Determination of High-temperature Deformation Mechanism in Crystalline Materials by the Strain-rate Change Test. Acta Metall., 29, 1815-1824. http://dx.doi.org/10.1016/0001-6160(81)90107-3

Yoshinaga, H., Matsuo, S., \& Kurishita, H. (1984). Dislocation Density and Internal Stress in an Al-5.7 at\% Mg Alloy Deformed at High Temperature. J. Jap. Inst. Met. Mater., 48, 35-42. Retreived from http://doi.org/10.2320/matertrans1960.26.423

Zener, C. (1952). Theory of Diffusion. In W. Schockley, J. H. Hollomon, R. Mauer, and F. Seitz (Eds.), Imperfections in Nearly Perfect Crystals (pp. 289-314). John Wiley \& Sons, NY. Retrieved from https://www.amazon.com/Imperfections-Nearly-Perfect-Crystals-Shockley/dp/B000JF240A 
Zhang, P., Watzinger, B., Kong, Q. P., \& Blum, W. (2000). Microstructural Evaluation during Creep of the Mg-Al-alloy AZ91hp. Key Eng. Mater., 171-174, 609-616. http://dx.doi.org/10.4028/www.scientific.net/ KEM.171-174.609

\section{Appendix}

\section{A1. Carbon Steel}

Hayakawa et al. (2007a) obtained the dislocation densities around the MCR at $543{ }^{\circ} \mathrm{C}$ and $\sigma=60 \mathrm{MPa}$ for $0.1 \mathrm{C}$ steel employing an SCH method. Figure A1 shows the correlation between the stress and MCR reproduced by reading creep curves for $0.24 \mathrm{C}$ steel (French, Cross, \& Peterson, 1928), which has a full-annealed microstructure similar to that of ferrite and pearlite with $0.1 \mathrm{C}$ steel. Though the amount of pearlite differs with each other according to the amount of carbon contents, the amounts of soluble carbon contents are considered to be the same as in a fully annealed condition. The values for $Q_{\mathrm{ex}}, V_{\mathrm{ex}}$, and $C_{\mathrm{ex}}$ of $0.24 \mathrm{C}$ steel become $637.6 \mathrm{kJmol}^{-1}$, $760.9 \mathrm{~cm}^{3} \mathrm{~mol}^{-1}$, and 33.58, respectively, using Equation 14 and the MCR data, and regression lines are drawn in the figure using these parameter constants. These values seem rather large as compared with those of similar steels (Tamura et al. 1999; Tamura et al., 2013), but they are not abnormal. In Figure A1, the data point of Hayakawa et al. (2007a) is plotted as a solid square and is connected to a regression line at $543{ }^{\circ} \mathrm{C}$ for $0.24 \mathrm{C}$ steel. Though the creep rate of Hayakawa et al. (2007a) is approximately one order of magnitude higher than that of the regression line, this is not unusual for heat-resistant steel for practical uses; $\gamma=-16.0 \mathrm{kJmol}^{-1}$ is obtained using the dislocation density of $0.1 \mathrm{C}$ steel, $\rho_{\mathrm{sch}}=4 \mathrm{E} 10 \mathrm{~m}^{-2}$, and the abovementioned values of $Q_{\mathrm{ex}}, V_{\mathrm{ex}}$, and $C_{\mathrm{ex}}$, where the value of $\dot{\varepsilon}$ in Equation 13 is calculated using Equation 14, these constants and the test temperature and stress of $0.1 \mathrm{C}$ steel. The absolute value of $\gamma$ is low, being approximately $2.5 \%$ of $Q_{\mathrm{ex}}$. The temperature-dependence term of the shear modulus is calculated as $\phi=2.741$ using Young's modulus of carbon steel (Ledbetter et al., 1973) and $v=0.30$. Although carbon steel is the most frequently used heat-resistant steel, we cannot find more appropriate creep data for which the test conditions and chemical compositions are close to those of the specimen for which the dislocation density was measured.

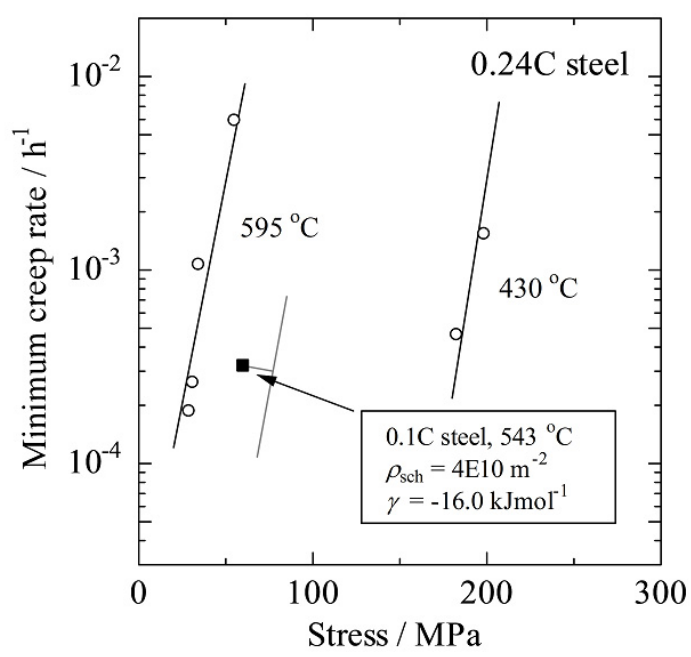

Figure A1. MCRs for 0.24C steel (French et al., 1928) and 0.1C steel (Hayakawa et al., 2007a) as functions of stress. The correction term, $\gamma$, for $0.1 \mathrm{C}$ steel is calculated using Equation 13, the evaluated dislocation density, $\rho_{\text {sch }}$, is obtained in stress change tests (Hayakawa et al., 2007a), and parameter constants, $Q_{\text {ex }}$ and $V_{\text {ex }}$, are obtained for the MCR data of $0.24 \mathrm{C}$ steel shown in the text, and $\dot{\varepsilon}$ is calculated using Equation 14 with $C_{\mathrm{ex}}$ for $0.24 \mathrm{C}$ steel and stress and temperature information for $0.1 \mathrm{C}$ steel given in the text, and the result is shown in the figure. Similar plots are presented in the following figures, but the detailed explanation is omitted for brevity

\section{A2. 2.25Cr-1Mo Steel}

Hayakawa, Terada, Yoshida, H. Nakashima, Kanaya, and S. Nakashima (2007b) evaluated the dislocation densities around the MCR at 600 to $700{ }^{\circ} \mathrm{C}$ of a full-annealed 2.25Cr-1Mo steel pipe employing an SCH method. Figure A2 shows the correlation between the stress and MCR of a full-annealed 2.25Cr-1Mo steel tube from a data sheet No. 3B of the NIMS, heat MAF (NIMS, 1986a) that corresponds to the test conditions of the dislocation 
density data. The fitness of Equation 14 to the MCR data improves when all data are classified into two groups; i.e., Gr. I (higher stress) and Gr. II (lower stress). The values of $Q_{\mathrm{ex}}, V_{\mathrm{ex}}$, and $C_{\mathrm{ex}}$ for $G r$. I become $498.9 \mathrm{kJmol}^{-1}$, $224.6 \mathrm{~cm}^{3} \mathrm{~mol}^{-1}$, and 26.01, respectively. Although the test temperatures at which the dislocation densities and the MCRs were observed by Hayakawa et al. (solid marks) are higher than those obtained by the NIMS, there is good consistency between creep data reported by the two, except for a data point obtained at $600{ }^{\circ} \mathrm{C}$ by Hayakawa et al. Therefore, the two creep data sets are classified into Gr. II and analyzed together using Equation 14 . The values of $Q_{\mathrm{ex}}, V_{\mathrm{ex}}$, and $C_{\mathrm{ex}}$ for $G r$. II become $417.1 \mathrm{kJmol}^{-1}, 714.6 \mathrm{~cm}^{3} \mathrm{~mol}^{-1}$, and 16.37 , respectively. Regression lines are drawn as shown in the figure for each temperature of Grs. $I$ and II using these parameter constants. The correction term, $\gamma$, is calculated using Equation 13 together with the dislocation density listed in the figure and the parameter constants, and the results are shown in Figure A2. Hayakawa et al. (2007b) also reported dislocation densities at $630{ }^{\circ} \mathrm{C}$ and $675{ }^{\circ} \mathrm{C}$ and the corresponding values of $\gamma$ are $11.9 \mathrm{kJmol}^{-1}$ and $9.2 \mathrm{kJmol}^{-1}$, respectively. The absolute values of the correction term for $2.25 \mathrm{Cr}-1 \mathrm{Mo}$ are small and below $9 \%$ of $Q_{\mathrm{ex}}$ of $\mathrm{Gr}$. II. The temperature-dependence term of the shear modulus is set at $\phi=1.740$ to 2.134 using Young's modulus of low-alloy steel and $v=0.30$ (ASME, 2015).

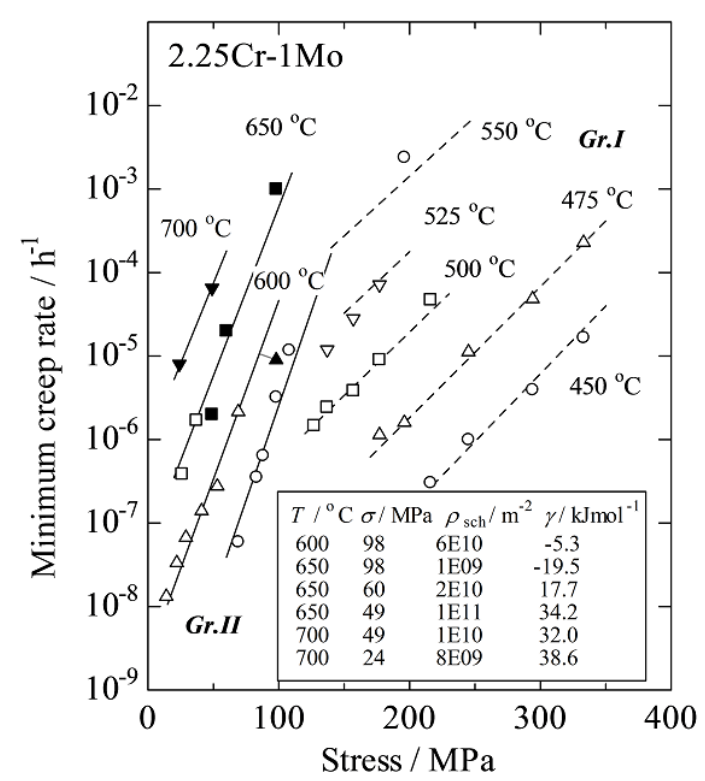

Figure A2. MCRs for a 2.25Cr-1Mo steel tube (NIMS, 1986a) (open marks) and a steel pipe (Hayakawa et al., 2007b) (solid marks) as functions of stress. The values of $\gamma$ are also shown for the dislocation density evaluated employing an SCH method at 600, 650, and $700{ }^{\circ} \mathrm{C}$ (Hayakawa et al., 2007b).

\section{A3. Gr. 91}

Hayakawa, Terada, Yoshida, Nakashima, and Goto (2003) calculated the dislocation densities around MCRs at 640 to $700{ }^{\circ} \mathrm{C}$ for a modified $9 \mathrm{Cr}-1 \mathrm{Mo}$ steel tube employing an SCH method. Sawada et al. (1997) observed the dislocation densities in a state near the MCR at $600{ }^{\circ} \mathrm{C}$ for a Gr. 91 steel plate employing TEM. Panait, Zielinska-Lipiec, Koziel, Czyrska-Filemonowicz, Gourgues-Lorenzon, and Bendick (2010) observed the dislocation density of a ruptured specimen of a modified $9 \mathrm{Cr}-1 \mathrm{Mo}$ steel pipe at $600{ }^{\circ} \mathrm{C}$ for $113,431 \mathrm{~h}$ employing TEM. Figure A4 shows the correlation between the stress and MCR of a Gr. 91 steel plate from a data sheet No. D-1 of the NIMS, heat MgC (NIMS, 2007) that is coupled with the dislocation density data. The creep behavior of high-alloy martensitic steel is more complex than that of low-alloy steels shown in Figure 2 in the main text and Figure A2. Data were therefore classified into four groups: Grs. I to III are characterized by stress levels and Gr. IV corresponds to long-term data around $600{ }^{\circ} \mathrm{C}$. A critical issue relating to high-alloy martensitic steel is that the long-term rupture strength unexpectedly decreases at high temperatures (Kushima, Kimura, \& Abe, 1999; Tamura, 2015). The creep behavior of $G r . I V$ may be related to this problem. The values of $Q_{\mathrm{ex}}, V_{\mathrm{ex}}$, and $C_{\mathrm{ex}}$ are respectively calculated as $793.1 \mathrm{kJmol}^{-1}, 445.8 \mathrm{~cm}^{3} \mathrm{~mol}^{-1}$, and 39.50 for $G r . I, 862.4 \mathrm{kJmol}^{-1}, 600.0 \mathrm{~cm}^{3} \mathrm{~mol}^{-1}$, and 41.41 for Gr. II, $772.1 \mathrm{kJmol}^{-1}, 693.3 \mathrm{~cm}^{3} \mathrm{~mol}^{-1}$, and 35.33 for $G r . I I I$, and $409.6 \mathrm{kJmol}^{-1}, 351.5 \mathrm{~cm}^{3} \mathrm{~mol}^{-1}$, and16.03 for $G r$. $I V$. Regression lines for each group are drawn in the figure using the regression coefficients 
mentioned above. Data points obtained by Sawada et al. (1997) (solid triangle) and Panait et al. (2010) (solid diamond) are close to the regression lines at $600{ }^{\circ} \mathrm{C}$ for Grs. III and $I V$, respectively. All dislocation densities reported are given in the figure together with the test conditions. Hayakawa et al. (2003) reported the dislocation densities as functions of creep strain with test conditions, though the MCR for each test condition is unknown except in the case for $700{ }^{\circ} \mathrm{C}$. However, the creep rate at $700{ }^{\circ} \mathrm{C}$ and $59 \mathrm{MPa}$ is close to the regression line at 700 ${ }^{\circ} \mathrm{C}$ for the NIMS data; therefore, the remaining data are plotted with cross marks on each regression line of Gr. III of the NIMS data. According to the NIMS data sheet (NIMS, 2007), the MCRs of Gr. 91 steel are observed at a creep strain near 0.01 ; therefore, dislocation densities at a strain of 0.01 are read from the density vs. creep strain curves obtained by Hayakawa et al. (2003). The values of $\gamma$ are calculated by substituting the dislocation densities, the test conditions listed, and the values of $Q_{\mathrm{ex}}, V_{\mathrm{ex}}$, and $C_{\mathrm{ex}}$ for $G r s . I I I$ and $I V$ mentioned above into Equations 13 and 14 and the results are given in the figure. The dislocation densities calculated employing an SCH method may be considerably lower than those obtained by TEM as shown in Figure 2 for $1 \mathrm{Cr}-0.5 \mathrm{Mo}$ steel. However, the values of $\gamma$ obtained by Hayakawa et al. are large and negative and are comparable to those obtained by Sawada et al. (1997); i.e., the absolute value of $\gamma$ is large and ranges from $16 \%$ to $25 \%$ of $Q_{\mathrm{ex}}$. In other words, the value of $\gamma$ seems to be independent of the test method for dislocation density. Only $\gamma$ obtained by Panait et al. (2010) among the given values is positive and rather small. It is reasonable to judge that this is not due to experimental error, and rather that the microstructure of Gr. 91 approaches the microstructures of the low-alloy steels as shown in Figure 2 and Figures A1 and A2 owing to microstructural degradation during long-term testing. Although the dislocation density obtained by Panait et al. (2010) was measured for a rupture specimen as described above, Panait's data should not be distinguished from those for the state of the MCR, because Panait et al. (2010) also showed that there were small variations in the initial dislocation density and the dislocation densities in the gauge and gripped portions of the rupture specimen over a period of 113431 hours, that is, the dislocation density of Gr. 91 was stable during the whole duration of the creep rupture test at $600{ }^{\circ} \mathrm{C}$ under $80 \mathrm{MPa}$. The temperature-dependence term of the shear modulus is set at $\phi=1.661$ to 1.976 using Young's modulus of high-Cr alloy steel and $v=0.30$ (ASME, 2015).

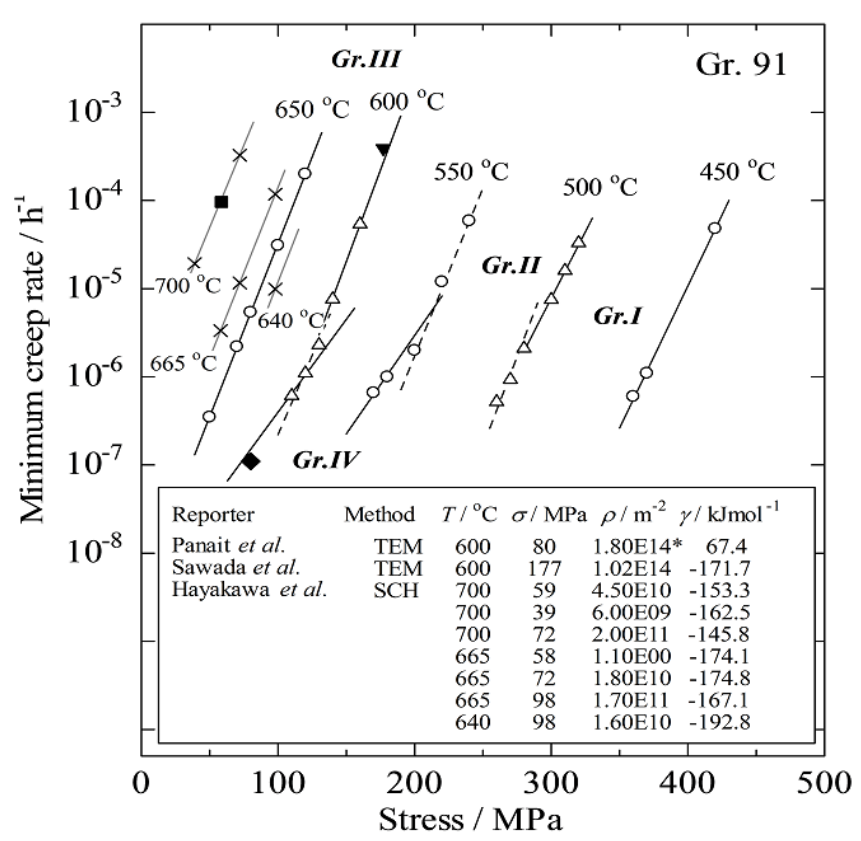

Figure A3. MCRs for a steel plate of Gr. 91 (heat MgC) (NIMS, 2007) as functions of stress. MRC data obtained by Panait et al. (2010) (solid diamond), Sawada et al. (1997) (solid triangle), and Hayakawa et al. (2003) (solid square) are also plotted. Creep rates other than solid marks were not reported by Hayakawa et al. (2003) and, therefore, the data were plotted as cross marks on the regression lines for Gr. III calculated using the MCR data for heat $\mathrm{MgC}$. The test method, test conditions, and dislocation densities for each report are given in the figure and the calculated values of $\gamma$ are also given for each dislocation density. The dislocation density indicated by an asterisk, reported by Panait et al. (2010), was measured employing TEM for a gauge portion of a ruptured specimen 
A4. Gr. 92

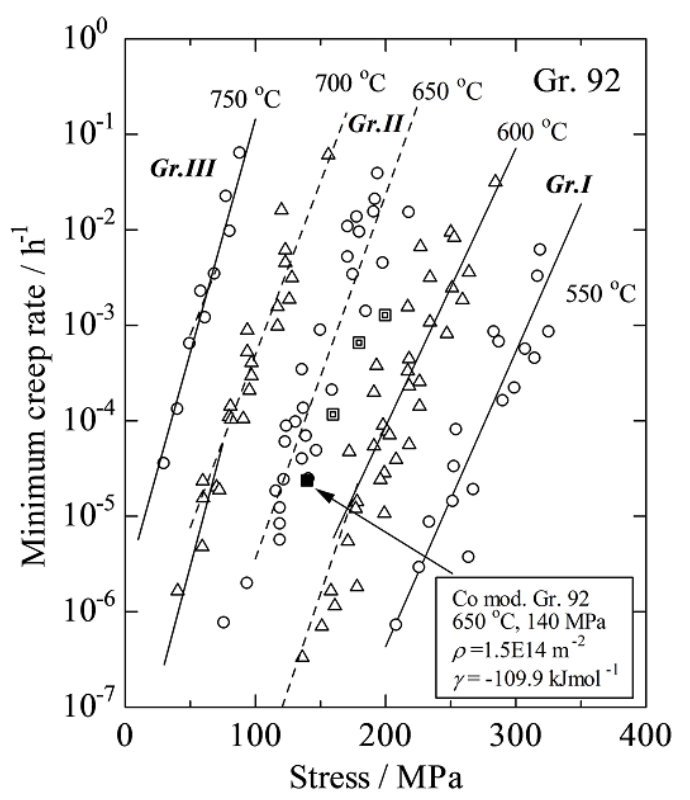

Figure A4. MCRs for Gr. 92 steel (Hasegawa, 2014) as functions of stress. MRC data at $650{ }^{\circ} \mathrm{C}$ of Co-modified Gr. 92 steel (Dudova, 2012) are also plotted as square marks, among which the dislocation density obtained by TEM was reported only for $140 \mathrm{MPa}$ (solid square mark). The value of $\gamma$ for the Co-modified Gr. 92 steel calculated using the parameter constants for Gr. II of the Gr. 92 steel (see text) is also given in the figure with the observed dislocation density

Dudova, Plotnikova, Molodov, Belyakov, and Kaibyshev (2012) conducted creep tests at $650{ }^{\circ} \mathrm{C}$ for a $3 \%$ Co-modified Gr. 92 steel pipe and observed the dislocation density of a crept specimen at an MCR under $140 \mathrm{MPa}$ employing TEM. Since we cannot perform an analysis with Equation 14 using their data alone, Figure A4 shows the MCRs of Gr. 92 (Hasegawa, 2014), comparing with Dudova et al.'s data. The MCRs of Gr. 92 are classified into three groups, Grs. I-III, and regression lines are given according to stress levels. Despite a discrepancy in the slopes at $650{ }^{\circ} \mathrm{C}$ between the MCR of Gr. 92 (circles) and the Dudova's data (squares), Dudova's data are judged to belong to $\mathrm{Gr}$. II of Gr. 92 steel, because the Dudova's data fall in the scatter band of Gr. 92 at $650{ }^{\circ} \mathrm{C}$. The values of $Q_{\mathrm{ex}}, V_{\mathrm{ex}}$, and $C_{\mathrm{ex}}$ for $G r$. II are calculated as $801.3 \mathrm{kJmol}^{-1}, 673.2 \mathrm{~cm}^{3} \mathrm{~mol}^{-1}$, and 36.14 , respectively. The value of $\gamma=-109.9 \mathrm{kJmol}^{-1}$ is obtained for Co-modified Gr. 92 steel using Equation 13 with parameter constants for Gr. II of Gr. 92 steel and using the creep data and the observed dislocation density of Co-modified Gr. 92 steel. The absolute value of $\gamma$ is $14 \%$ of $Q_{\mathrm{ex}}$ and is rather large. The temperature-dependence term of the shear modulus is set at $\phi=1.898$ using Young's modulus of high-alloy martensitic steel and $v=0.30$ (ASME, 015).

\section{A5. High-Cr Forged Rotor}

Spiradek, Bauer, and Zeiler (1994) reported MCRs at $600{ }^{\circ} \mathrm{C}$ and $650{ }^{\circ} \mathrm{C}$ for $9 \mathrm{Cr}-1 \mathrm{MoVNbB}$ forged rotor steel; the results are shown in Figure A5. All data are analyzed using Equation 14 and the values of $527.7 \mathrm{kJmol}^{-1}$, $354.7 \mathrm{~cm}^{3} \mathrm{~mol}^{-1}$, and 22.20 are obtained for $Q_{\mathrm{ex}}, V_{\mathrm{ex}}$, and $C_{\mathrm{ex}}$, respectively. In the figure, regression lines are drawn using these parameter constants. Spiradek et al. (1994) themselves also observed the dislocation densities obtained employing TEM before and after creep rupture tests. The dislocation density of a ruptured specimen decreased only $50 \%$ from the initial dislocation density, and a similar trend was reported for a similar Gr. 91(Panait et al., 2010) martensitic steel. Furthermore, the dislocation density of a similar X20 martensitic steel changes little after the MCR to rupture (Bazazi, 2009). Therefore, the dislocation densities after rupture, $\rho_{\mathrm{tr}}$, were used in the calculation of $\gamma$ for the MCR. The values of $\gamma$ at $600{ }^{\circ} \mathrm{C}$ and $650{ }^{\circ} \mathrm{C}$ are calculated as $28.2 \mathrm{kJmol}^{-1}$ and $-0.9 \mathrm{kJmol}^{-1}$, respectively. The absolute values of $\gamma$ are small and below $5 \%$ of $Q_{\mathrm{ex}}$. The temperature-dependence term of the shear modulus is set at $\phi=1.661$ and 1.801 using Young's modulus of high-alloy martensitic steel and $v=0.30$ (ASME, 2015). 


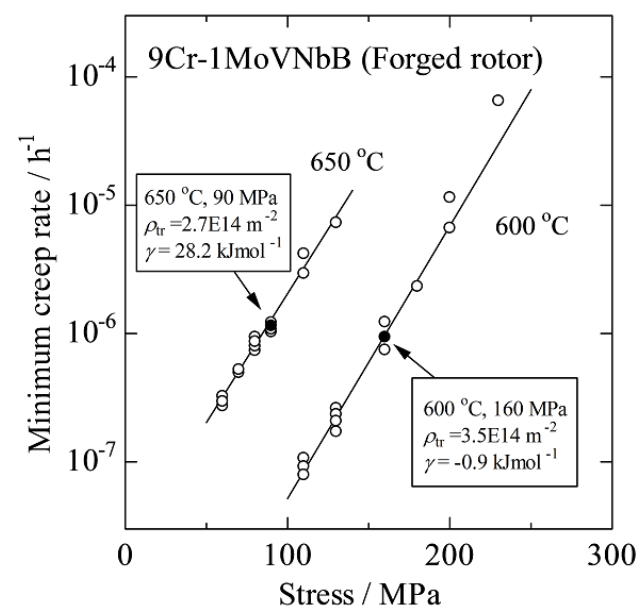

Figure A5. MCRs for forged rotor steel of $9 \mathrm{Cr}-1 \mathrm{MoVNbB}$ steel (Spiradek et al., 1994) as functions of stress. The values of dislocation density observed by TEM using ruptured specimens under the conditions given in the figure and the values of $\gamma$ for each dislocation density calculated using parameter constants for the MRCs are also shown

\section{A6. X20 CrMoV 121 Steel}

Pesicka et al. (2003) and Bazazi (2009) observed the dislocation densities around the state of the MCR at 650 and $550{ }^{\circ} \mathrm{C}$ under stress of $120 \mathrm{MPa}$ employing TEM and obtained values of $3 \mathrm{E} 13$ and $1 \mathrm{E} 13 \mathrm{~m}^{-2}$, respectively. Straub et al. (Straub, Meier, Ostermann, and Blum, 1993; Straub 1995) observed the MCRs of X20 steel under a wide range of conditions. Creep data obtained by Straub et al. (1993) are shown in Figure A6 together with those obtained by Pesicka et al. (2003) and Bazazi (2009). Among the data obtained by Straub et al. (1993), the MCRs at 600 and $550^{\circ} \mathrm{C}$ are judged to lie on approximately parallel linear lines and comprise one group named Gr. II. However, several MCR data in a low-strain-rate range at 600 and $550{ }^{\circ} \mathrm{C}$ seem to be approximately parallel to the data at $500{ }^{\circ} \mathrm{C}$ and this data group is named $G r$. I. The values of $Q_{\mathrm{ex}}, V_{\mathrm{ex}}$, and $C_{\mathrm{ex}}$ are respectively $428.1 \mathrm{kJmol}^{-1}, 230.1 \mathrm{~cm}^{3} \mathrm{~mol}^{-1}$, and 19.08 for $G r . I$ and $640.8 \mathrm{kJmol}^{-1}, 343.5 \mathrm{~cm}^{3} \mathrm{~mol}^{-1}$, and 31.19 for $G r$. II. Using these parameter constants, regression lines and an extrapolation line at $650{ }^{\circ} \mathrm{C}$ for Grs. $I$ and $I I$ are drawn as shown in Figure 8. The MCRs obtained by Pesicka et al. (2003) and Bazazi (2009) are plotted by a solid square and a solid triangle, respectively. Bazazi's data point (solid triangle) seems to be on an extrapolation line at $550{ }^{\circ} \mathrm{C}$ for $G r$. II. However, it is well known that the rupture strength of high-Cr martensitic steel unexpectedly decreases after long-term tests (Kushima et al., 1999; Tamura, 2015), and therefore, if degradation like this occurs, the creep strength of X20 steel at $550{ }^{\circ} \mathrm{C}$ varies along a line from Gr. II to Gr. I after a long time. In this scenario, the creep strength of Bazazi's heat is strong by chance. In other words, we cannot decide to which group Bazazi's data belongs because the creep strength depends on not only the chemical composition but also heat treatment. The same is true of the data obtained by Pesicka et al. (2003). The values of $\gamma$ for the data of Pesicka et al.(2003) and Bazazi (2009) are calculated as shown in Figure A6 for Grs. I and II. It is reasonable to conclude that the values of $\gamma$ range from -132.5 to $-8.4 \mathrm{kJmol}^{-1}$ at $550{ }^{\circ} \mathrm{C}$ and from -102.2 to $+24.4 \mathrm{kJmol}^{-1}$ at $600{ }^{\circ} \mathrm{C}$, because we cannot categorically decide to which group the data of Pesicka et al. (2003) and Bazazi (2009) belong. In the following numerical treatment, four values of $\gamma$ shown in Figure A6, and not the average, are regarded as the values for X20 steel. The absolute values of $\gamma$ are respectively $2 \%$ to $5.6 \%$ and $16 \%$ to $21 \%$ of $Q_{\text {ex }}$ for $G r s$. $I$ and $I I$, and X20 steel seems to behave intermediately between low-alloy steel and high-alloy martensitic steel from the point of view of the values of $\gamma$ and $\gamma / Q_{\mathrm{ex}}$. In any case, the correction term, $\gamma$, tends to increase or to be positive at higher temperatures. Pesicka et al. (2003) also reported a lower dislocation density of $1.4 \mathrm{E} 13 \mathrm{~m}^{-2}$ obtained by XRD analysis relative to that obtained by TEM for the same specimen. The values of $\gamma$ obtained by XRD analysis for Grs. I and II are respectively 18.5 and $-108.1 \mathrm{kJmol}^{-1}$, and the value of $\gamma$ tends to shift slightly to the negative side as suggested by Equation 13. It is found that to obtain an adequate value of $\gamma$, the collection of both creep data and the dislocation density by the same research group employing a specified method is necessary, yet it is unfortunately difficult to select such data at the present time. It is thus important to verify the collected data especially when we need to extrapolate the data. The temperature-dependence term of the shear modulus is set at $\phi=1.547$ and 1.801 for 650 and $550^{\circ} \mathrm{C}$, respectively, using Young's modulus of high-Cr alloy steel and $v=$ 0.30 (ASME, 2015). 


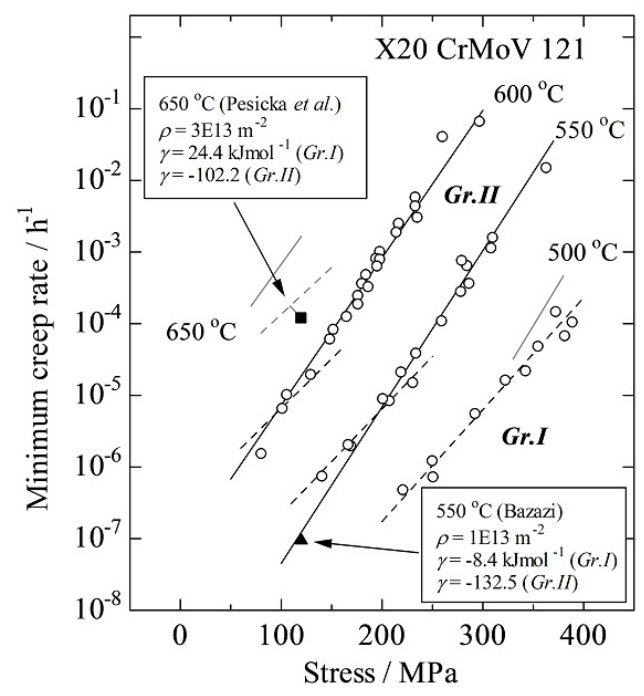

Figure A6. MCRs for X20 CrMoV 121 steel (Straub et al., 1993; Straub, 1995) as functions of stress. MRC data at $650{ }^{\circ} \mathrm{C}$ Pesicka et al., 2003) and $550{ }^{\circ} \mathrm{C}$ (Bazazi, 2009) of X20 steel are also plotted as a solid square mark and a triangle mark, respectively. The values of $\gamma$ for X20 steel calculated using the parameter constants for Grs. I and II and the dislocation densities observed by TEM are also shown in the figure

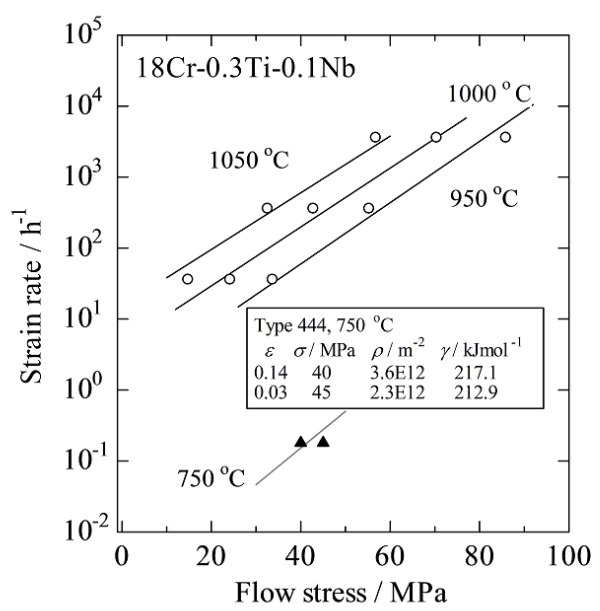

Figure A7. Relations between the strain rate and flow stress at 0.4 strain for $18 \mathrm{Cr}-0.3 \mathrm{Ti}-0.1 \mathrm{Nb}$ steel (Mehtonen, 2014) obtained in hot compression tests. Flow stresses at different strains and at $750{ }^{\circ} \mathrm{C}$ of type- 444 steel (Yamoah, 2013) are also plotted as solid triangle marks. The line near these triangles is an extrapolated regression line drawn using the higher temperature data of $18 \mathrm{Cr}-0.3 \mathrm{Ti}-0.1 \mathrm{Nb}$ steel. The values of $\gamma$ for type- 444 steel calculated using

Equation 13 and the parameter constants, $Q_{\mathrm{ex}}$ and $V_{\mathrm{ex}}$, for $18 \mathrm{Cr}-0.3 \mathrm{Ti}-0.1 \mathrm{Nb}$ steel are also shown with the dislocation density observed by TEM

\section{A7. 18 Cr steel}

Yamoah (2013) conducted tensile tests of ferritic stainless steel of type 444 (18Cr-2Mo- $0.5 \mathrm{Nb}$ steel) at $750{ }^{\circ} \mathrm{C}$ and observed the dislocation density during a steady-state flow employing TEM. No data for the deformation rate of the same material near the conditions of $750{ }^{\circ} \mathrm{C}$ were obtained, but Mehtonen (2014) summarized the results of high-temperature compression tests at temperatures ranging from 950 to $1050{ }^{\circ} \mathrm{C}$ for $18 \mathrm{Cr}-0.3 \mathrm{Ti}-0.1 \mathrm{Nb}$ steel, the composition of which is near to that of type-444 steel. Figure A7 shows the results obtained by Yamoah and Mehtonen. Mehtonen reported flow stresses at strain of $\varepsilon=0.4$ and Yamoah reported 
flow stresses at $\varepsilon=0.03$ and 0.14 , but both flow stresses were for a steady state. By analyzing Mehtonen's data using Equation 14, the parameter constants of $Q_{\mathrm{ex}}=801.3 \mathrm{kJmol}^{-1}, V_{\mathrm{ex}}=673.2 \mathrm{~cm}^{3} \mathrm{~mol}^{-1}$, and $C_{\mathrm{ex}}=36.14$ are obtained. Regression lines for Mehtonen's data and an extrapolation line for Yamoah's data are drawn in the figure. Yamoah's data surprisingly lie on the line extrapolated using Mehtonen's data, though extrapolation is conducted beyond $200{ }^{\circ} \mathrm{C}$. This coincidence seems to arise from the fact that the chemical compositions of matrixes of the two steels may be similar, because the precipitation of the Laves phase is approximately completed and the precipitates are sufficiently coarsened, despite the difference in chemical composition of $2 \%$ of Mo between the two steels. The correction term of $\gamma$ obtained using the dislocation density of type-444 steel is a considerably large positive value and is calculated as 217.1 and $212.9 \mathrm{kJmol}^{-1}$ for strains of 0.14 and 0.03 , respectively. The temperature-dependence term of the shear modulus is set at $\phi=14.28$ for a temperature of $750{ }^{\circ} \mathrm{C}$ using Young's modulus of high-Cr alloy steel and $v=0.30$ (ASME, 2015).

\section{A8. Type-304 Steel}

Cuddy (1970) conducted creep tests of type-304 stainless steel at temperatures of 704 to $927^{\circ} \mathrm{C}$ and observed the dislocation densities within the subgrains of specimens that crept to a strain of 0.23 employing TEM. Kassner et al. (1985) conducted torsion tests at 865 and $1065{ }^{\circ} \mathrm{C}$ and observed the dislocation densities of deformed specimens in a steady state employing TEM. Figure A8 shows the relation between the stress and steady-state creep rate at a strain of 0.15, which was reported by Cuddy himself (solid and open circles). Cuddy's data are classified into three groups, Grs. I-III, according to the stress level. For each data group, regression analyses were conducted using Equation 14 and the parameter constants $Q_{\mathrm{ex}}, V_{\mathrm{ex}}$, and $C_{\mathrm{ex}}$ were respectively obtained as $463.4 \mathrm{kJmol}^{-1}, 383.3 \mathrm{~cm}^{3} \mathrm{~mol}^{-1}$, and 19.38 for $G r . I, 413.4 \mathrm{kJmol}^{-1}, 825.9 \mathrm{~cm}^{3} \mathrm{~mol}^{-1}$, and 14.72 for $\mathrm{Gr}$. II, and $598.1 \mathrm{kJmol}^{-1}, 1207.7 \mathrm{~cm}^{3} \mathrm{~mol}^{-1}$, and 22.43 for $G r$. III. Using these parameter constants, regression lines are drawn as shown in the figure. Among the data obtained by Kassner et al. (1985), only a data point for a temperature of $865^{\circ} \mathrm{C}$ is indicated by a solid square with a regression line for $865^{\circ} \mathrm{C}$ as a member of $G r$. II. The values of $\gamma$ are calculated using Equation 13, the parameter constants given above, and the dislocation densities indicated in the figure, and the results are given in the figure. The calculated values of $\gamma$ range from -76.9 to $+38.4 \mathrm{kJmol}^{-1}$. The absolute values of $\gamma / Q_{\mathrm{ex}}$ are widely distributed in the range from $2 \%$ to $17 \%$. The calculation of $\gamma$ at high temperatures requires the values of elastic properties; the elastic properties of type 304 are listed up to $700{ }^{\circ} \mathrm{C}$ in a table published by the ASME (2015). In the above calculations, the elastic properties of $20 \mathrm{Cr}-30 \mathrm{Ni}-6 \mathrm{Mo}-1 \mathrm{Cu}$ alloy (UNS N808031) were used instead, and the temperature-dependence term of the shear modulus is set at $\phi=1.485$ to 1.711 using the relation $v=0.31$ (ASME, 2015). The NIMS (1986b) also provides creep data for type 304 at temperatures of 600 to $700{ }^{\circ} \mathrm{C}$ and the MCRs of heat ABE in the NIMS data sheet (triangles) are shown in Figure A8. These data were classified into three groups, Grs. IV-VI, as shown in the figure, and regression analyses were conducted for each group. When we correlate $G r . I V$ of the NIMS data with Gr. I of Cuddy's data, it is found that the two groups can be regarded as the same. This suggests that the strain rate at a strain of 0.15 that Cuddy (1970) reported is metallurgically equivalent to the MRC observed at low temperatures, although, in general, an MCR is hardly observed at temperatures as high as those in Cuddy's test.

In the calculation of Figure A8, there are problems relating to the difference in the deformation mode and the extrapolation of elastic properties. Thus, to ensure the reliability of the values of $\gamma$, the dislocation density obtained by Kassner et al. (1985) was reanalyzed using creep data for alloy 800, the chemical composition and microstructure of which are similar to those of type 304. Figure A9 shows the relation between the stress and steady-state creep rate reported by Milicka (triangles) (1989) and the MCRs reported by the NIMS (heat fCD in the NIMS data sheet (1998), circles) together with the data obtained by Kassner et al. (1985) (solid square). The creep data obtained by the NIMS and Milicka are classified into Grs. I-IV as shown in the figure. The parameter constants in Equation 14 for Grs. III and $I V$ are $Q_{\mathrm{ex}}=492.0 \mathrm{kJmol}^{-1}, V_{\mathrm{ex}}=471.4 \mathrm{~cm}^{3} \mathrm{~mol}^{-1}$, and $C_{\mathrm{ex}}=$ 20.52 for $G r$. III and $Q_{\mathrm{ex}}=544.4 \mathrm{kJmol}^{-1}, V_{\mathrm{ex}}=2115.0 \mathrm{~cm}^{3} \mathrm{~mol}^{-1}$, and $C_{\mathrm{ex}}=16.88$ for $G r$. $I V$. Regression lines are drawn in the figure. As shown in Figure A9, the data point of Kassner et al. (1985) is near the regression lines for $865^{\circ} \mathrm{C}$ and, therefore, the data point of Kassner et al. (1985) for $865^{\circ} \mathrm{C}$ is regarded as a member of Gr. III or $I V$. The values of $\gamma$ for the data of Kassner et al. (1985) in the cases of Grs. III and $I V$ are calculated as $-41.0 \mathrm{kJmol}^{-1}$ and $-6.1 \mathrm{kJmol}^{-1}$, respectively. Combining the results of Figures A8 and A9, the value of $\gamma$ for the data of Kassner et al. (1985) is considered to be between -6.1 and $+38.4 \mathrm{kJmol}^{-1}$. 


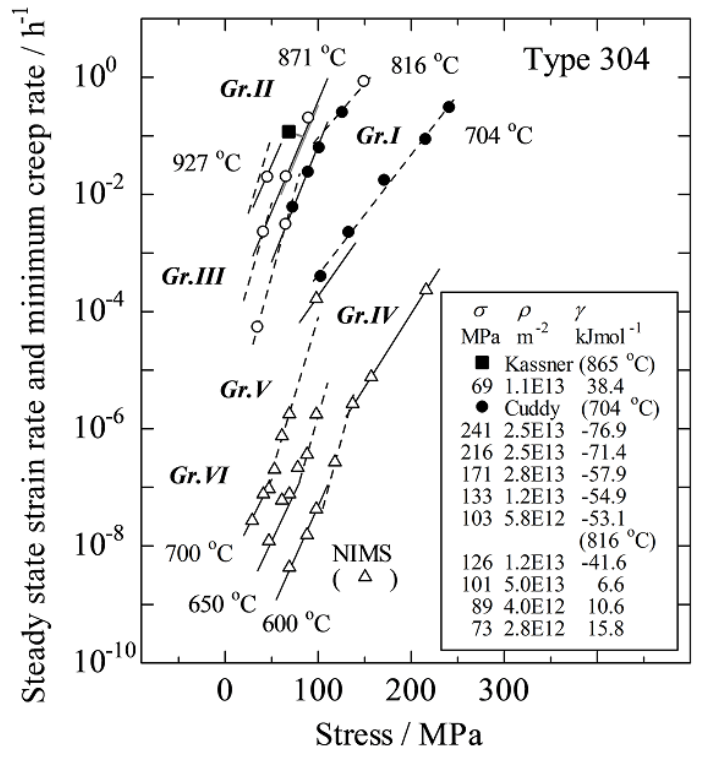

Figure A8. Steady-state strain rate at a creep strain of 0.23 (circle) (Cuddy, 1970), deformation rate obtained in a torsion test (square) (Kassner et al., 1985), and minimum creep rate (triangle) (NIMS, 1986b) as functions of stress for type-304 steel. The values of $\gamma$ for type-304 steel calculated using the parameter constants for Grs. I and II, and dislocation density observed by TEM are also shown in the figure

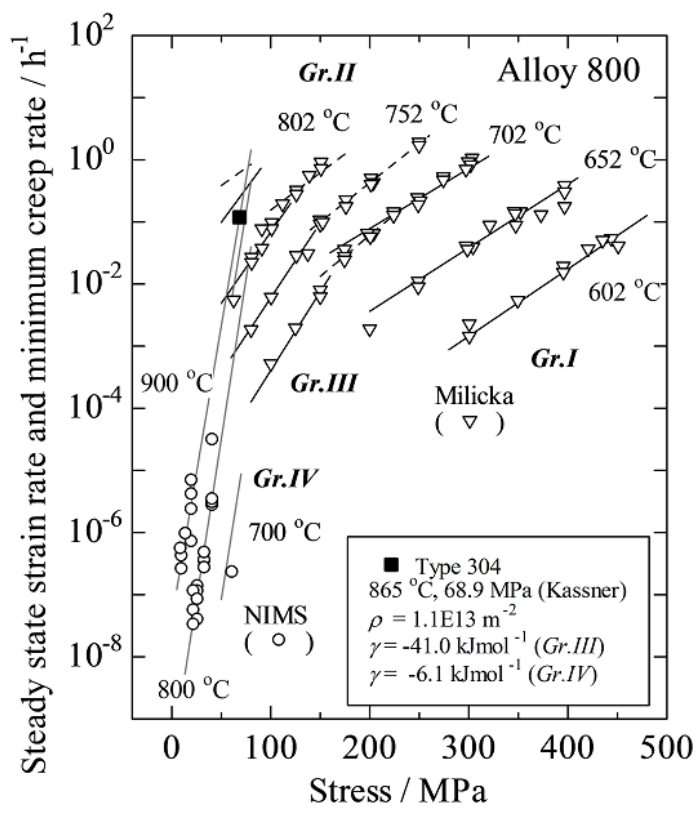

Figure A9. Relations between stress and the steady-state creep rate for alloy 800 of Milicka (1989) (triangles) and the MCR provided by NIMS (1998) (circles). Data point for type-304 steel obtained in a torsion test (Kassner et al., 1986) shown in Figure A8 is replotted (square). Lines near a solid square mark are the extrapolated regression lines for Grs. II to $I V$ at $865^{\circ} \mathrm{C}$. The values of $\gamma$ for type-304 steel calculated using the parameter constants for Grs. III and $I V$, and the dislocation density observed by TEM are also shown in the figure 
A9. Type-316 steel

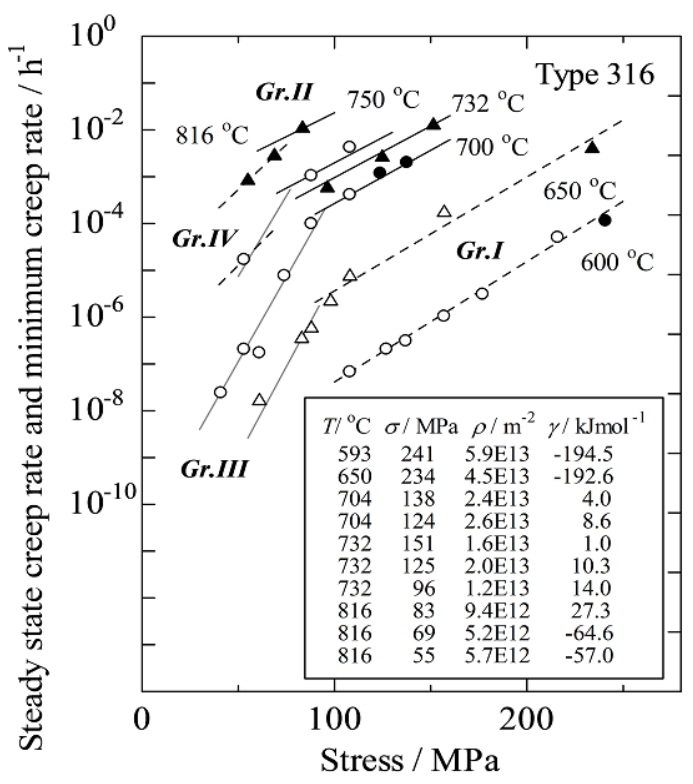

Figure A10. Relations between stress and the steady-state creep rate or MCR for type-316 steel (Challenger et al. 1973; NIMS, 2000). Dislocation densities for solid marks were measured by Challenger et al. (1973) employing TEM and the results are given in the figure. The values of $\gamma$ calculated using the dislocation densities and the parameter constants for Grs. I, II, and $I V$ are also shown in the figure

Challenger and Moteff (1973) conducted creep tests of type-316 stainless steel at temperatures from 593 to $816^{\circ} \mathrm{C}$ and observed the dislocation densities of specimens that crept under a strain of 0.12 employing TEM. The NIMS (2000) also provided MCRs of type-316 stainless steel (heat ALL in the NIMS data sheet). Figure A10 shows the steady-state creep rates (Challenger et al., 1973) and MCRs (NIMS, 2000) of type-316 stainless steel as functions of stress. All data were classified without distinction into Grs. I to $I V$ as shown in the figure and analyzed using Equation 14. The parameter constants, $Q_{\mathrm{ex}}, V_{\mathrm{ex}}$, and $C_{\mathrm{ex}}$, of Equation 14 are respectively $642.7 \mathrm{kJmol}^{-1}, 429.7 \mathrm{~cm}^{3} \mathrm{~mol}^{-1}$, and 28.54 for $G r . I, 387.5 \mathrm{kJmol}^{-1}, 423.7 \mathrm{~cm}^{3} \mathrm{~mol}^{-1}$, and 14.94 for Gr. II, $759.6 \mathrm{kJmol}^{-1}, 1346.2 \mathrm{~cm}^{3} \mathrm{~mol}^{-1}$, and 30.26 for Gr. III, and $561.1 \mathrm{kJmol}^{-1}$, $802.7 \mathrm{~cm}^{3} \mathrm{~mol}^{-1}$, and 21.74 for $G r . I V$. Regression lines are drawn for each data group as shown in the figure. In Figure A10, the dislocation densities were measured for the test conditions as indicated by solid marks. The values of $\gamma$ were calculated using these dislocation densities and Equation 13 and the results are given in the figure. The temperatures indicated near the solid marks slightly differ from the temperatures listed in the figure; e.g., $600{ }^{\circ} \mathrm{C}$ as an indicated temperature versus $593^{\circ} \mathrm{C}$ as a listed temperature. This is because Challenger et al. (1973) performed creep tests at temperatures that were rounded numbers in the Fahrenheit unit, whereas the calculations were made using the correct temperatures. The absolute values of $\gamma$ for high stresses at 593 and $650{ }^{\circ} \mathrm{C}$ are large, and $\gamma / Q_{\mathrm{ex}} \approx 30 \%$. Excepting these two cases, however, the absolute values of $\gamma / Q_{\text {ex }}$ are small and $\gamma / Q_{\mathrm{ex}} \approx 0 \%$ to $11.5 \%$. The temperature-dependence term of the shear modulus is set at $\phi=1.370$ to 1.634 using the elastic properties of $20 \mathrm{Cr}-30 \mathrm{Ni}-6 \mathrm{Mo}-1 \mathrm{Cu}$ alloy (UNS N808031), which is similar to type-316 steel, and $v=0.31$ (2015). 
A10. Al and Al alloy

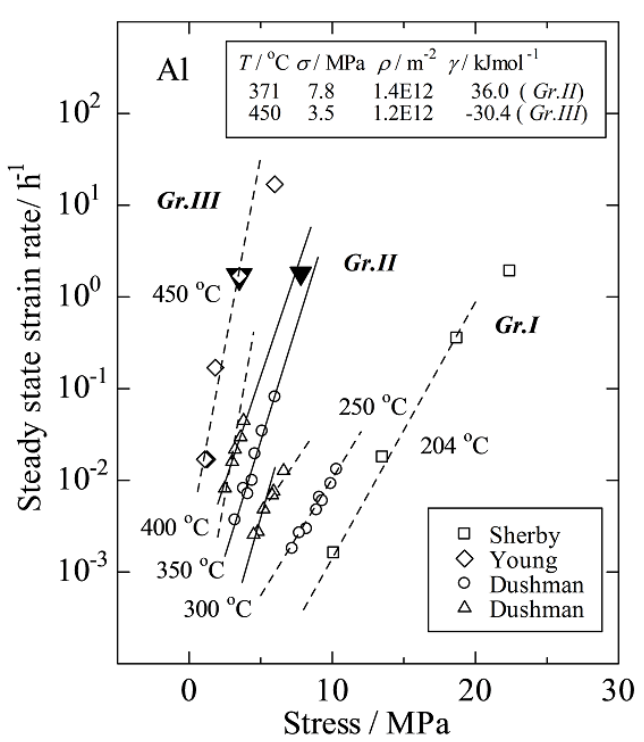

Figure A11. Relation between stress and the strain rate in a steady state for pure Al (Dushman et al., 1944; Sherby et al., 1954; Young et al., 1975), Dislocation densities for solid marks were reported for 371 and $450^{\circ} \mathrm{C}$ by Kassner (1990). The values of $\gamma$ calculated using the dislocation densities and the parameter constants for Grs. II and III are also shown

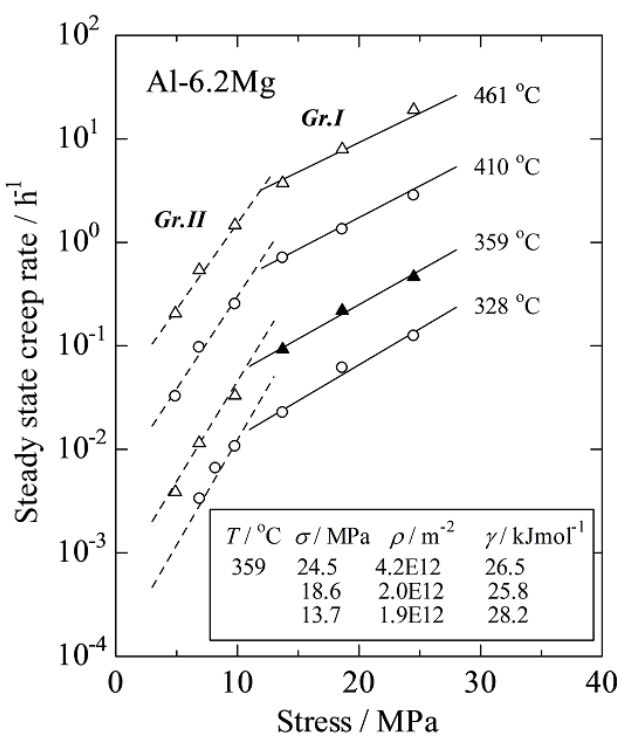

Figure A12. Relation between stress and the steady state creep rate for Al-6.2Mg alloy. Dislocation densities for solid marks were also measured by Horiuchi et al. (1972) employing TEM. The values of $\gamma$ calculated using the dislocation densities and the parameter constants for $G r . I$ are also shown 


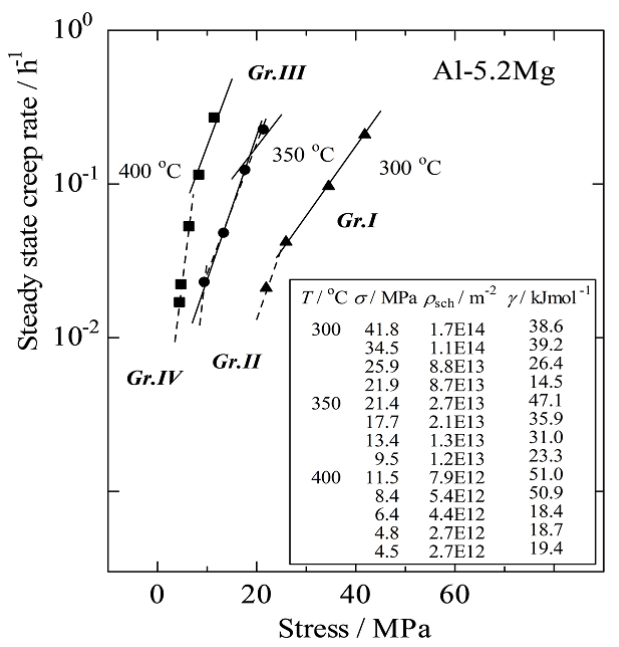

Figure A13. Relations between stress and the MCR for Al-5.2Mg (Yoshinaga et al., 1984). Dislocation densities for all specimens were evaluated by Yoshinaga et al. (1984) using a stress change method. The values of $\gamma$ calculated using the dislocation densities and the parameter constants for Grs. $I$ and $I V$ are also shown

Kassner (1990) reported the dislocation densities in a steady state in torsion tests conducted at 371 and $450{ }^{\circ} \mathrm{C}$ for pure Al. Figure A11 shows the strain rates in a steady state obtained by Dushman, Dunbar, and Huthsteiner (1944), Sherby and Dorn (1954), and Young, Robinson, and Sherby (1975) as functions of stress. Although the data of Young et al. (1975) are the flow rates obtained in compression tests and the other data are obtained in tensile creep tests, all data plotted were classified into Grs. I to III as shown in the figure without distinction. The parameter constants, $Q_{\mathrm{ex}}, V_{\mathrm{ex}}$, and $C_{\mathrm{ex}}$, of Equation 14 are respectively $115.5 \mathrm{kJmol}^{-1}, 2547.7 \mathrm{~cm}^{3} \mathrm{~mol}^{-1}$, and 7.02 for $G r . I, 143.4 \mathrm{kJmol}^{-1}, 5967.2 \mathrm{~cm}^{3} \mathrm{~mol}^{-1}$, and 7.96 for $G r$. II, and $331.5 \mathrm{kJmol}^{-1}, 11468 \mathrm{~cm}^{3}$ $\mathrm{mol}^{-1}$, and 21.36 for $G r$. III. Regression lines are drawn as shown in the figure for each data group. The data obtained by Kassner are plotted as solid triangles and belong to Grs. II and III. The values of $\gamma$ at 371 and $450{ }^{\circ} \mathrm{C}$ are calculated using Equation 13, dislocation densities, and the parameter constants mentioned above as +36.0 and $-30.4 \mathrm{kJmol}^{-1}$, respectively. These values seem to be small, but the absolute values of $\gamma / Q_{\mathrm{ex}}$ for Grs. II and III are respectively large and rather large; i.e., $25 \%$ and $9 \%$, respectively. The temperature-dependence term of the shear modulus is set at $\phi=1.53$ and 1.91 using the elastic properties of pure Al (Takeuchi, Noda, Komori, Nyuko, \& Kitagawa, 1977). Horiuchi and Otsuka (1972) performed tensile creep tests on Al-6.2Mg alloy at 328 to $461{ }^{\circ} \mathrm{C}$ and observed the dislocation densities at $359^{\circ} \mathrm{C}$ during a steady state. Figure $\mathrm{A} 12$ shows the steady-state creep rates as functions of stress. All data were classified into Grs. $I$ and $I I$ as shown in the figure. The parameter constants, $Q_{\mathrm{ex}}, V_{\mathrm{ex}}$, and $C_{\mathrm{ex}}$, of Equation 14 are respectively $152.2 \mathrm{kJmol}^{-1}, 798.9 \mathrm{~cm}^{3} \mathrm{~mol}^{-1}$, and 10.67 for $G r$. I and $156.2 \mathrm{kJmol}^{-1}, 2336.0 \mathrm{~cm}^{3} \mathrm{~mol}^{-1}$, and 9.65 for $G r$. II. Regression lines are drawn using these parameter constants as shown in the figure. The values of $\gamma$ at $359^{\circ} \mathrm{C}$ are calculated as about $27 \mathrm{kJmol}^{-1}$ using Equation 13, the dislocation densities indicated, and the parameter constants mentioned above. These values seem to be small, but the absolute values of $\gamma / Q_{\text {ex }}$ are rather large like those of high-alloy martensitic steel; i.e., about $18 \%$. Yoshinaga et al. (1984) performed tensile creep tests on Al-5.2Mg alloy at 573 to 300 to $400{ }^{\circ} \mathrm{C}$ and reported the steady-state creep rates and dislocation densities employing an SCH method. The temperature-dependence term of the shear modulus is set at $\phi=1.491$ using the elastic properties of pure $\mathrm{Al}$ (Takeuchi et al., 1977) and results are shown in Figure A13. A comparison of Figures A12 and A13 confirms that Yoshinaga et al. (1984) investigated in detail the region near the boundary between Grs. I and II in Figure A12. In Figure A13, all data are classified into Grs. I to $I V$. To ensure a minimum number of data for each group, two or three data groups share a single data point as necessary; e.g., Grs. I to III share a single data point of $350{ }^{\circ} \mathrm{C}$ and 17.7 MPa. The parameter constants, $Q_{\mathrm{ex}}, V_{\mathrm{ex}}$, and $C_{\mathrm{ex}}$, of Equation 14 are respectively $133.1 \mathrm{kJmol}^{-1}, 497.0$ $\mathrm{cm}^{3} \mathrm{~mol}^{-1}$, and 9.58 for $G r$. I, $176.7 \mathrm{kJmol}^{-1}, 1011.1 \mathrm{~cm}^{3} \mathrm{~mol}^{-1}$, and 12.40 for $G r$. II, $150.6 \mathrm{kJmol}^{-1}$, $1118.3 \mathrm{~cm}^{3} \mathrm{~mol}^{-1}$, and 10.08 for $G r$. III, and $218.0 \mathrm{kJmol}^{-1}, 3323.2 \mathrm{~cm}^{3} \mathrm{~mol}^{-1}$, and 14.01 for $G r$. IV. The values of $\gamma$ are calculated using these parameter constants and the dislocation density for each data point. However, since the same data are used as a member of different groups, different values are obtained for a single data, in some cases; e.g., the values of $\gamma$ are 47.2, 21.2, and $39.3 \mathrm{kJmol}^{-1}$ for Grs. $I, I I$, and $I I I$, respectively, for a single data point of $350{ }^{\circ} \mathrm{C}$ and $17.7 \mathrm{MPa}$, and therefore, the average values of $\gamma, 35.9 \mathrm{kJmol}^{-1}$, are given in the 
figure. The values of $\gamma$ tend to decrease at higher temperatures and lower stresses in a manner similar to the variation in dislocation density. The values of $\gamma$ investigated range from 4.5 to $51.0 \mathrm{kJmol}^{-1}$ and seem to be small, but the absolute values of $\gamma / Q_{\text {ex }}$ are large like those of high-alloy martensitic steel; i.e., about $20 \%$. The temperature-dependence term of the shear modulus is set at $\phi=1.341$ to 1.641 using the elastic properties of pure (Takeuchi et al., 1977). A comparison of the values of $Q_{\mathrm{ex}}, V_{\mathrm{ex}}$, and $C_{\mathrm{ex}}$ of $G r$. III in Figure A13 with those of $G r$. I in Figure A12 shows that, with these two data groups having being obtained under similar conditions, the values of $Q_{\mathrm{ex}}, V_{\mathrm{ex}}$, and $C_{\mathrm{ex}}$ are similar and therefore correspond to investigations of similar creep phenomena. However, it is found that the dislocation densities obtained employing an $\mathrm{SCH}$ method are approximately 7 times as large as those obtained by TEM, comparing the dislocation densities at $350{ }^{\circ} \mathrm{C}$ in Figure A13 with those at 359 ${ }^{\circ} \mathrm{C}$ in Figure 12A. In spite of these differences, the values of $\gamma$ and $\gamma / Q_{\mathrm{ex}}$ under similar test conditions are similar and do not depend on the test method; i.e., TEM or SCH.

A11. Pure $\mathrm{Cu}$

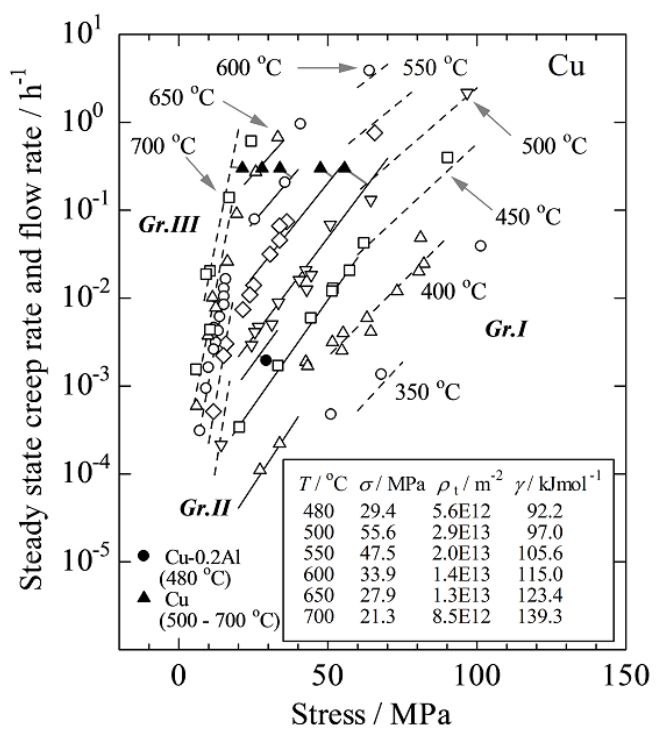

Figure A14. Relation between stress and the steady state strain rate or flow rate for pure $\mathrm{Cu}$ (Raj et al., 1989). Total dislocation densities obtained by Staker and Holt (solid triangle) (Staker et al., 1972) for pure Cu strained to 0.1 under tension and by obtained Hasegawa et al. (1973) (solid circle) for $\mathrm{Cu}-0.2 \mathrm{Al}$ alloy in a steady-state creep employing TEM are shown. The values of $\gamma$ calculated using the dislocation densities and the parameter constants for Grs. II and III are also shown.

Staker and Holt (1972) conducted tensile tests of pure $\mathrm{Cu}$ at temperatures at 500 to $700{ }^{\circ} \mathrm{C}$ and measured the total dislocation densities of specimens strained to $\varepsilon=0.1$ employing TEM. Hasegawa, Karashima, and Ikeuchi (1973) observed the total dislocation density of $\mathrm{Cu}-0.2 \mathrm{Al}$ alloy that crept in a steady state at $480{ }^{\circ} \mathrm{C}$ employing TEM. Raj and Langdon (1989) reported steady-state creep rates under widely ranging conditions, which cover the test conditions for the abovementioned dislocation densities. The results are shown in Figure A14. Barrett, Lytton, and Sherby (1967) presented similar creep data for high-purity $\mathrm{Cu}$ at 412 to $538{ }^{\circ} \mathrm{C}$, but for clarity and because their data were limited, their results are not plotted. The data obtained by Raj et al. (1989) were classified into Grs. $I$ to $I I I$ as shown in the figure. The parameter constants, $Q_{\mathrm{ex}}, V_{\mathrm{ex}}$, and $C_{\mathrm{ex}}$, of Equation 14 are respectively $179.1 \mathrm{kJmol}^{-1}, 435.7 \mathrm{~cm}^{3} \mathrm{~mol}^{-1}$, and 9.56 for $G r . I, 184.7 \mathrm{kJmol}^{-1}, 666.0 \mathrm{~cm}^{3} \mathrm{~mol}^{-1}$, and 8.93 for $G r$. II, and $222.8 \mathrm{kJmol}^{-1}, 3143.8 \mathrm{~cm}^{3} \mathrm{~mol}^{-1}$, and 8.51 for $G r$. III. Regression lines for each data group are drawn as seen in the figure. The test conditions and the dislocation densities are also shown in the figure. The values of $\gamma$ are calculated using Equation 13, the dislocation densities, and the parameter constants, and the results are given in the figure. The values of $\gamma$ calculated are rather large, approximately $+100 \mathrm{kJmol}^{-1}$, and the values of $\gamma / Q_{\mathrm{ex}}$ are considerably large, approximately $59 \%$. The temperature-dependence term of the shear modulus is set at $\phi=1.935$ to 2.599 using the elastic properties of $\mathrm{Cu}$ (Ledbetter et al., 1974). 
The pure $\mathrm{Cu}$ that Staker et al. (1972) used was oxygen-free high-conductivity (OFHC) $\mathrm{Cu}$ with rather high impurity (e.g., P: 1000 to $10000 \mathrm{ppm}$ ) and had fine grains with an average diameter of $0.05 \mathrm{~mm}$. Meanwhile, the specimen of Hasegawa et al. (1973) was a $\mathrm{Cu}-0.24 \mathrm{Al}$ alloy melted in the laboratory using ultra-high-purity raw materials and had coarse grains. Moreover, the specimen of Raj et al. (1989) was high-purity OFHC Cu (O: 150 $\mathrm{ppm}$ ) with an average grain size of $0.25 \mathrm{~mm}$. The variations among these specimens may affect the deformation behavior of each, but the relations of the stress and strain rate are qualitatively similar among specimens. We therefore phenomenologically regarded these materials as similar pure $\mathrm{Cu}$. Only the data of Staker and Holt at a temperature of $500{ }^{\circ} \mathrm{C}$ do not lie on the regression line of $\mathrm{Gr}$. II; this discrepancy is not reduced by recalculating using the regression parameters of $G r$. I. There are other references on the creep of pure $\mathrm{Cu}$ (Jenkins \& Johnson, 1958; Andersson-Ostling \& Sandstrom, 2009), but the creep strengths in the cited studies are far higher than those shown in Figure A14. Moreover, Staker et al. (1972) reported the dislocation densities of pure $\mathrm{Cu}$ at temperatures lower than those shown in Figure A14, but we did not find systematic creep data that are needed for the calculation of $\gamma$.

A12. Pure Ni

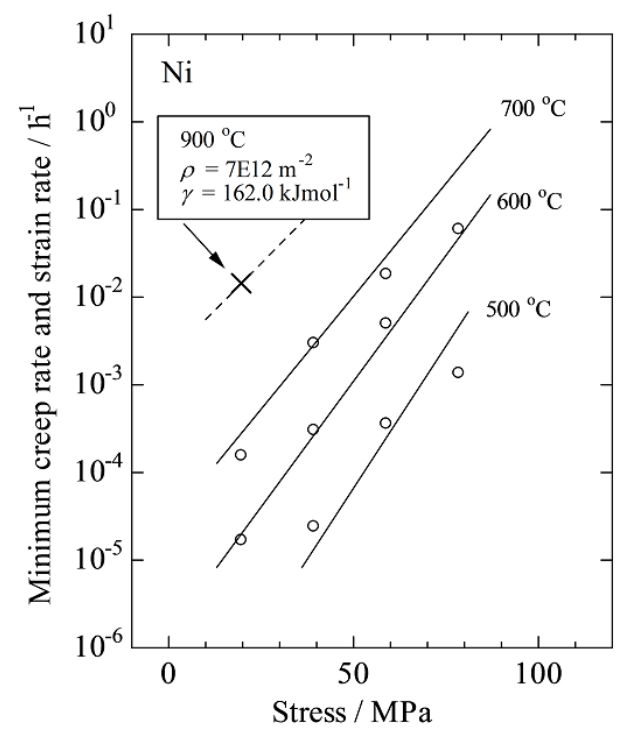

Figure A15. Relations between stress and the MCR or strain rate for pure Ni (Ohara, 1958). The value of $\gamma$ is calculated using the dislocation density obtained by Moiseeva et al. (1984) and parameter constants given in the text, and the result is shown in the figure

Moiseeva, Okrainets, and Pishchak (1984) observed the dislocation density of pure Ni with coarse grains that crept in a steady state under tension at $900{ }^{\circ} \mathrm{C}$ and $19.8 \mathrm{MPa}$ employing TEM. Ohara (1958) reported creep curves obtained at 500 to $700{ }^{\circ} \mathrm{C}$ for pure Ni with coarse grains. Figure A15 shows the relation between the stress and MCR, the values of which are read from the creep curves published by Ohara. The values of $Q_{\mathrm{ex}}, V_{\mathrm{ex}}$, and $C_{\mathrm{ex}}$ of Equation 14 were calculated as $205.3 \mathrm{kJmol}^{-1}, 958.1 \mathrm{~cm}^{3} \mathrm{~mol}^{-1}$, and 6.47 , respectively. Regression lines are drawn using these parameter constants and an extrapolated regression line at $900{ }^{\circ} \mathrm{C}$ is drawn as a dotted line. The creep rate reported by Moiseeva et al. (1984) is not indicated and a data point is therefore indicated on the extrapolated regression line by a cross mark. The dislocation density shown in the figure was read as $\rho=7 \mathrm{E} 12 \mathrm{~m}^{-2}$ at a strain of $\varepsilon=0.06$ on a curve of the density versus strain, because the variations of cell size, also reported in their report, was saturated at $\varepsilon=0.06$. We obtained $\gamma=162.0 \mathrm{kJmol}^{-1}$ using the dislocation density and the parameter constants. This value of $\gamma$ is a large and positive value and $\gamma / Q_{\mathrm{ex}}=79 \%$ is also large. In this calculation, extrapolation was conducted beyond $200{ }^{\circ} \mathrm{C}$ but the high values of $\gamma$ and $\gamma / Q_{e x}$ are not strange, because a similar phenomenon was observed for $\mathrm{Cu}$ (see Figure A14). The temperature-dependence term of the shear modulus is set at $\phi=1.863$ using the elastic properties of Ni (Farraro \& McLellan, 1977) and $v=0.31$. 


\section{A13. $W$ and $W$ alloy}

Although we cannot find information on the observed dislocation density of pure W, Robinson et al. (1969) evaluated the dislocation density as $5 \mathrm{E} 12 \mathrm{~m}^{-2}$ for $\sigma / E=0.0001$, where $E$ is Young's modulus at a certain temperature, discussing the relation between $Q_{\mathrm{apc}}$ and $T / T_{\mathrm{m}}$ and the empirical relation among $\dot{\varepsilon} / D_{\text {eff }}, \sigma / E$, and $\rho$, where $D_{\text {eff }}$ is the effective diffusion coefficient. Figure A16 shows the relation between stress and the steady-state creep rate of pure W obtained by Flagella (found in Robinson et al., 1969). The creep data shown are classified into Grs. $I$ to $I V$ as seen in the figure. The parameter constants, $Q_{\mathrm{ex}}, V_{\mathrm{ex}}$, and $C_{\mathrm{ex}}$, of Equation 14 are respectively $435.5 \mathrm{kJmol}^{-1}, 1989.6 \mathrm{~cm}^{3} \mathrm{~mol}^{-1}$, and 7.40 for $G r . I, 626.5 \mathrm{kJmol}^{-1}, 4251.8 \mathrm{~cm}^{3} \mathrm{~mol}^{-1}$, and 10.51 for $G r$. II, $807.6 \mathrm{kJmol}^{-1}, 10540 \mathrm{~cm}^{3} \mathrm{~mol}^{-1}$, and 12.47 for $G r$. III, and $826.9 \mathrm{kJmol}^{-1}$, $16036 \mathrm{~cm}^{3} \mathrm{~mol}^{-1}$, and 12.11 for $G r . I V$. Regression lines are drawn using these parameter constants as seen in the figure. The test temperature near $T / T_{\mathrm{m}}=0.5$ is $1800^{\circ} \mathrm{Cand}$ the stress for $\sigma / E=0.0001$ at this temperature is $30.6 \mathrm{MPa}$. The creep rates at $1800^{\circ} \mathrm{C}$ and $30.6 \mathrm{MPa}$ were calculated for Grs. $I$ and $I I$ using the abovementioned parameter constants and are plotted as cross marks in Figure A16. The values of $\gamma$ are calculated using Equation 13, the dislocation densities, and the parameter constants as 244.5 and $160.9 \mathrm{kJmol}^{-1}$ for Grs. I and II, respectively These values are large and $\gamma / Q_{e x}=79 \%$ and $26 \%$, respectively. The temperature-dependence term of the shear modulus is set at $\phi=1.723$ using the elastic properties of $W$ (Armstrong, 1964) and $v=0.30$.

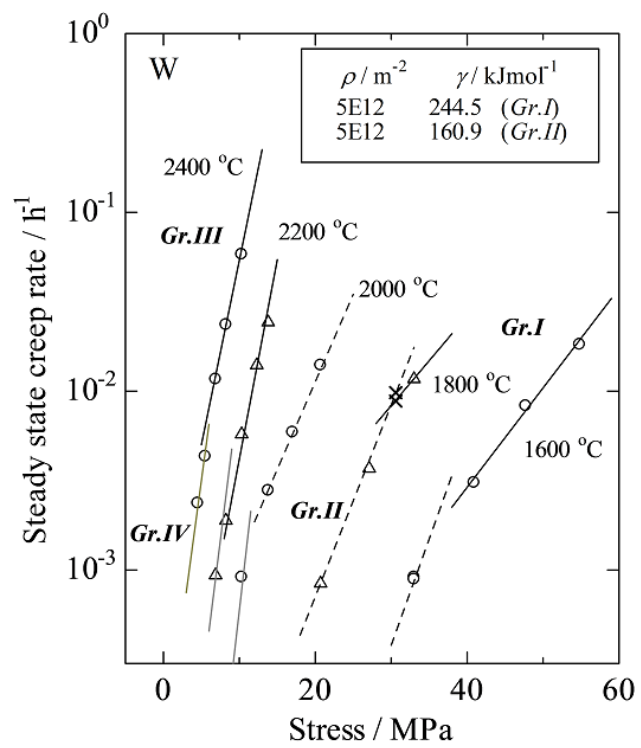

Figure A16. Relations between stress and the creep rate in the steady state for pure W (Robinson et al., 1969). The dislocation density of a crept specimen for $\sigma / E=0.0001$ is estimated to be approximately $5 \mathrm{E} 12 \mathrm{~m}^{-2}$ by Robinson et al. (1969). The corresponding stress at $1800^{\circ} \mathrm{C}$ is plotted with cross marks on the regression lines for Grs. $I$ and $I I$ and the calculated values of $\gamma$ are also shown

Vandervoort (1970) observed the total dislocation densities of W-5Re alloy strained to 0.05 under tension at $1700{ }^{\circ} \mathrm{C}$ employing TEM. He also examined the stress dependence of the strain rate by changing the stress in a steady-state creep range at 1600 to $1900^{\circ} \mathrm{C}$, and the results are shown in Figure A17. All data were classified into Grs. $I$ and $I I$ according to stress levels. The parameter constants, $Q_{\mathrm{ex}}, V_{\mathrm{ex}}$, and $C_{\mathrm{ex}}$, of Equation 14 are respectively $580.3 \mathrm{kJmol}^{-1}, 1972.3 \mathrm{~cm}^{3} \mathrm{~mol}^{-1}$, and 10.79 for $G r . I$ and $609.1 \mathrm{kJmol}^{-1}, 4515.7 \mathrm{~cm}^{3} \mathrm{~mol}^{-1}$, and 9.65 for $G r$. II. Regression lines are drawn using these parameter constants as shown in the figure. The test conditions for the TEM observations are shown by squares in the figure. The values of $\gamma$ are calculated using Equation 13, the dislocation densities, and the parameter constants and they are given in the figure. The average of $\gamma$ is $121.6 \mathrm{kJmol}^{-1}$. The average of $\gamma / Q_{\mathrm{ex}}$ is a large value of $21 \%$. The temperature-dependence term of the shear modulus is set at $\phi=1.589$ using the elastic properties of $\mathrm{W}$ (Armstrong et al., 1964) and $v=0.30$. 


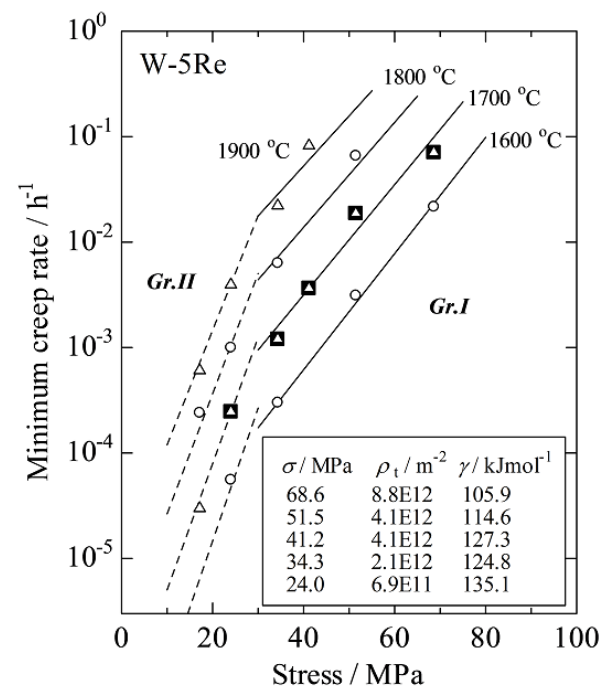

Figure A17. Relations between stress and the MCR for W-5Re alloy (Vandervoort, 1970). Total dislocation density at $1700{ }^{\circ} \mathrm{C}$ under various stresses (Vandervoort, 1970) and the calculated values of $\gamma$ are also shown

A14. Mo alloy

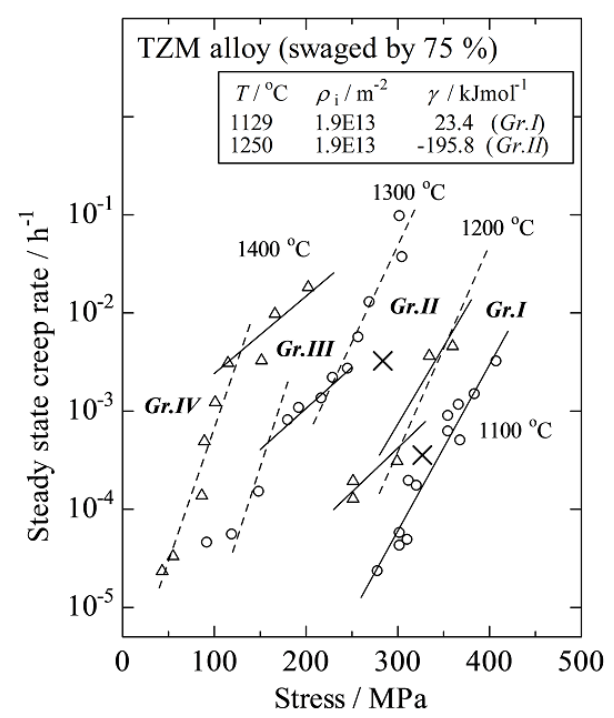

Figure A18. Relations between stress and the creep rate in a steady state for $75 \%$ swaged TZM alloy (Agronov et al., 1985). The values of $\gamma$ for Grs. I and II calculated using the initial value of the dislocation density, 1.9E13 $\mathrm{m}^{-2}$ (Agronov et al., 1986) are shown and cross marks are plotted at the average stress and the estimated strain rate using Equation 14 for each

Agronov, Freund, and Rosen (1986) observed the initial dislocation densities within sub-grains of TZM alloy swaged by $75 \%$, and they also conducted creep tests of the alloy at 1100 to $1400{ }^{\circ} \mathrm{C}$ (Agronov Freund, \& Rosen, 1985). Figure A18 shows the results of the creep tests. All data were classified into Grs. $I$ to $I V$ according to the stress level. The parameter constants, $Q_{\mathrm{ex}}, V_{\mathrm{ex}}$, and $C_{\mathrm{ex}}$, of Equation 14 are respectively $533.3 \mathrm{kJmol}^{-1}$, $435.8 \mathrm{~cm}^{3} \mathrm{~mol}^{-1}$, and 11.13 for $G r . I, 910.3 \mathrm{kJmol}^{-1}, 469.0 \mathrm{~cm}^{3} \mathrm{~mol}^{-1}$, and 24.20 for $G r . I I, 625.9 \mathrm{kJmol}^{-1}$, $252.1 \mathrm{~cm}^{3} \mathrm{~mol}^{-1}$, and 16.16 for $G r$. III, and $1014.0 \mathrm{kJmol}^{-1}, 868.4 \mathrm{~cm}^{3} \mathrm{~mol}^{-1}$, and 25.81 for $G r$. IV. Regression lines are drawn using these parameter constants as shown in the figure. The creep strengths of the swaged TZM alloy shown in Figure A18 are considerably higher than the creep strength of the recrystallized 
TZM alloy by Majumdar et al. (2009). This is considered to be due to the introduction of fine precipitates and a dislocation substructure by swaging. The creep data of Grs. I and II, which are obtained at relatively low temperatures, become analysis objects if we assume that the initial dislocation structure introduced by swaging is almost stable at least up to the strain of the MCR as in the case of high-Cr martensitic steel (Panait et al., 2010). The values of $\gamma$ calculated for the average temperature and stress of Grs. I and II using Equation 13, the parameter constants mentioned above, and the observed initial dislocation density shown in the figure are $23.4 \mathrm{kJmol}^{-1}$ and $-195.8 \mathrm{kJmol}^{-1}$, respectively. The value of $\gamma$ for $G r$. II is a large negative value, but the absolute value of $\gamma / Q_{\mathrm{ex}}$ is of the order of $22 \%$. The temperature-dependence term of the shear modulus is set at $\phi=1.377$ and 1.480 for Grs. $I$ and II using the elastic properties of pure Mo (Ciulik, 2005) and $v=0.30$.

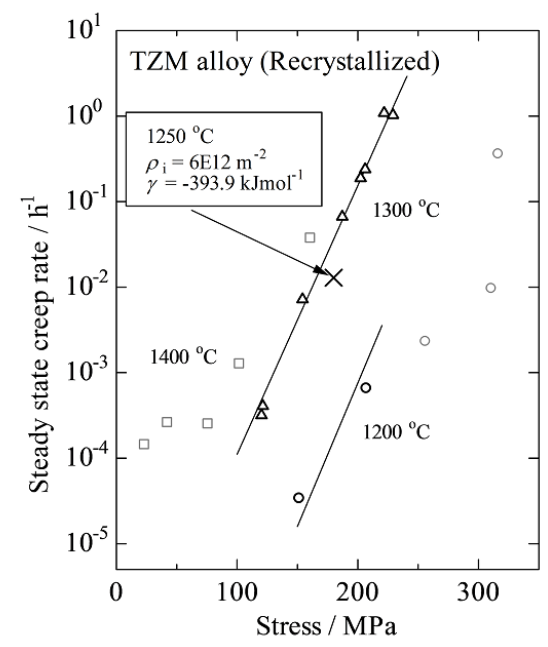

Figure A19. Relations between stress and the steady-state creep rate for fully recrystallized TZM alloy (Ciulik, 2005). Data for the black bold symbols are analyzed using Equation 14 and the parameter constants shown in the text are obtained. The value of $\gamma$ is calculated as $-393.3 \mathrm{kJmol}^{-1}$ using the initial value of the dislocation density, $6 \mathrm{E} 12 \mathrm{~m}^{-2}$ (Majumdar et al., 2009). The strain rate is calculated for the average stress and average temperature and the strain rate as a function of stress is plotted with a cross mark

\section{A15. $C P-T i(H C P)$}

Dragomir et al. (2005) evaluated the dislocation density of the CP-Ti at $268{ }^{\circ} \mathrm{C}$ rolled for a $40 \%$ reduction in thickness employing XRD analysis. They also confirmed that a basal plane slip was a major slip system. This value is comparable to that of the rolled $\mathrm{CP}-\mathrm{Ti}$ at room temperature determined by analysis of the synchrotron peak profile (Alkhazraji et al., 2014). Figure A20 shows the relation between the stress and MCR of CP-Ti around the rolling temperature (Taira, Koterazawa, \& Fukumori, 1960). The creep data were classified into Grs. I and II. During classification of the creep data, creep data that were obtained at lower temperatures with lower strain rates and at higher temperatures with lower stresses by other researchers were also referred to (Fabian, Trojanova, \& Kuzel, 2007). The parameter constants, $Q_{\mathrm{ex}}, V_{\mathrm{ex}}$, and $C_{\mathrm{ex}}$, of Equation 14 are respectively $107.7 \mathrm{kJmol}^{-1}, 122.6$ $\mathrm{cm}^{3} \mathrm{~mol}^{-1}$, and 8.86 for $G r$. I and $393.5 \mathrm{kJmol}^{-1}, 1132.5 \mathrm{~cm}^{3} \mathrm{~mol}^{-1}$, and $17.70 \mathrm{for} G r$. II. Dragomir et al. (2005) reported neither the flow resistance nor the strain rate during hot rolling. Then, assuming a strain rate of $1000 \mathrm{~h}^{-1}$ during rolling in a laboratory, the flow resistance of $212.8 \mathrm{MPa}$ can be estimated using the parameter constants of $G r$. II and the data point is marked by a cross on the regression line at $268^{\circ} \mathrm{C}$. This flow resistance is higher than the proof stress at $268{ }^{\circ} \mathrm{C}$ (approximately $100 \mathrm{MPa}$ ), and sufficiently lower than the tensile strength at room temperature for the $40 \%$ hot-rolled CP-Ti (i.e., $580 \mathrm{MPa}$ (Alkhazraji et al., 2014)); therefore, this value is reasonable. The value of $\gamma$ calculated for Gr. II using Equation 13, the parameter constants mentioned above, and the observed initial dislocation density shown in the figure is $-103.7 \mathrm{kJmol}^{-1}$. The absolute value of $\gamma / Q_{\mathrm{ex}}$ is $26 \%$. The temperature-dependence term of the shear modulus is set at $\phi=1.444$ using the elastic properties of pure Ti (ASME, 2015) and $v=0.32$. 


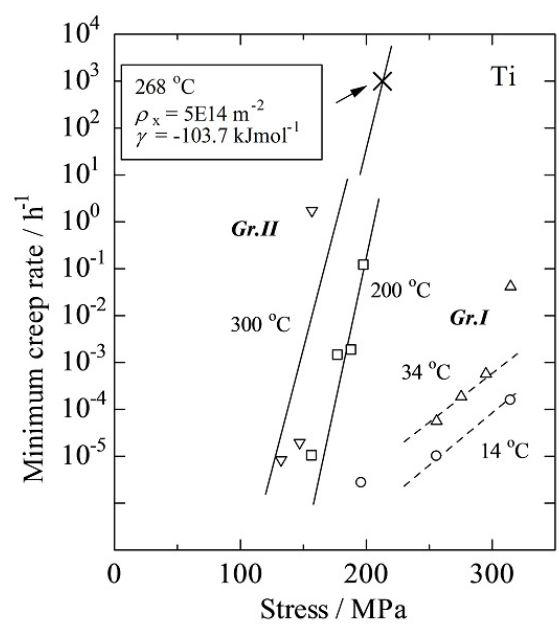

Figure A20. Relations between stress and the creep rate in the steady state for commercially pure Ti (Taira et al., 1960). The value of $\gamma$ was calculated as $-103.7 \mathrm{kJmol}^{-1}$ using the parameter constants for $G r$. $I I$ and the dislocation density estimated employing the X-ray method for the hot-rolled CP-Ti (Dragomir et al., 2005)

A16. Mg alloy (HCP)

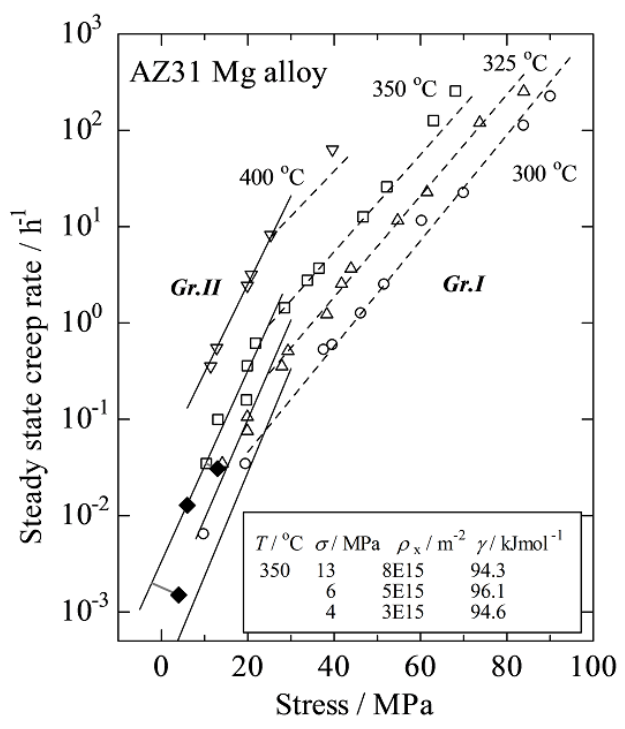

Figure A21. Relations between stress and the creep rate in the steady state for AZ31 Mg alloy Hyun et al. (2014). Creep data (solid diamond marks) (Roodposhti et al., 2015), the dislocation density obtained employing XRD analysis, and the calculated value of $\gamma$ for each stress are also shown

Fabian, Trojanova, and Kuzel (2007) reported the dislocation densities of pure Mg with ultra-fine grains smaller than $0.4 \mu \mathrm{m}$ compressed at 23 to $200^{\circ} \mathrm{C}$ employing XRD analysis and Matsunaga, Kameyama, Takahashi, and Sato (2009) reported the creep data of pure $\mathrm{Mg}$ with coarse grains of $120 \mu \mathrm{m}$. The combination of these data for pure $\mathrm{Mg}$ is unfortunately not suitable for the calculation of $\gamma$. Roodposhti et al. (2015) evaluated the dislocation densities of AZ31 Mg alloy with grains having an average diameter of $30 \mu \mathrm{m}$ that crept to a steady state at $350{ }^{\circ} \mathrm{C}$ and 4 to $35 \mathrm{MPa}$ employing XRD analysis. They also confirmed that a basal plane slip was a major slip system. Hyun and Kim (2014) conducted creep tests of AZ31 Mg alloy with 48- $\mu \mathrm{m}$ grains at 150 to $400{ }^{\circ} \mathrm{C}$. Ishikawa, Watanabe, and Mukai (2005) reported similar creep data at 23 to $450^{\circ} \mathrm{C}$. Among these data, the steady-state creep 
rates at temperatures higher than $300{ }^{\circ} \mathrm{C}$ obtained by Hyun and Kim (2014) are plotted as functions of stress in Figure A21. The indicated data were classified into Grs. $I$ and $I I$. The parameter constants, $Q_{\mathrm{ex}}, V_{\mathrm{ex}}$, and $C_{\mathrm{ex}}$, of Equation 14 are respectively $158.2 \mathrm{kJmol}^{-1}, 601.4 \mathrm{~cm}^{3} \mathrm{~mol}^{-1}$, and 12.0 for $G r$. I and $167.7 \mathrm{kJmol}^{-1}$, $1180.1 \mathrm{~cm}^{3} \mathrm{~mol}^{-1}$, and 11.60 for $G r$. II. Regression lines for each data group are drawn in the figure. The steady-state creep rates are read from the creep curves presented by Roodposhti et al. (2015) and are indicated by diamond marks in the figure. Roodposhti et al. (2015) also reported the dislocation densities at $350{ }^{\circ} \mathrm{C}$ and 19 to $36 \mathrm{MPa}$, but the related steady-state creep rates could not be read with sufficient accuracy from their creep curves. The average value of $\gamma$ calculated for Gr. II using Equation 13, the parameter constants mentioned above, and the dislocation densities shown in the figure, $3 \mathrm{E} 15$ to $8 \mathrm{E} 15 \mathrm{~m}^{-2}$, is $95 \mathrm{kJmol}^{-1}$. The absolute values of $\gamma / Q_{\mathrm{ex}}$ are approximately $56 \%$, which is considerably large. The temperature-dependence term of the shear modulus is set at $\phi=1.983$ using the elastic properties of pure Mg (Ishikawa, Watanabe, \& Mukai, 2005; Somekawa, Hirai, Watanabe, Takigawa, \& Higashi, 2005).

\section{A17. Ge single crystals (diamond structure)}

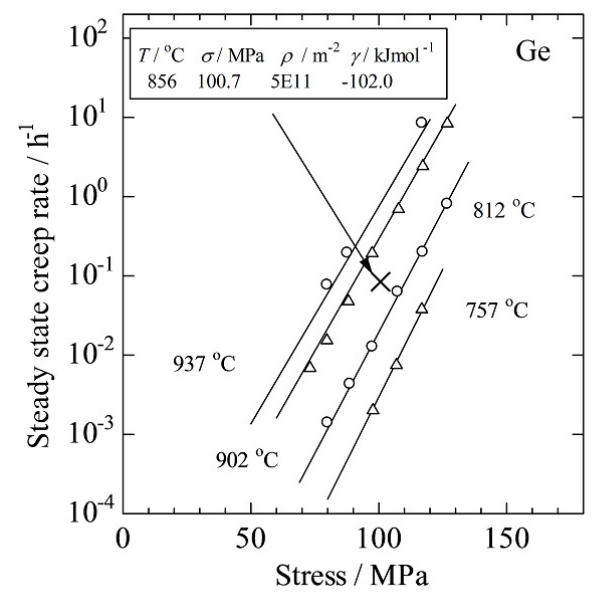

Figure A22. Relations between stress and the steady-state creep rate of Ge single crystals (Myshlyaev et al., 1971). The dislocation density (Myshlyaev et al., 1971) observed employing TEM (cross mark), and the calculated value of $\gamma$ for the average temperature and the average stress are also shown

Myshlyaev and Khodos (1971) conducted compression creep tests of Ge single crystals in the direction <111> at high homologous temperatures of 757 to $937^{\circ} \mathrm{C}\left(T / T_{\mathrm{m}}=0.84\right.$ to 0.98$)$ and reported the average dislocation density in subgrains of a crept specimen to a steady state as $5 E 11 \mathrm{~m}^{-2}$ employing TEM. Figure A22 shows the relation between the stress and steady-state creep rate of the Ge single crystals. The parameter constants, $Q_{\mathrm{ex}}, V_{\mathrm{ex}}$, and $C_{\mathrm{ex}}$, of Equation 14 for all data are $445.1 \mathrm{kJmol}^{-1}, 1268.6 \mathrm{~cm}^{3} \mathrm{~mol}^{-1}$, and 13.63 , respectively. The value of $\gamma$ was calculated using Equation 13, the parameter constants mentioned above, and the observed dislocation density as $-102.0 \mathrm{kJmol}^{-1}$ for the average temperature and stress, because Myshlyaev and Khodos (1971) did not indicate creep conditions at which the dislocation density was observed. The creep rate for the average stress and temperature was calculated using Equation 14 and is indicated by a cross mark in the figure. The value of $\gamma$ is rather large and the absolute value of $\gamma / Q_{\mathrm{ex}}, 23 \%$, is also rather large. The temperature-dependence term of the shear modulus is set at $\phi=1.297$ using the elastic properties of Ge (Kardashev et al., 1985) and $v=0.30$.

\section{Copyrights}

Copyright for this article is retained by the author(s), with first publication rights granted to the journal.

This is an open-access article distributed under the terms and conditions of the Creative Commons Attribution license (http://creativecommons.org/licenses/by/4.0/). 